


$$
\text { · }
$$ 

TH E A N A T 0 M Y

OF THE

$\begin{array}{lllllllllll}\mathrm{C} & 0 & \mathrm{M} & \mathrm{M} & 0 & \mathrm{~N} & \mathrm{~S} & \mathrm{Q} & \mathrm{U} & \mathrm{I} & \mathrm{D} .\end{array}$ 



$$
\|\|
$$




\title{
THE ANATOMY
}

\author{
$0 \mathrm{~F}$ T II E

\section{Co M II O N S Q U I D \\ LOLIGO PEALII, LESUEUR,}

B Y

\section{LEONARD WORCESTER WILLIAMS}

HARVARD MEDICAL SCHOOL, BOSTON MASS.

PUBLISHED UNDER THE PATRONAGE OF THE AMERICAN MUSEUM OF NATURAL HISTORY. NEW-YORK CITY.
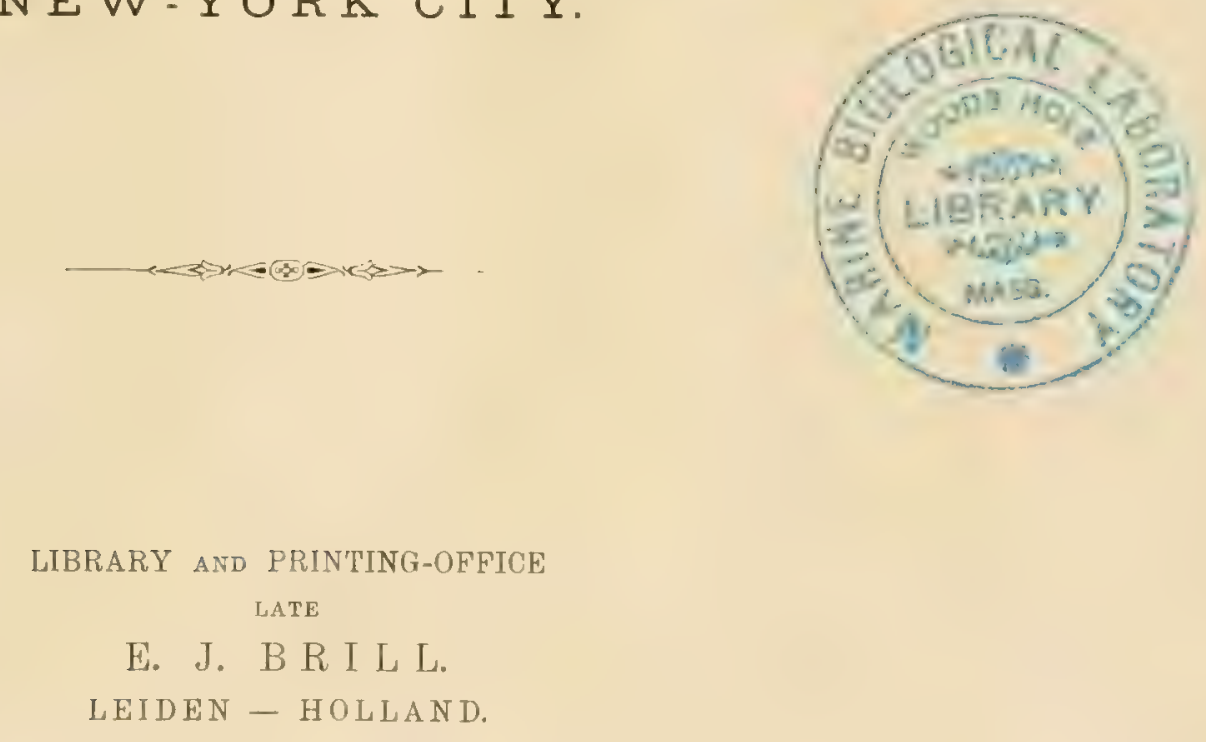

ETDEN - HOLLAND. 


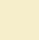


C O N T E N T S.

INTRODUCTION.

1. Distribution of Species

2. Migration

3. Longevity and Rate of Growth.

4. Food

5. Economic Value.

6. Review of Previous Work.

Anatomy.

1. Orientation .

2. General Anatomy

3. The Skin

4. The Skeleton

a. Exaskeleton

b. Endoskeleton .

5. The Skull or Cephalic cartilages

6. The Muscular System.

a. Mantle and Fins

b. Foot.

Arms, Hectocotylus

Siphon

c. Muscles of the Visceral Mass

7. The Head

8. The Pallial Chamber, Viscera, and Pallial Complex

9. The Alimentary Canal.

a. General Form.

b. Pharynx, Jaws, Muscles, Radula and Glands

c. Oesophagus

d. Stomach .

c. Caecum, Liver and Pancreas

f. Intestine, Rectum, and Ink Sac.

10. The Reproductive System .

a. Male.

b. Female

11. The Circulatory System

a. Systemic Circulation; Nephridium

b. Respiratory Circulation, Gill.

c. Blood glands, Branchial gland and White Bodies

12. The Body Cavities

13. The Nervous System .

14. The Sense Organs

a. Statocysts

b. Eye.

15. Bibliography . 



\section{I.IS'T OF 'I'EXT' FIGURES.}

1. Diagram of an hypothetical primitive mollusc. . . . . . . . . . . . 5

2. Sagittal section of an embryo; modified from Korschelt \& Heider. . . . . . . 5

3. $n$ n a later embryo; $n$ n $n$ n . . . . . . . 6

$4 . "$ 4. $"$ an adult squid . . . . . . . . . . . . . . 6

5. The nuchal cartilage. . . . . . . . . . . . . . . . . . . . . . . . . . . 15

6. Lateral view of an adult squid . . . . . . . . . . . . . . . . . 11 i

7. Diagram of the muscles of the fin. . . . . . . . . . . . . . . 17

8. Section of fin. . . . . . . . . . . . . . . . . . . . . . . . . . . . . 18

๑. Ring of an unsymmetrical sucker . . . . . . . . . . . . . . . . . 22

A. upper aspect.

B. lateral aspect.

10. Muscles of the siphon, from above. . . . . . . . . . . . . . . . 23

11. The jaws . . . . . . . . . . . . . . . . . . . . . . . 31
A. upper mandible.
B. lower
C. jaws articulated.

12. Three rows of radular teeth . . . . . . . . . . . . . . . . . 33

13. Pseudopodial (?) rectal cells . . . . . . . . . . . . . . . . . . 41

I. from a squid $2 \mathrm{~cm}$. long.

II. " adult squid.

14. Model of the forward (proximal) portion of the lumen of the third gland (blind sac) of the seminal vesicle.

A. from onter side.

B. " behind (in section).

15. Diagram of the oesophageal, buccal, and brachial nerve rings, seen from the side . . $\quad 68$

16. Photographs of the giant nerve cells . . . . . . . . . . . . . 74

A \& B. two adjacent sagittal sections of the pedal ganglion.

C. transverse section of the pedal ganglion.

D. median sagittal section of the visceral ganglion. 


\section{EXPLANA'IION OF 'IEX'I' FIGURES.}

'TEXT FIGURES 1-4.

$A^{1}, a^{2}-a^{5}$, first, second etc. arm.

An. anus.

Ca. crecum.

C.G. corebral ganglion.

E. eуe.

$F$. fin.

Ft. foot.

Gi. gill.

Go. gonad.

$H$. heart.

I. G. Visceral, ganglion.

I.S. ink sac.

I.V. lateral siphonal valve.

M. mantle.

M. C. mantle chamber.

Me. mesenteron. 21o. mouth.

Ne, nephridium.

O. statocyst.

$P . G$. pedal ganglion.

Ph. pharynx.

Pn. pen.

Sa. salivary gland.

Sh. Shell.

Si. siphon.

Si.f. siphonal folds.

Si. $V$. median siphonal valve.

S.S. shell sac.

St. stomach.

$V . g$. visceral ganglion.

$S . V$. valve of siphon.

TEXT FIGURE ๊. Nuchal cartilage.
d. dorsal point.
1. lateral point.
v. ventral point.

1. articular surface.

2. groove for the insertion of the siphonal valve.

3. edge for insertion of nuchal retractor.

4. origin of cephalic retractor.

TEXT FIGURE 6. Left side of the squid.
A. anterior surface.
D. dorsal point.
1. fin.
2. lateral angle of collar (siphonal cartilage).
3. siphon.
4. aquiferous pore.
9. median angle of collar (pen point).
1. muscles which pass over the dorsal point of the mantle.
2. dorsal angle of fin.
3. muscles connecting the fins .
4. lateral angle of fin.
5. ventral angle of fin.
6. Iongitudinal muscles.
7. fin cartilage.

$P$. posterior surface.

$V$. ventral point.

5. fiftls arm.
6. tentacle.
7. first arm
8. iris.

TEXT FIGURE 7. Diagram of the muscles of the fin. 
TEXT FIGURE 8. Section of the fin.

1, 4, 6. upper, middle and lower fasciae of the fin.
2. muscle bundles parallel to the surface and perpendicular to the base of the fin.
3. blood vessel.
5. muscle fibres parallel to the base and surface of the fin.
7. muscular septa perpendicular to the surface of the fin.

TEXT FIGURE 9. Ring of an unsymmetrical sucker.
A. from above.
1. outline of ring of accessory teoth.
$B$. in section.
2. outline of sucker.

TEXT FIGURE 10. The upper surface of the siphon.

1. siphonal (articular) cartilage.

2. lateral siphonal valve in section.

3. the anterior siphonal protractor.
4. the posterior siphonal protractor.

5. siphonal retractor.

6. oblique surface of origin of the siphonal retractor.

7. lower wall of siphon.

TEXT FIGURE 11. The jaws.

A. the upper jaw.

$B$. the lower jaw.

C. the jaws articulated.
Al. ala of upper jaw.

$A l_{0} 1$ " "lower "

$A x$, axis around which the jaws move.

R.M. retractor mandibuli.

1. Course of the muscle fibres which draw down the lower jaw.

$2 . "$ " " upper muscle fibres of adductor of jaws.

3.

TEXT FIGURE 12. Three rows of radular teeth.

TEXT FIGURE 13. Section through the epithelium of the rectum.
A. of a squid $2 \mathrm{~cm}$. long.
$B$. of an adult.

$F . V$. food vacuole?

TEXT FIGURE 14. Model of the lumen of the forward end of the third gland of the seminal vesicle $\mathrm{X}$.
A. from the outer side.
$B$. from behind (in section).

TEXT FIGURE 15. The oesophageal, buccal, and brachial nerve rings, seen from the side.

1-5. first, second etc. brachial ganglia.

6. infrabuccal connective.

7. propedo-buccal connective.

8. cerebro-buccal "

9. cerebro-propedal "

10. bucco-spanchnic "

11. sinall nerve to the nuchal and cephalic retractors.

12. viscero-stellate connective with the pallial nerve.

13. visceral nerve with the viscero-branchial connective. 
14. norvo of siphomal rotractors.

16. " " crista statica.

16. " $"$ macula statica.

17. siphonal nervo.

18. nerve which is distributed to the lower side of the head.

19. olfactory nerve.

20. nelve which is distributed (?) to muscles of eye.

21. " " " to base of arms.

Bc. G. brachial nerve ring and ganglia.

$B . G$. suprabuccal ganglion.

$B . G .1$ infrabuccal "

C. G. corebral

O. G. outline of the optic ganglion.

Pe.G. pedal ganglion.

Pr.G. propedal ganglion.

$V i$.G. visceral

TEXT FIGURE 16. Photographs of the giant nerve cell and its fibre.

A. \& B. adjacent sagittal sections thru the pedal ganglion.

C. transverse section " " " $" ~ "$

D. median sagittal section " "visceral " showing the chiasma of the fibres of the giant cells.

C. giant cell.

F. fibre.

M. epithelium of the macula statica.

$P . P$. pedal process of skull in section.

$S$. statolith lying in the cavity of the statocyst.

Si. $N$. siphonal nerve. 


\section{LIST OF PLATES AND FIGURES.}

Frontispiece. Photographs of a model of a male squid in The American Mfuseum of Natural History.

Plate I, Fig. 1. Cophalic and preorbital cartilages (enlarged foul diameters), right-ventral aspect.

. 2. The gastro-caecal opening seen from below.

"3. Section thru a symmetrical sucker.

$" 4$. " an unsymmetrical sucker.

" 5. Distal end of spermatophore.

"6. The arterial system.

" 7 . The alimentary canal.

Plate II, Fig. 8, The venous system.

"9. Venous and arterial systems.

"10. Outer side of the sperm duct.

$" 11$. Inner side of proximal portion of the sperm duct.

"12. Diagram of the spermatophoric gland.

"13. Outer side of oviduct.

"14. Inner side of oviduct.

"15. The nervous system, right aspect.

Plate III, Fig. 16. The nervous system, anterior aspect.

"17. A sagittal section of the head.

" 18. A median section of a male squid, left side.

"19. " " " " " right side.

,20. Lens of a very young squid.

"21. Ciliary body of squid $20 \mathrm{~mm}$. long.

, 22. Horizontal section through the eye and one side of the head.

PLA TE I.

Fig. 1. Cephalic cartilage (skull) and preorbital cartilages.

C.P. cephalic process.

$F .1$ large (oesophageal) foramen.

$F .^{2}$ formen for the vein which connects the orbital sinus and anterior vena cava.

L. Lig. lateral ligament.

$L . P$. lateral process.

P.C. preorbital cartilage.

P.P. pedal plocess.

Fig. 2. Lower aspect of the gastro-caecal opening.
C. caecum.
$E$. oesophagus.
I. intestine.
$P$. pancreas with the hepatico-pancreatic duct.
St. stomach. 
1. hepatic valvo.

2 intestinal valve,

3. gastric valve,

4. edges of the partition which separates the uppor and lower lobes of the caecum, the lower lobe having been removed with the adjacent portions of the lower wall of the stomach and intestine.

Fi.. :) Drawing (somewhat diagrammatic) of a median section of a sucker, from one of the central rows of the tentacle. $\mathrm{X} 15$.

Fig. 4. Section of an unsymmetrical sucker.
A. artery.
M. marginal membrane of arm.
$N$. nerve.
$P d$. pedicle of sucker.
$R i$. chitin ring.
S. superficial brachial voin.
$\nabla$. vein of sucker.
1. upper muscle of ring.
2. lower muscle of ring.
3 sphincter muscle.
4. columnal epithelium forming pit glands.
5. columnar epithelium of the base of sucker.
6. basal muscle.
7. circular basal muscle.
8. longitudinal muscle fibres of arm.
9. transverse muscle fibres of arm.

Fig. 5. Distal end of a spermatophore.
D. distal end.
7. constriction at base of filament.
$P$. proximal end.
8. contractile fibres of case.
1. sperm rope.
2. inner wall of case.
3. outer ", "
4. flask-like sac.
5. outer flask tube
6. cavity of outer flask case.
9. "spring".
10. enlargement distal to constriction.
11. filament.
13. cavity around filament.
13. cavities of case.

Fig. 6. Arterial system, posterior aspect.

Fig. 7. Left side of the digestive system.
$A N$. anus.
$B G$. suprabuccal ganglion.
$B G .1$ infrabuccal ganglion.
$B . L$. buccal tentacle or lobe.
$C A$. caecum; a portion of the wall has been removed so as to show the ridge between the lobes of the caecum and the hepatic valve.
GO. gonad.
$H$. heart.
$I N$. intestine.

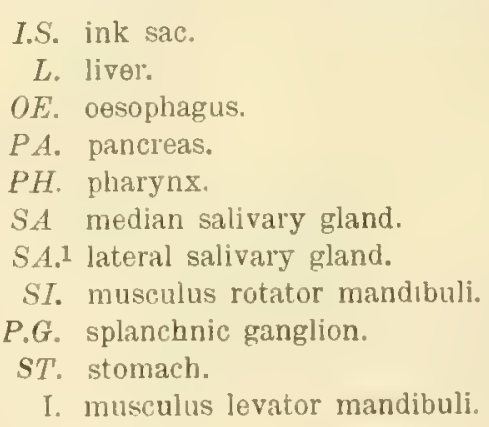

Fig. 8. Venous system, posterior aspect.

Fig. 9. Arterial and venous systems, left side.
GI. gill.
GO. gonad.
$H$. heart.

P.H. peripheral heart. $B L . G D$. blood gland. Br.H. branchial heart. 
I. Anterior aorta.

11. a. lamus to lower caecal lobe.

b. r. to adjacont walls of stomach and caecum.

c. r. to caecal folds.

$d$. $r$. to pancreas.

21. r. to dorsal plexus.

31. 1. to blood gland.

41. $r$. to siphonal retractors.

51 . 1 . to liver.

61. $r$. to nuchal retractors and mantle.

71. r. to cephalic retractor and part of liver.

81. $r$. to median salivary gland.

91. r. to eye.

101. r. to siphon.

11. 3. to pharynx.

121. pedal ramus.

131.

141.

151. rami to the five arms.

161.

II. Posterior aorta.

12. r. to ink sac.

22. 1 . to rectum.

32. r. to branchial heart.

$4^{2}$. I. to sperm duct or oviduct,

52. lateral pallial artery.

62. median pallial artery.

72. r. to mantle.

82. r. to fin.

92. arterial plexus.

III. Genital aorta.
JV. Branchial vein.

V. Nophridial sinus.

15. vein from rectum

25. v. from liver.

35. $v$. from gonad.

45. v. from heart.

55. v. from caecal folds.

65. ventro-lateral mantle vein.

75 . v. from gill muscle and nerve.

85. v. from blood gland.

95. v. from sperm or oviduct.

105. v. from nidamental gland.

115 . $v$. from venous plexus.

VI. Anterior vena cava.

$16 \mathrm{v}$. from ink sac.

26. v. from liver $\left\{a_{0}\right.$ upper branch.

36 . salivary sinus.

46. v. from eye.

$5^{6}$ optic sinus.

66. cephalic sinus.

76. brachial sinus.

86. inner buccal sinus.

96. outer

106. central brachial vein.

116. superficial brachial vein.

VII. Posterior vena cava.

17. mantle vein

27. v. from fin.

VIII. Branchial artery.

Fig. 10. Outer (right) surface of the sperm duct.

Fig. 11. Inner surface of the proximal portion of the sperm duct.

Fig. 12. Diagram of the spermatophoric gland.

App. appendix, the second loop of the sperm duct.

Ci.C. ciliated canal of Chun.

D. vas deferens.

Di. small tubuliar diverticulum from the appendix.

D.Pr. duct of the prostata.

G.S. genital sac.

$P$. penis.

Pr. prostata.

S. C. sperm canal of the first two portions of the seminal vesicle.

Sp.S. spermatophoric sac.

$V .1$. first portion of the seminal vesicle.

$V .1{ }^{1}$ accessory lobe of the first portion of the seminal vesicle.

$V$. 2. second portion of seminal vesicle.

T. 3. third 
V.D. vas deferens.

$V . E$. vas efferens.

The position of the spermatophore in the several portions of the gland is indicated by a heavy line, with a dot to mark the distal end of the spermatophore.

Fig. 13. Outer surface of the oviduct.

Fig. 14. Inner surface of the oviduct.

a. outer segment of oviducal gland.

b. inner " " " "

c. line of attachment of the body wall to the external oviduct.

Ext. Ov. external oviduct.

Int. Ov. internal "

Mo. internal opening of the oviduct.

Ov. Gl. oviducal gland.

Fig. 15. Nervous system; right aspect.

P L A T E III.

Fig. 16. Nervous system; anterior aspect.

BR.G. branchial ganglion.

N.C. nuchal cartilage.

SL.G. stellate ganglion.

SP.G. splanchric ganglion.

1. bucco-splanchnic connective.

2. r. to lateral siphonal valve.

3. r. to siphonal retractor.

4. pleural nerve and viscero-stellate connective.

5. visceral nerve and viscero-branchial connective.

6. r. to cephalic retractor.

7. r. to siphonal retractor.
8. r. to rectum.
9. $r$. to ink sac.
10. interbranchial commissure.
11. r. to branchial heart.
12. branchial nerve cord.
13. interstellate commissure.
14. nerve from the stellate ganglion to the mantle.
15. stellate component of fin nerve.
16. visceral
17. r. to mantle.
18. viscero-stellate connective.

Fig. 17. Median section of the head. Nerves are represented in yellow, arteries in pink, veins, cartilage and chitin in blue, muscle and connective tissue in vurnt umber.
1. cerebral ganglion.
2. visceral
3. pedal
4. propedal
5. suprabuccal ganglion.
6. infrabuccal
7. cerebral process of skull.
8. statocyst.
9. pedal process of skull.
10. nuchal cartilage.
11. pleural nerve and viscero-stellate connective.
12. visceral nerve and viscero-branchial connective.
13. propedo-buccal connective.
14. celebro-buccal
15. cerebro-propedal "
16. outer buccal sinus.

17. inner buccal sinus.

18. oesophagus.

19. palate.

20. tongue.

21. radula.

22. opening of the left salivary gland.

23. duct of median salivary gland.

24. upper mandible.

25. lower

2ti. peristomial membrane.

27. lobe of buccal membrane.

28. opening from outer to inner buccal sinus.

9. brachial sinus.

30. upper muscle of radular tube.

31. lower " " "

32. muscle connecting the inner lamellae of upper jaw.

Fig. 18 and 19. Median section of squid. 
Fig. 18 left side.

Fig. 19 right side.

$A^{1}, A^{2}, A^{3}$, etc. arms one, tivo three, etc.

A. hectocotylus.

$A C$. accessory gland.

B.L. buccal lobe.

C.C. cephalic cartilage, ol skull.

$C A$. crecum.

$C L$. coelom.

F.C. tin cartilage.

GO. gonad.

$H$. heart.

I.S. intestine.

L. liver.

L. I hepatic duct.

J. upper jaw.

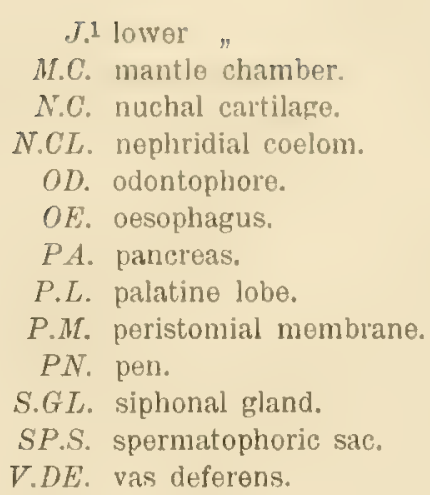

Fig. 20. Section through the ciliary body and lens of an embryo of $2 \mathrm{~mm}$.
1. outer layer of ectoderm (outer part of ciliary body).
2. inner
3 . lens.
4. processes from the ciliary body to the lens.

Fig. 21. Section through the ciliary body of a squid of $20 \mathrm{~mm}$.
1. supporting ligament of lens and ciliary body.
6. epithelium of inner chamber.
2. fold in the outer part of the ciliary body.
7. fascia supporting a fold of the ciliary body.
3. epithelium of the outer chamber of the eye.
8. fibres in fold of the ciliary body.
4. lamella of lens.
5. processes of cells of ciliary body.
9. epithelium of ciliary body.

Fig. 22. Horizontal section thru the eye.

A. muscular base of the arms.

A.C. outer chamber of eye.

B.S. outer and inner buccal sinuses.

C. corneit.

Ca. accessory, or supporting cartilage of the eye. $C i . B$. ciliary body.

Ci.M. ciliary muscle (musculus retractor lentis).

E. oesophagus.

$F$. fascia separating the liver from the oesophageal sinus.

I. iris.

L. lens.

Lig. lateral ligament of skull.

M. orbital fascia.

O.G. optic ganglion.

O.S. orbital sinus.

$P$. "aquiferous pore".

$P . C$. inner chamber of eye.

R. retina.

Scl. sclera.

Sk. skull.

T'S. tentaculor sac.

W.B. lower white body:

W.B.1 upper 



\title{
THE ANATOMY OF THE COMMON SQUID,
}

\author{
LOLIGO PEALII, LESUEUR.
}

The Common Squid, Loligo pealii, is a littoral species confined to the Eastern coast of the United States. Its exact geographical range has not been determined, but it is found from Naine to South Carolina and is so abundant between Cape Cod and Cape Hatteras that it is justly called the "Common Squid". North of Cape Cod the "Short-finned Squid", Ommastrephes, is more common, and south of Cape Hatteras members of other species of Loligo are more numerous.

'The bathymetric distribution of the species is also undetermined, but the fact that its eggs, which are attached to objects on the bottom, have been dredged from water 25 to 50 fathoms deep indicates that squid go at least to that depth.

Our knowledge of the habits of the squid is very incomplete. Little is known of the whereabouts of the squid during the Winter and early Spring but about the last of April or the first of May large schools, often containing thousands of squid, appear along the shore and are taken by hundreds of barrels in the weirs. 'This first "run" is believed by the New Jersey fisherman to precede the "run" of the Sea Bass. After it, the large schools are not common, but throughout the Spring and Summer large schools occasionally enter the traps. A few squid are usually caught each week until the weirs are taken in to save them from the November storms. The egg clusters and the young squid appear two or three weeks after the "run" of the large schools and are common until cold weather, when both old and young squid become scarce.

Our knowledge is not sufficient to justify precise and positive assertions about the life history of the squid, but the observations stated above tend to justify the belief that the following sketch is fairly correct.

The squid probably spend the winter scattered at the bottom ${ }^{1}$ ) in moderately deep water, and as Spring approaches they form large schools that come into the shallow water. After a short time the large schools are broken up into

1 That this statement is not true in reference to the Short-finned Squid, Ommastrepes, is shown by the fact that in November and Decembel 1902 large quantities ran ashore on Cape Cod and in October 60 barrels were taken in a single haul of one trap. Small quantities of the common squid are brought into the markets at New York during the winter. 
small shools, containing from a dozen to a hundred or more squid. The individuals of these small schools breed near the shore. The first eggs are deposited very soon after the arrival of the squid and the young begin to hatch within two or three weeks The young squid, immediately after hatching, form lirge schools which hold together for a month or more until the squid are about an inch long. In October or November the cold drives the squid into deeper water. That the migrations of the squid are bathic rather than zonal is indicated by the squid's manner of swimming, which does not admit of steady and longcontinued lapid motion, and by the fact that they seem to "run" before the Sea Bass whose migration is generally conceded to be bathic. Both these facts, however, have little weight, but until we find something to suggest a zonal migration, they may be accepted.

The rate of growth and longevity of the squid have not been accurately determined because squid do not live long in aquaria and because the breeding season is so long that the youngest squid of one year are not readily distinguishable from the oldest of the succeeding year. Very little can be added to the results of Professor VERRILL's study of the rate of growth of squid, which are substantially as follows: - At Woods Hole, Mass., in the middle of July the largest young of the year, which have developed from eggs deposited in May, are 20 to $30 \mathrm{~mm}$. long. Near the end of September the largest immature squid, which cannot be more than five months old, are between 60 and 90 $\mathrm{mm}$. long. Soon the squid disappear, and in the following May the squid vary in size from 70 to $400 \mathrm{~mm}$. and practically all are sexually mature. The smallest of these represent the younger broods of the preceding year and are eight or ten months old. The largest squid that appear in the spring are 350 to $400 \mathrm{~mm}$. long and, since they can scarcely have grown to that size during the winter, it is probable that they are the adults of the preceding year. Some writers have maintained that the squid breed in their second year and then die, but the inferred rate of growth of squid suggests that some squid live through at least three summers. However, the small number of very large squid leads us to suppose that the greater proportion of the adults of each summer are unable to survive until their third or fourth season.

The food of the squid, so far as known, consists of small fish, crustacea, and squid, but since most of our knowledge of their food is derived from the identification of undigested food in the stomach, it is exceedingly probable that other animals, which do not have easily recognizable hard parts, are also eaten by the squid. The very young squid feed largely upon copepods and other small or larral crustacea. Squid of every age are greedy and persistent camnibals. 
Large squid 20 to $30 \mathrm{~cm}$. long often accompany schools of small squid and feed constantly upon them. 'The extent to which this habit is carried is indicated by one stomach, - not an exceptional one, - which contained fourteen squid mandibles, several crystalline lenses and many bits of broken pen - the remains of at least seven squid. 'The size of some of the suckers found in the stomach show that squid devour others nearly or quite as large as themselves. It is certain that, in the aquaria, defensive power or abundant food is the only safeguard for a squid against the attacks of others of the same size. Squid often bite off and swallow pieces of eelgrass, but such pieces are not digested since they are found unchanged in the rectum.

The squid is of considerable economic value since it furnishes a highly esteemed food to the immigrants of the Romanic and Chinese races, and is probably the best bait for line and trawl fishing. A serious drawback to its use as bait is the irregularity of the supply. When large schools of squid are running, hundreds of barrels more than can be sold are taken, but at other times practically none are available. In 1902, 93,850 pounds of squid, probably all of our species, valued at $\$ 2,531$, were taken in Rhode Island waters, and 37,535 pounds valued at $\$ 538$, were taken in Connecticut, while 5,365,076 pounds, probably consisting largely of the "short-finned squid" Ommastrephes, and valued at $\$ 25,340$, were taken in Massachusetts. (Report, U. S. Bureau of Fisheries, 1904). This difficulty is being overcome by preserving in cold storage the squid taken in excess of immediate wants. Mr. W. I. ATwoon of the Consolidated Weir Company has kindly given me the following remarkable figures. In 1901, 9000 barrels of the "short-finned" squid were frozen by the company for bait; and in 1902, 13,000 barrels were preserved. Considerable quantities of frozen squid have been exported. He also estimated that 5000 barrels of squid were destroyed in one day by rumning ashore. 'The "short tinned squid", Ommastrephes, is used as bait much more than the common squid, partly because it is more abundant than the common squid north of Cape Cod where line fishing is more important, and partly because, being easily taken with hook and line, the supply is more constant. The squid is indirectly of great economic value as an important food supply for marketable fish.

The genus Loligo was described by LAMARCK in 1799 and was subsequently restricted by d'ORBIGrY. All of the species included in the genus, (about 40), are littoral and the genus is cosmopolitan. The species was defined by Lesueur in 18\%1. A good description of the squid, including its gross anatomy, distribution and rate of growth, was published in 1880 by A. E. VerriLl in his "Report on the Cephalopoda of the Northeastern Coast of America". A good 
though incomplete account of the embryology of the squid, "The Development of the Squid", was published in the same year by W. K. Brooks, and eight years later S. WATASE issued his beautiful work upon the segmentation of the orum and the homology of the germ layers. 'I'he embryology and organogeny of the common European species, Loligo vulgaris, have been carefully studied by Kölitier, Faussek, Bobretzki, Korschelt and others. Furthermore comparative studies of various organs of the Cephalopoda (not including this species) have been published. 'The reproductive system of Cephalopoda has been described by J. Brock; the coelom by Grobben; the gills by Joubin; the ink sac by Girod; and the skin (chromatophores) by Girod, Physalix, Rabl, Chur and others. However, a large amount of work yet remains to be done upon the organogeny, anatomy and physiology of the squid. In this work, the vascular, alimentary and nervous systems have received especial attention, but an effort has also been made to give a full account of the gross anatomy of the squid. In the work dissection has been supplemented by the study of a number of serial sections of embryos, of young squid and of adult tissues. The squid studied were obtained at Woods Hole, Mass, and at Elberon, N. J. The work was done at Princeton University, at the Marine Biological Laboratory, Woods Hole, at Brown University, at the Harvard Medical School, and at the Woods Hole Laboratory of the United States Fish Commission. I am especially indebted to Professor Ulric DAhlarren and to Dr. H. C. Bumpus for advice and assistance in this work.

This work, in a less complete form, was presented to the faculty of Brown University in partial fulfilment of the requirements for the degree of Doctor of Philosophy.

Mr. W. 'T. Otrven, draughtsman, of Lynn, Mass. has redrawn or retouched several of the figures.

The class to which the Squid belongs, the Cephalopod Molluse, is very highly specialized. That this specialization shows itself in a very striking manner in the general form of the Squid and in the position that it normally maintains, will be readily seen after a glance at the diagrams of an unspecialized mollusc and of the embryo of the Squid.

'The hypothetical unspecialized molluse (text figure 1) is bilaterally symmetrical, its back is convex, and its anterior end, bearing the mouth, the eyes, and a pair of tentacles, forms a distinct head. The ventral portion of the body is a thick, muscular plate, the foot, by means of which the animal creeps. The upper part of the arched body contains the viscera and is called the visceral dome. From the side of the visceral dome there arises a circular fold of skin. 
the mantle, which hangs downward on all sides so that it encloses between itself and the risceral mass and the foot, a ring-shaped cavity, the pallial or mantle cavity. 'I'his cavity is largest posteriorly where it contains the anus, pairs of gills, of nephridial openings, and of sexual openings. These structures

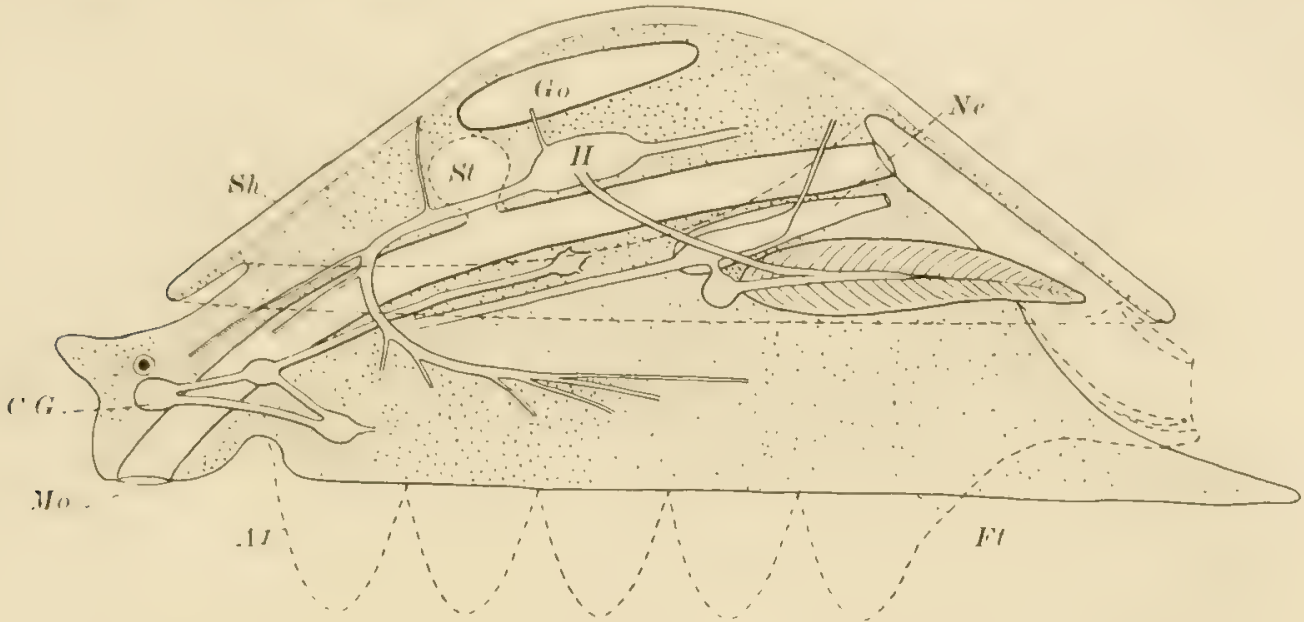

Fig. 1.

are called collectively the "pallial complex." 'The visceral dome is covered by a saucer-shaped or conical shell which extends downward over the mantle and mantle chamber. The intestine is a straight tube which is connected with a large digestive gland. 'The nervous system consists of a cerebral ganglion in the head, a pedal ganglion in the foot, joined to the cerebral ganglion by a pair of ganglionated nerve cords, and a visceral ganglion in the body also united to the cerebral ganglion by a pair of nerve cords.

'The general body-form and arrangement of organs

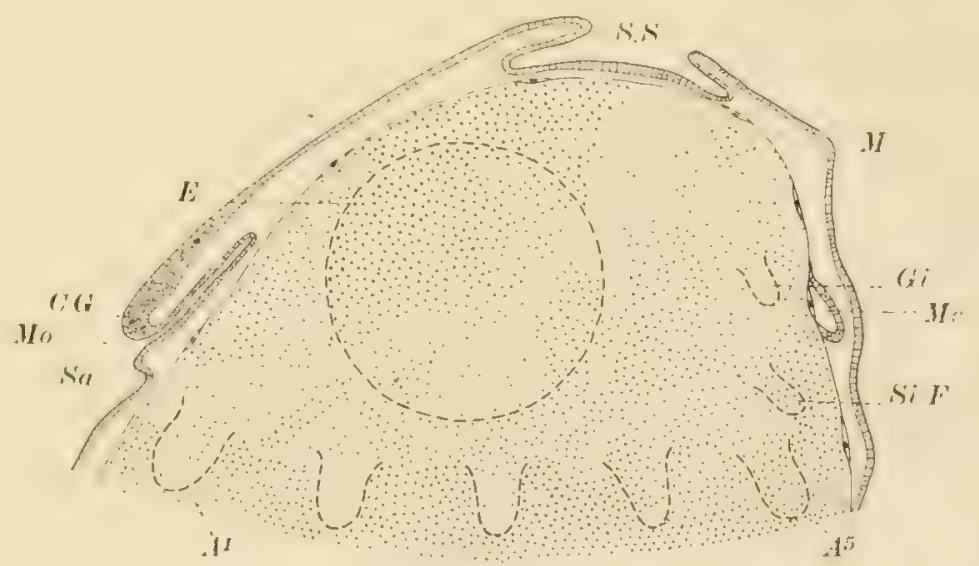

Fig. 2. of the unspecialized mollusc are for a short time partially realized in embryonic Cephalopoda. The egg of the Cephalopoda contains a large amount of yolk and undergoes a discoidal cleavage, hence the form of the embryo is greatly modified from its primitive condition. The dorsal surface of the embryo is 
indicated (text figure 2) very early by the appearance of a pit, the beginning of the shell gland, around which the mantle ridge forms. The oral invagination and the anlage of the cephalic ganglion mark the anterior end of the embryo. The large head-folds, partly surrounding the optic pits, form the greater portion of the sides of the embryo. 'The statocyst, the anlagen of the siphon, and of the gills lie on the posterior surface. The foot is represented by a band of tissue which connects the embryo. with the yolk and from which five pairs of elevations. the anlagen of the five pairs of arms, project. The anus has not yet formed

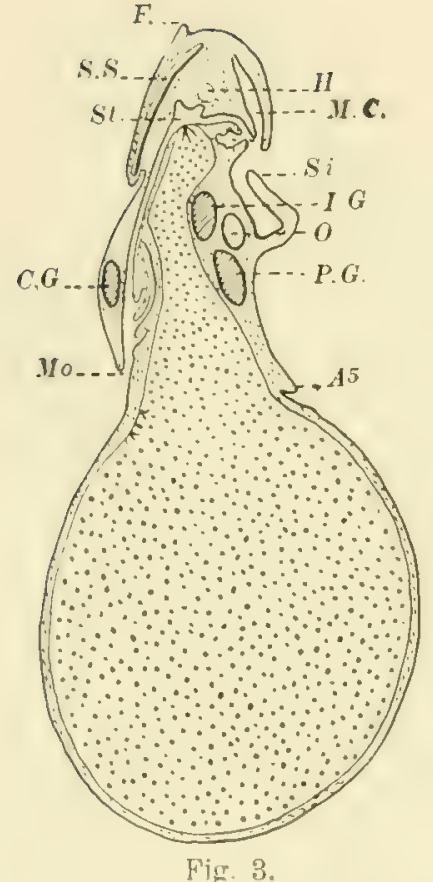

Fig. 3.

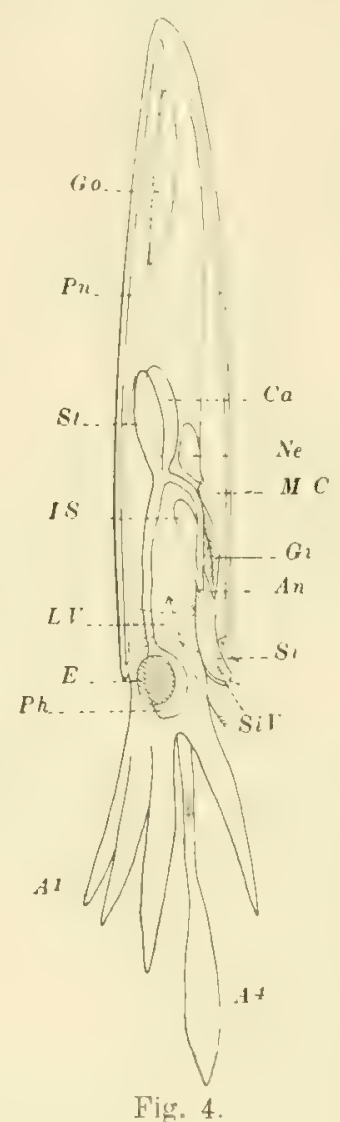

Fig. 4 . but its future position is indicated by the mesenteron which lies beneath the ectoderm of the back of the embryo. The essential relations to be noted are, that the foot is ventral, the mouth anterior, and the shell-gland dorsal. A more advanced embryo is represented by text figure 3 . The convex visceral dome of the younger embryo. has become conical and at the same time the ventral portion of the embryo has contracted constricting the yolksac from the embryo. The mantle has grown downward so that it now covers the gills and the newly formed anus. The gut is complete and near its middle, makes an angle from which two evaginations, the undeveloped stomach and caecum, project upward. The heart is dorsal to the gut. The statocysts, two pairs of siphonal folds, the pedal, and the visceral ganglia are on the posterior side of the embryo between the mantle and the arms. This change may be summed up by saying that the dorso-ventral axis has elongated while the sagittal and transverse axes have become relatively short. This process continues in the Decapoda beyond the stage represented in text figure 3 until the adult form (text figure 4) is reached.

In the adult Decapod the dorsal and ventral surfaces are reduced to mere points at the ends of a fusiform body. The reduction of the ventral surface has 
been accompanied by a forward growth of the arms until finally they surround the mouth and almost corer the head. A comparison of the structure and habits of the various Cephalopods shows that the height of the visceral dome and power of swimming are directly proportional. For example: Nautilus, a Tetrabranch, the most primitive Cephalopod has a low visceral dome. It lives upon the bottom and probably swims but little. 'The Octopoda, the lowest members of the higher group, the Dibranchiata, have a higher visceral dome and, although they frequent the bottom, are better swimmers than Nautilus. The Decapods, the highest Cephalopods and the group to which the Squid belongs, have an extremely elevated visceral dome and are free swimmers. In fact, the ability to swim is directly dependent upon the elongation of the dorso-ventral axis; for the Cephalopoda swim by ejecting water from the body cavity thru the siphon, a tube formed by the posterior part of the foot, hence the longer the body the less the resistance it encounters and the greater the capacity of the mantle cavity. As the dorso-ventral axis becomes longer, i. e. as the visceral dome becomes more elevated it becomes less vertical until, in the Decapods, it is horizontal. Squid swim with equal facility either forward or backward, but because of the abore mentioned change of the dorso-ventral axis from the vertical to the horizontal position, the ventral, not the anterior surface, is forward, the anterior surface is uppermost, and the dorsal, not the posterior surface, is hindmost. The fact that the axis which is usually vertical is horizontal in the Decapods has naturally led to great confusion in terminology. 'The majority of systematists, the English, French and some American morphologists have used the morphological terms anterior, posterior, dorsal, and ventral in a positional or physiological sense while the German zoologists, and some others have used the same terms in a strictly morphological sense. In this description, the terms anterior, posterior, dorsal, ventral are used in a morphological sense and the terms upper, lower, fore, and hind are employed in their ordinary meaning. Hence the anterior surface is uppermost, the ventral surface or point is forward, and the dorsal point is backward. Further confusion of terms has arisen because of the partial union of the head with the foot; in this paper, the term foot denotes all the structures formed from the primitive foot viz. the arms, tentacles, and siphon. The mass formed by the fusion of the true ol" primitive head with a portion of the foot, i. e. the arms, is called the head.

The head of the squid is lance-shaped and is attached by a very short neck to a cigar-shaped body so that the squid is nearly fusiform. The body consists of a thick muscular mantle and a risceral mass enclosed by the mantle. The otherwise cylindrical mantle tapers to a dorsal point. Ventrally the mantle ends 
in a free edge, the collar, which surrounds the neck and thru which a conical muscular tube, the siphon, projects. 'T'he collar articulates by three pairs of interlocking surfaces with the visceral mass and the siphon, mesially with the upper surfice of the visceral mass (with the nuchal cartilage) and laterally with each side of the siphon. A pair of triangular fins is attached to the dorsal point of the mantle and to three-fifths of the anterior (upper) surface in such a manner that they form a rhomboidal plate.

'The lance-shaped head consists of the true or primitive head and the anterior part of the primitive foot. The back part of the head, representing the true head, is short and is kidney-shaped in cross-section since the posterior surface is hollowed out for the accommodation of the siphon. A pair of large eyes forms almost the entire sides of the true head and an olfactory fold, just behind the eye, projects backward under the collar. The remainder of the head is formed by a circle of ten foot-lobes, comprising eight sessile arms and two tentacles, which are attached to the ventral surface of the true head and which surround the mouth. While the Squid is swimming the arms and tentacles are pressed together so that they form an acute, thick, horizontal plate which is used alternately as a rudder and as a cutwater.

The siphon, a conical muscular tube attached to the lower surface of the visceral mass and to the head, projects downward and forward from the mantle chamber between the head and the mantle. A jet of water ejected thru the siphon whose tip may be directed forward or backward propels the squid backward or forward. 
I'HE SKIN.

Girod has studied carefully the skin of Cephalopods, and this account is little more than a confirmation for this species of his description.

The epidermis is a simple epithelium which secretes a very thin striated cuticle. It contains small clusters of, or more rarely isolated, cells in various stages of mucous secretion. 'The shape of its cells varies according to the stresses to which it is subjected. In the embryo and in a contracted state the cells are cubical or columnar, while in the adult or when expanded they are slightly or greatly flattened. 'The large nucleus lies near the center of the cell. A clearly defined basement membrane is usually absent and irregular protoplasmic processes interlock with the dermal cells. 'The epidermis which lines the siphon forms two pairs of glands which were described by H. NüLLer in 185.3 as characteristic Cephalopod organs. 'I'his description seems, as Brock has pointed out, to have been overlooked by VerRLL who described them more recently, by Hoyte who named them collectively the "organ of VerriLt", and by LAURIE who adopts Hoyle's name and who does not find them in the adult. The form of these glands is described in connection with the siphon. 'The epithelium of the glands is very highly columnar and contains vast numbers of goblet cells which are contiguous ol separated by very slender resting or recently emptied cells. All the nuclei have a very unusual position at the distal ends and the secretion gather's in the proximal ends of the cells, which seem inverted. 'The secretion seems to consist of mucin and the glands seem to be active periodically, for at times they are very conspicuous both in living and preserved animals, while again they are inconspicuous. 'The glands are present in both sexes and at all ages.

Hoyle has described in the embryo of Sepia a trifid and in that of Loligo a single line of modified epithelium. The tract in Loligo is longitudinal and lies on the upper and dorsal surface of the mantle between the fins. It seems to be a row instead of the usual cluster of mucous secreting cells. 'This has been called Hoyle's organ. We have failed to find it, probably because the embryos examined were too old.

The epidermis also secretes the pen and the chitin-like rings of the suckers. These will be described in connection with the skeleton and suckers. 
'The dermis is formed of four ill-defined layers; an outer layer of fibrous comnective tissue, a sheet of chromatophores, a deep fibrous layer and a layer of iridiocysts. 'The superficial fibrous layer supports the epidermis and has numerous nerve tibres in its deeper portion.

'The second layer is characterized by the remarkably specialized chromatophores. Each chromatophore consists of a pigment cell, its capsule of elastic tissue, and a circle of radiating muscle cells. 'The chromatophores have been a subject of lively interest and protracted controversy and innumerable papers upon their anatomy, ontogeny and physiology have appeared. We have not indulged the natural desire to enter upon an extended investigation and discussion of such beautiful, attractive and much studied objects. We are, however, in essential agreement with CHun's results. The pigment cell and muscle cells of each chromatophore arise from a single mesodermal cell. The central cell secretes a granular pigment which in our species is of a dark reddish brown color in the larger and more numerous chromatophores and yellow in the others. The pigment is laid down in a fluid within a rather sharply marked cavity and the mucleus is gradually forced to the periphery and usually lies beneath the pigment mass. The yellow pigment is a lipochrome, the brown pigment has been found by Dr. Alsberg of the Harvard Medical School, to be melanin and is consequently essentially like the ink. The nucleus is large, takes deep colors with chromatic stains, and has a large nucleolus.

The capsule is thin, elastic, and is formed by a number of cells, a part or all of which probably arise from the original chromatophoric cell. The flattened, lightly stained nuclei are easily distinguishable from those of the pigment and muscle cells. The elasticity of this sheath keeps the pigment mass spherical except during the contraction of the muscle cells.

The nuclei of the cells which are to become muscle cells group themselves in an irregular circle around the pigment cell. Each cell sends out a long tapering process which extends into the loose connective tissue of the dermis and is attached either by branches which are attached to the connective tissue, or fixed by anastomosis with other muscle fibres. 'The broad central end of the muscle cell, - or perhaps we should say of a muscular portion of the chromatophoric syncytium, since the boundaries of pigment, sheath and muscle cells are at least indistinct if not absent, - contains the elliptical or oval nucleus which is surrounded by a small amount of granular protoplasm. The remainder of the protoplasm is fibrillar. 'The contraction of the muscle cell, producing as it does a large expansion of the circumference of the pigment cell, necessarily broadens its own base, and the nucleus takes a position perpendicular to the 
tibre instead of parallel to it as in the resting condition. Each muscle cell is penetrated by a nerve fibre which ends in an irregular arborization near the mucleus. Between ten and thirty muscle cells are attached to the equator of the sheath of the pigment cell, and theii contraction transforms the almost invisible spherical pigment mass into a conspicuous colored plate which varies in size from a diameter of less than a millimeter to a diameter of is or more millimeters. 'The chromatophores appear in a definite sequence and arrangement in the embryo, but later this order is obscured or lost. In the adult each of the largest chromatophores, which are somewhat elliptical, is surrounded by a circle of smaller chromatophores. 'The minute yellow chromatophores are placed between the brown ones. The chromatophores lie at various levels, so that during expansion they overlap one another considerably. New chromatophores are formed throughout life.

The chromatophores are slightly more numerous upon the upper surface of the animal and are absent from the lower surface of the fins, from the interior of the mantle and siphon and from the portions of the arms which are not ordinarily exposed to light. In other words, excepting the lower surfaces of the fins only those surfaces which are ordinarily exposed to light either from above or below have chromatophores.

Normally the chromatophores expand and contract in a rythmic manner owing, as Steivach believes, to the tonic action of the suckers. Direct or diffused light causes the chromatophores to expand as long as the suckers are present. In addition to these reflex or tonic causes of expansion or pulsation of the chromatophores, they respond to states of excitement or ferl by rapid and more or less simultaneous expansion. 'Thus under normal conditions the color of the squid is uniformly pinkish brown, but when attacked or attacking or frightened, the squid changes its color with startling rapidity from a pale translucent white to a yellowish white, or pink, or brown color. The animal also assumes at times a mottled brown color.

The deep fibrous layer is usually thinner than the superficial layer. The two fibrous layers unite wherever the chromatophores are absent.

The pretty and startling color changes of the squid are heightened by the delicate sheen of the iridiocysts. 'The layer of iridiocysts usually underlies the chromatophores, but in our species it is beneath the deep fibrous layer except for a fer large oval masses of iridiocysts which form scattered spots upon the upper surface of the mantle and fins and which lie under the chromatophores. Each iridiocyst is a much flattened cell whose cytoplasm contains a vast number of sinuous rods which are parallel to the surface of the cell and of the body. 
In some cells the rods form bundles or sheets which are inclined to one another at varions angles; in other cells the rods are all parallel. 'The iridiocysts overlap) one another so ats to form from one to many layers. 'The closely laid rods reflect and interfere with light waves, producing a sheen and iridescence which is indescribably beautiful. Like the chromatophores, the iridiocysts are absent from the integument which is not exposed to light, and from the lower surface of the fins. 'The layer of iridiocysts is thickest above the rentral end of the mantle and hides the dark colored organs in the viscera. 'The chromatophores upon the lower side of the head, which is largely protected from light by the siphon, are scattered, and the iridiocysts are replaced by a layer of short, broad rods, or platelets, placed at right angles to the surface. 


\section{THE SKELETON.}

A. Exoskeleton. Shell or Pen.

The shell of the Squid is represented by the pen, a feather-shaped plate of chitin which is buried under the skin and muscle of the anterior surface and which extends from the dorsal to the ventral point of the mantle. The pen is secreted by the shell-gland which is formed by an invagination of the ectoderm of the dorsal surface of the very early embryo. The edges of this pit soon unite with one another so that the shell-gland becomes a closed sac and the shell or pen, formerly and morphologically external, becomes internal. The inner or lower wall of this sac secretes the pen and is formed by a secretory epithelium which at first is composed entirely of columnar cells, but which, as the pen enlarges, becomes cubical or even pavemental except around the edges and beneath the thick ventral part of the shaft where growth is most active and where thruout life high columnar epithelium is present. The chitin of the pen is transparent and almost colorless and is marked by delicate striae, the lines of growth, parallel to the edge. The substance of the pen yields all the usual chemical reactions of chitin.

The median axis or shaft of the pen is a trough-shaped plate which is thicker ventrally and which extends the whole length of the pen. 'The concave surface of the shaft is underneath and interlocks with a ridge of the nuchal cartilage which lies in the visceral mass just behind the neck. The vane or body of the pen is attached to the sides of the shaft, extending from its dorsal end three-fourths of its length, forming a thin, fusiform, convex sheet which covers the upper surface of the visceral mass. At the middle of the vane and dorsal to this point, the sides of the pen extend nearly or quite half way around the visceral mass, but ventrally the rane narrows until, at the middle of the body, it covers only the anterior surface of the visceral mass. The inner surface of the pen is separated from the viscera by the epithelium which secretes the pen, by a strong sheet of connective tissue and by the coelomic epithelium. The upper surface of the ventral end of the shaft is subcutaneous and the muscle fibres of the mantle are attached to the sides of the shaft. Near the ventral end of the vane, muscle fibres begin to pass over the shaft and from this point backward, more and more fibres pass over the pen and ferver are attached to 
it until, beyond the middle of the vane, practically all the muscle fibres pass above the pen and the dorsal end of the pen is deeply buried in the mantle. 'The chief' muscles of the visceral mass are attached to the inner or lower surface of the pen.

B. 'The Hndoskeleton.

The endoskeleton consists of a number of disconnected pieces of cartilage which protect the brain, form articular surfaces, and support muscles. Omitting the small cartilages which will be described in connection with the eye and the odlontophore, the skeleton consists of eleven pieces of cartilage, viz. four paired cartilages, the fin, the pallial, the siphonal, and the preorbital cartilages; and three unpaired cartilages, the skull, the nuchal, and the postcephalic cartilages.

\section{'The Shuld or Cephalic Cartilage.}

The skull (Plate I Fig. 1) is a very irregular cartilaginous plate, perforated by a large foramen thru which the oesophagus, the nerves of the viscera and the arteries of the head pass. The ventral surface of the plate is hollowed out for the reception of the optic ganglia and the oesophageal nerve-ring. The lower portion of the plate contains the two large statocystic cavities and the two special depressions for the pedal ganglion in front of, and the visceral ganglion above, the statocysts. The cartilage is prolonged into two strong median, ventral processes, one, the cerebral, above the cerebral ganglion, the other, the pedal, below the ganglion of the same name. These two processes, one above and one below the nerve-ring, are connected by a pair of hour-glass shaped ligaments, the lateral ligaments, which separate the front end of the oesophageal nerve-ring from the optic ganglia. Each ligament is attached above along the greater part of one side of the cerebral process and below to one side of the pedal process. 'The cerebral and pedal processses, the lateral ligaments, and the lateral portion of the skull form, at each side of the skull, a large concavity which faces outward and forward and which lodges the optic ganglion. The dorsal surface of the skull is a vertical arched plate. Its edge is covered by the insertion of the retractor muscles of the head and its central portion by the liver. 'The ventral surface is very irregular and is largely covered by ganglia but the muscles of the foot are attached to the cerebral and pedal processes, to the lateral ligaments, and to the upper and lower edges of the cartilage. The two statocysts form a pair of low rounded projections from the dorsal surface of the skull. The saucer or cup-shaped concavities for the visceral ganglion above, and for the pedal ganglion in front of the statocystic capsule, have been 
mentioned. 'Two or three pairs of foramina for the transmission of the statocystic nerves pierce the rentral wall of the capsule. A foramen at the edge of the depression for the pedal ganglion transmits the nerve of the crista. Another foramen, for the macular nerre, is situated a short distance inward from the formen for the cristic nerve.

Just in front of the statocysts, two pairs of foramina pierce the cartilage at the base of the pedal process: one pair allows the siphonal nerves to pass from the pedal ganglion to the siphon; and the other, which is in front of the preceding and is just exterior to the lateral ligaments, transmits a pair of veins from the orbital sinuses to the anterior vena cava. Several small foramina which are represented in the drawings but which do not merit description, transmit small blood-ressels and nerves.

The two preorbital cartilages (Plate I Fig. 1) are attached side by side to the pedal process of the skull and reach outward and forward between the eyes and the pharynx. Each eartilage is a flattened, stocking-shaped bar whose tip (toe) projects downward. This bar lies against the inner surface of the eye and supports certain muscles of the eye.

'The nuchal cartilage (text figure õ) lies in the muscles of the liver case

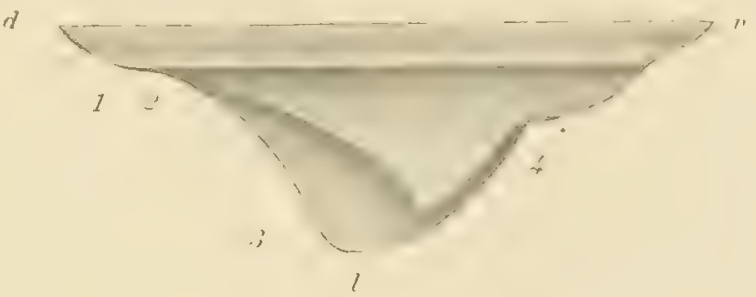

Fig. 5. between the liver and the ventral end of the pen with which it articulates. It is a thick, quadrangular", trough-shaped plate. Two of its angles are directed, one forward, and one backward, and the lateral angles are bent downward around the liver. On the upper side of the cartilage there is a linear grooved surface which articulates with the pen. This articular surface has three grooves, of which the two lateral, articulate with the edges of the pen. The upper edges of the lateral siphonal valves are attached to the cartilage just below the articular surface; the cephalic retractor is attached to the ventral edge of the cartilage: and the nuchal retractor is inserted on the dorsal edge and on the greater portion of the lower surface of the cartilage.

The postcephalic or "diaphragmal" cartilage is a thin oval plate which lies just behind the head in the lower wall of the liver-case between the liver and the anterior rena cava and stiffens the liver-case.

Each fin cartilage lies at the base or inner side of the fin. These will be further described in connection with the fins (text figure 7 ).

The siphonal cartilages are a pair of grooved linear plates attached to the 
sides of the siphon. 'The groove of each cartilage interlocks with a corresponding ridge on one of the pallial cartilages.

'L'he pallial cartilages are lidged linear' plates inserted on the inner surfaces of the two lateral points of the mantle. The siphonal with the pallial cartilages, and the nuchal cartilage with the ventral end of the pen, form three sliding joints which allow the siphon and the neck a large amount of motion and which, nevertheless, hold them in place. Considerable force is required, both in the living and the dead squid, to dislocate these joints.

\section{'T'he Muscutar Systeir.}

'T'he muscular organs of the squid include the mantle, the fins, the siphon, the arms, and the cephalic and nuchal retractors.

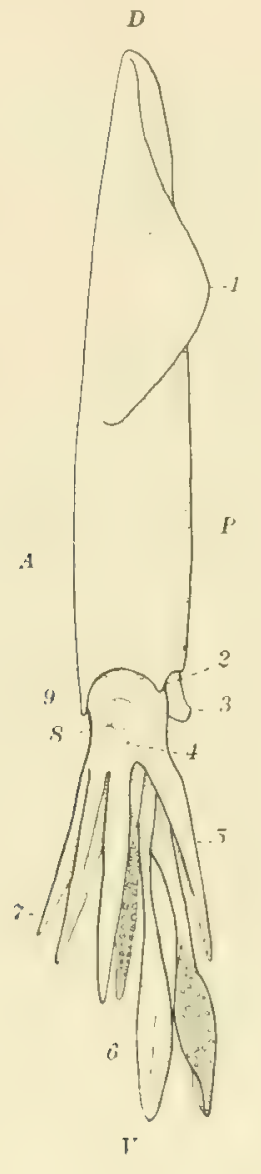

Fin. ti.

'The Mantle. The mantle (text figure 6) is a bulging muscular cone, open ventrally and tapering beyond the middle to a dorsal point. The free ventral edge of the mantle surrounds the neck and is called the collar. 'The tips of the pen and of the two pallial cartilages form three equidistant points on the collar, dividing it into three arcs and, as the tip of the pen extends farther forward, the two ares adjacent to it do not extend as far back as the arc between the two pallial cartilages. The former arcs are opposed to the lateral siphonal valves and the latter are embraces the siphon.

The mantle is formed of long, coarse, fusiform fibres. MARCEAU has shown that each fibre consists of a peripheral sheath formed of somewhat flattened, spirally wound fibrillae separated by sarcoplasm, and a core of granular sarcoplasm which contains the long rod-shaped nucleus. The fibres are all parallel and form circular muscle bands which extend from one side of the pen around the mantle cavity to the opposite side or pass outside the pen and so completely encircle the body. The muscle fibres are bound into rectangular bundles by means of thin muscular septa which bind together the two fasciae that lie on the inner and outer surfaces of the mantle. The mantle is covered and lined by the integument which is reflected from its inner surface over the visceral mass and helps to attach it to the mantle. In addition to this attachment and to the articulation of the collar with the body, the mantle is attached to the visceral mass by a pair of ligaments which arise near the middle of the 
visceral mass and extend over the edge of the pen to the mantle. However, the chief comnection is furnished by the pen, to whose upper surface the mantle is attached, whereas the large siphonal, nuchal and cephalic retractors are attached to its lower surfice.

'The pallial cavity is very large and extends back nearly to the dorsal point of the mantle. By the expansion and contraction of the mantle a large quantity of water is drawn into and expelled from the pallial chamber.

'The two triangular fins are thin muscle-sheets and together, they form a flat rhomboidal plate which is attached to the upper surface of the mantle and extends from its dorsal point over $3 / 5$ of its length. 'The longest side, the base, of each fin is attached to the mantle and the two firee edges are of nearly equal length. The dorsal angles of the two fins form together an acute angle which ends in a rounded tip. 'The lateral angle of each fin is obtuse and very much rounded. 'The rentral ends of the tins are some distance apart and each forms a small auricular lobe. The dorsal points of the cartilages of the fins are firmly united by strong masses of connective tissue, but at the middle the fins are not closely connected and overlap one another considerably. They are united by a thin subcutaneous sheet of muscle. which extends across their upper surfaces, as well as by the muscles which bind them to the mantle. The long attached base of the fin is underlaid and supported by a strip of cartilage - the fin cartilage - which is thin and broad except at its dorsal end where it

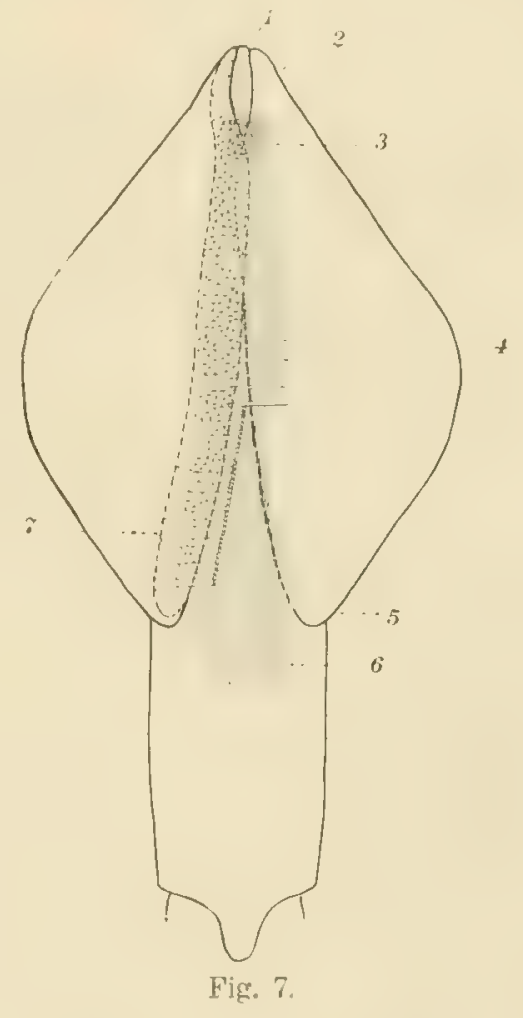
becomes a strong bar that curres downward and inward over the dorsal gpoint of the mantle. 'The fin has very thin free edges, and increases in thickness gradually toward the base where it is attached to the cartilage at an angle jof about $30^{\circ}$ (text figure (j). The fins are attached to the mantle by the following three muscles. A strong muscular band arises from the lower surface of the fin cartilage near its dorsal end and passes backward around the tip of the mantle to the opposite cartilage. A broad thin sheet of muscle arises from the upper surface of the mantle in front of the fins and is inserted upon the upper surface of the bases of the fins. A second broad thin muscle arises 
from the lower surfice of the fin and, passing downward, is inserted partly on the side of the mantle and partly upon the opposite fin.

The fin (text figure 8 ) is formed by three sets of muscle fibres, longitudinal, transverse and vertical. enclosed between three fasciae. 'l'wo fasciae are subcutaneous, forming the surfaces of the fin, and the third lies at the middle of the fin. 'The longitudinal muscle fibres form two thin sheets which lie upon the upper and lower surfaces of the middle fascia. 'They extend from one to the other free edge of the fin. The transverse fibres arise from the obliquely inclined upper surface of the cartilage and, passing outward beneath the superficial fasciae, are inserted in them and among the muscles. These fibres

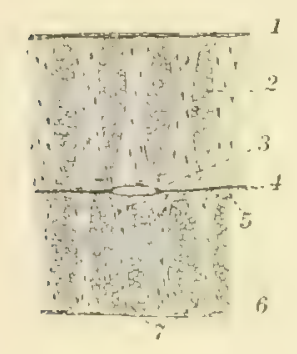

Fig. 8. are separated into long, strong and laterally compressed bundles by the short, vertical muscle fibres which, extending from the superficial fasciae to the middle fascia, form walllike septa that extend from the base to the free edges of the fin. The bundles of transverse fibres become more slender as they approach the free edge of the fin. 'This is due partly to the loss of fibres by insertion and partly to the branching of the bundles. 'This reduction of the muscle bundles as they approach the free edge of the fin is partly counterbalanced by the union of bundles with one another. 'The septa of vertical fibres become thinner, less high, and more numerous near the free edge. Each septum is from $1 / 3$ to $1 / 4$ as thick as the bundles which it separates. As its fibres approach the middle fascia they diverge to pass between the longitudinal muscle-fibres, and hence the septum seems broader near the fascia. These septa appear through the transparent skin of the lower side of the fin as dark lines. The longitudinal, transverse, and vertical fibres together form a strong flexible fin which is able to make strong upward or downward strokes that instantly change the direction of the squid's motion and also is capable of a slow undulating movement that propels the squid slowly forward or backward. 
'THE FOO'T'.

The morphological value of the arms of the Cephalopoda has been the subject of an extended controversy among morphologists. Some have maintained that the siphon represents the entire foot and that the arms are appendages of the head: others have held that the siphon is only the posterior part of the foot and that the arms represent its anterior portion. 'T'he fact that the arms appear along the ventral portion of the sides of the embryo and later move forward to their final position around the mouth and that the structure of the arms indicates that such a migration has occurred led finally to the general acceptance of the latter view.

THE ARMs. In the adult squid, five pairs of arms are borne by a circular mass of muscle that encircles the mouth, encloses the pharynx, and is attached to the ventral surface of the skull. The tentacle, the fourth arm on each side (numbering from above downward), is longer than the other's and has an expanded extremity, the "club", which bears four rows of suckers and which is supported by a long retractile stalk, the peduncle. The four remaining pairs of arms, the sessile arms, taper regularly from the base to the apex and bear two rows of suckers along their entire oral surfaces. In section, the first, second, and fifth arms are trapezoidal; the third is oval. The oral surface of each sessile arm is bordered by narrow engrailed membranes whose points are formed by the tips of small muscular buttresses which alternate with the suckers and support the membranes. When the muscles of the buttresses are relaxed the fold of skin which forms the membrane is drawn down to the surface of the arm so that there remains, as the only trace of the membrane, a line of fleshy protuberances, the relaxed buttresses. More substantial membranes border the outer mesial angle of the first arm, the lateral outer angle of the second, the single outer angle of the third, and both outer angles of the fifth arm. The outer lateral membrane of the fifth arm is very broad at its base where it stretches across outside the fourth arm and unites with the membrane of the third arm. The sheet thus formed by the proximal part of the membranes of the third and fifth arms is attached dorsally to the ventral edge of the capsule of the eye and forms part of the outer wall of a large sac which lies between this sheet and the inner side of the eye on one side, and the bases of the third 
and lifth arms on the other. 'This sic communicates with its mate and contains the peduncle of the fouth arm which is attached with the opposite arm to the lowel side of the head. 'The peduncle of the tentacle is oval in section and is very extensible so that the entire length of the tentacle varies from once and a half to thrice the length of the sessile arms. The club is ovate and acute and has fou rows of suckers. The margins of the club bear membranes somewhat wider than those of the sessile arms and the membranes are not supported by muscular buttresses but by the pedicles of the external rows of suckers. The external surface of the club bears a strong, keel-like membrane similar to the external membrane of the third arm. The distal portion of this membrane is folded upward against the club and lacks chromatophores upon its upper surface.

While the squid is swimming the arms are pressed together so that they form a flattened lance-shaped plate that is used, as a fin, for steering. The sessile arms form a flattened tube which encloses the peduncles of the tentacles and from which the two clubs project as the point of the fin. The edges of the fin are formed by the broad external membranes of the third arms and of the clubs. The squid always darts at its prey with the arms foremost and just as it comes within reach, it spreads out the sessile arms like the rays of a chrysanthemum and, by extending the peduncles of the tentacles, thrusts out the clubs, seizes the prey, and then draws it back to the mouth where it is grasped and held by the sessile arms.

Each arm is composed primarily of a cylindrical column of muscle which contains at its center a large nerve cord and which supports the suckers and the marginal membranes of the arm. This central column is formed by a large number of longitudinal muscle fibres which lie just inside the superficial fascia surrounding the column and by numerous short transverse fibres which extend from side to side and separate the longitudinal fibres into bundles. 'The transverse fibres interweave around the large central canal for the nerve and bloodvessels. One or more broad and thin sheets of longitudinal muscle fibres are attached to the external surface of this column.

'The muscular ridges which support the marginal ridges or membranes of the arms are formed by interlaced muscle fibres and are attached to the outer surface of the above described column by means of fibres which mingle with the transverse fibres of the arm. 'The pedicles of the arms are attached in the same way.

The suckers are shallow suction or adhesive cups, stiffened by rings of chitin-like material and attached to the arm by conical muscular stalks or pedicles. 
'The size and symmetry of the suckers depend upon their age and position. The arms grow continually and new suckers are added from time to time at the more rapidy growing apex. Hence, except on the tentacles, the largest suckers lie at the base of the arm and the smallest at the apex. At the base of the club of the tentacle, there are a few suckers that are smaller than those nearer the middle of the club. Lew, if any, of the suckers are symmetrical and the majority are very unsymmetrical. Those of the central rows of the club are the largest and most symmetrical while those of the lateral rows and of the sessile arms are very unsymmetrical. The side of the sucker farther from the center of the arm is enlarged and the opposite side is correspondingly reduced so that the most unsymmetrical sucker's become little mole than complex hooks. 'This arrangement of the suckers suggests that the obliquity of the strains to which they are subjected when in use causes the asymmetry of the suckers.

The pedicle of the sucker (Plate I, Fig. 3) projects inward from the inner surface of the arm. It is formed by a large number of longitudinal muscle fibres bound together by a few transverse fibres. 'The majority of the longitudinal fibres arise from the outer surface of the arm and bend around it beneath the marginal membranes of the arm to the inner surface where they join other fibres arising from the middle of the inner surface of the arm. The pedicle thus formed contains the nerve and blood ressels of the sucker and terminates in a strong fascia which lines the base of the cup of the sucker, and from which the muscle fibres of the sucker arise. 'This cup consists of a very thick muscular hase with a deep central depression and of a low rim supported by a thick toothed ring of chitin-like material. 'The center of the base of the cup is formed solely by the top of the pedicle which is called the "piston" because it acts as the piston of a pump whenever the arm is withdrawn after the sucker has been pressed against a surface. The muscle fibres which form the base of the sucker arise from the fascia that lines the cup and that is attached to the pedicle. The fibres pass obliquely downward and outward to the outer surface of the cup and end in a fascia which supports the sides of the sucker. 'The outer ends of the fibres are separated by a few small bundles of circular (sphincter) muscle fibres. The side of the cup is formed chiefly of three muscles. The largest of these is a strong sphincter which forms its lower part. The other two muscles arise from the external superficial fascia of the sucker and one is inserted upon the lower half of the ring; the other upon its upper half.

The ring is a broad band which is strengthened by a strong external ridge that separates the two muscles just mentioned. 'The free edge of the ring of the symmetrical suckers has about thirty large teeth separated by as many 
small teeth. Several rows of conical teeth, the accessory teeth, which gradually increase in height from within outward, are borne by the edge of the sucker and reinforce the teeth of the ring. Each accessory tooth is secreted by a single large epithelial. cell. 'The ring and accessory teeth are composed of a chitin-like substance which differs from chitin in being soluble in dilute alikalies.

'The external surfice of the sucker is covered by low cubical or flat epithelium and the sides of the cup are covered by a thicker epithelium which forms short tubular glands. The inner surface of the side of the cup is covered by a columnar epithelium which secretes the ring and whose height at each point is proportional to the thickness of the corresponding portion of the ring. The

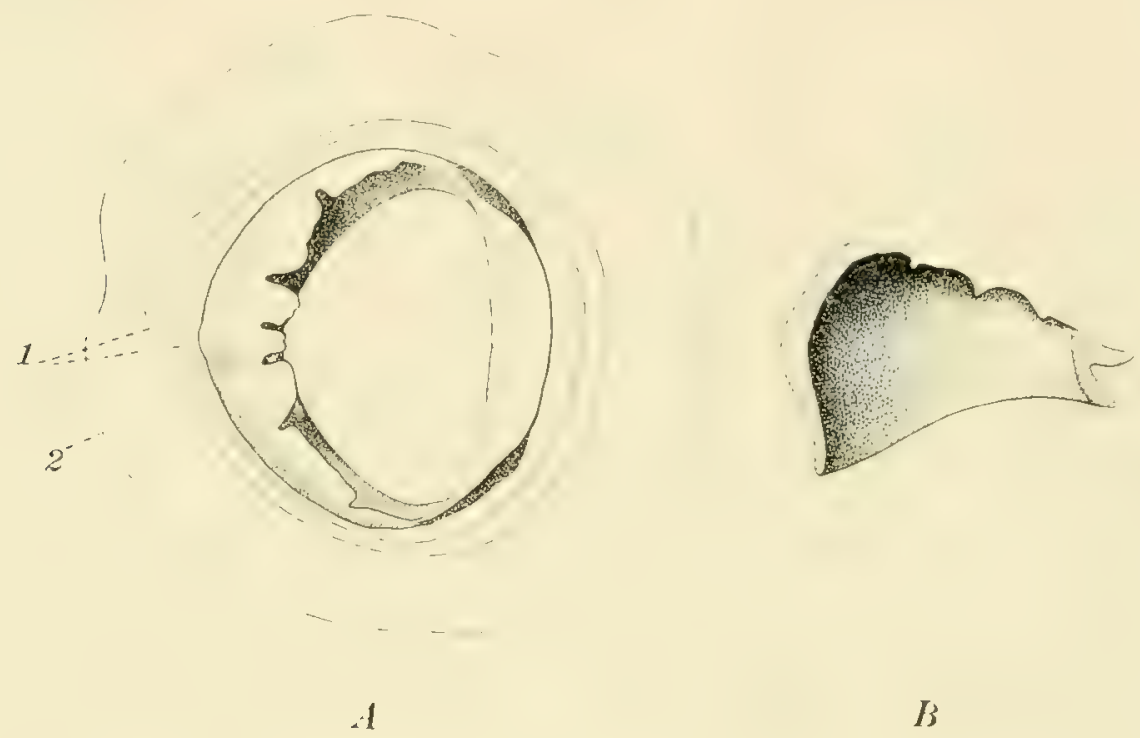

Fig. 9.

base of the cup is lined by a columnar epithelium, whose cells are several times as high as broad. 'The position of the nuclei of these cells varies greatly, in some cells the nuclei are at the base, in others at the middle, and in yet others at the free end of the cells.

The unsymmetrical suckers (Plate I, Fig. 4) have the basal muscle, the sphincter, and the lower ring muscle excessively developed on the large side and correspondingly reduced or lacking on the small side. The smaller side of the ring (text figure 9) is strongly ridged and is toothless while the large side lacks the ridge and has from five to seven large, strong, chisel-shaped, and incurved teeth. These suckers can serve only as hooks but the symmetrical suckers may be pressed against the surface of objects until the water is driven 
from the cup by the inpushed base and "piston", while when the arm is withdrawn, they hold by suction, often, until the pedicle breaks.

Argonauta and other Octopoda have one of the ams transformed into a sac. which, after receiving the spermatophores, is detached and placed in the mantle cavity of the female. 'This modified arm is called the Hectocotylus. The Decapoda have one or more rarely two of their arms slightly modified or "hectocotylized". In Loligo (Plate IJI, Fig. 18) the left fifth arm is hectocotylized. Some ten or twelve suckers on each side of the tip of the arm have their pedicles enlarged and their cups reduced, the pedicles becoming large blunt cones bearing minute cups or near the end of the arm both stalk and sucker are reduced. The inner row of suckers is less modified than the outer. 'The portion of the arm between the two rows of enlarged pedicles forms a rounded ridge as high as the pedicle. The hectocotylus probably represents the vestige of a functional structure of an ancestral form. It is barely possible that the arm may be used for the transference of suermatophores.

The siphon or funnel (text figure 10) derelopes from two pairs of ridges which appear upon the posterior surface of the embryo. The hinder pair appears between the mantle and the eye, and forms the siphonal valves which will be described later. The anterior pair lies below the gills and anus and between them and the arms. 'The latter ridges become elevated and incurved until their edges meet and unite, thus forming a conical tube, the siphon, which leads from the mantle cavity to the exterior. 'I'his muscular tube is attached dorsally by a pair of large muscles, the siphonal retractors. Each siphonal retractor is a strong rounded muscle which, arising from the side of the ventral end of the vane of the pen, passes obliquely downward

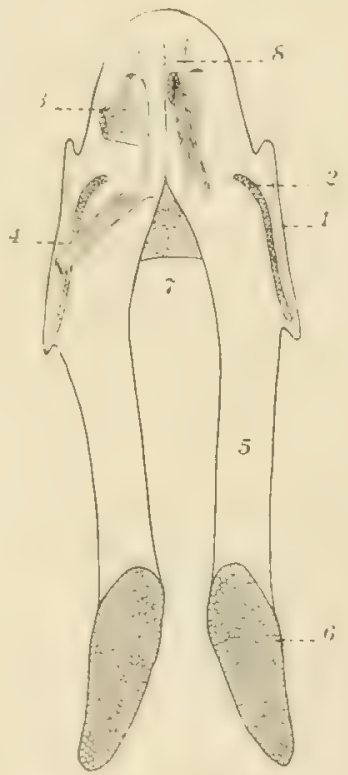

Fig. 10 . and forward in a depression between the liver above and in front, and the stomach, caecum, and nephridia below and behind, and terminates in one side of the siphon. Viewed from below, the two siphonal retractors appear as parallel bands which are separated at the back by the-anterior vena cava and which disappear between the nephridia and the gills.

'The arrangement of the intrinsic muscles of the siphon is very similar so that of the mantle fibres except. that there are longitudinal fibres which are apparently continuous with those of the retractor. The majority of these fibres form two pairs of bundles; an upper pair which lies near the median line, and 
a lowel pair which passes obliquely downward to the middle of the lower surfice. At the side of the siphon, but facing downward is the siphonal artilage, a grooved plate to which many muscle fibres are attached and which lits over the corresponding pallial cartilage. 'The siphon is attached to the head and liver case by the two siphonal valves and the "bridle." 'The latter is formed by two pairs of muscles, the siphonal protracters, which arise from the pedal process of the skull and pass outward and backward to their insertion upon the upper surface of the mantle. Each siphonal valve is a rectangular sheet of muscle which is attached by its upper edge to the nuchal cartilage, by its front edge to the liver case and by its lower edge to the siphonal cartilage. 'The free edge of this valve projects backward and prevents water which has entered the mantle chamber between the valve and the collar from escaping again through that opening. Another valve is formed by a muscular plate which projects outward from the inner surface of the upper half of the siphon as far as the end of the siphon and which prevents water from entering the mantle chamber through the siphon. The funnel is somewhat flattened to fit the space between the body and mantle. Its ventral half projects from the mantle cavity and may be directed forward or backward at will. Because of the presence of the valve in the siphon the expanding mantle draws water in only over the lateral siphonal valves and, because of the closure of the latter valves, expels the water from the pallial chamber only through the siphon. A jet of water from the siphon directed either forward or backward serves to propel the squid backward or forward.

The inner surface of the funnel has two pairs of long, elliptical glands, the siphonal glands, whose structure has been described in connection with the epidermis. The upper glands lie on the bases of the siphonal retractors and unite with one another in front. 'The lower glands are widely separate and lie upon the lower wall of the siphon. 'The surface of these glands is visibly elevated above the siphonal wall and is covered with slime. 'The function of the glands is unknown.

Muscles in the Viscerat mass.

The cephatic and muchal retractors. The cephalic and nuchal retractors with the nuchal and post-cephalic cartilages which are imbedded in them form a hollow cone or case which contains the liver. 'The base of this case is attached to the skull, and its apex is attached to the middle of the pen. The cephalic retractor arises partly from the pen and partly from the nuchal cartilage and is 
inserted on the dorsal surface of the skull. Its lower portion which arises from the pen, forms a thin sheet of muscle in which the post-cephalic cartilage is imbedded. Its upper portion is a thick short sheet of muscle which extends from the ventro-external edges of the nuchal cartilage to the skull. The whole muscle is a cylinder, short and thick above, and long and thin below.

'The nuchal retractor is a thick, strong muscle which arises from the pen in front of the origin of the cephalic retractor and which is inserted upon the dorso-lateral edges and the lower surface of the nuchal cartilage. The cephalic and muchal retractors move the head and also fasten it to the pen. 
'THE HEAD.

'The head of the squid consists of the primitive or true head and a portion of the foot. 'l'he portion representing the true head is slightly longer than broad and in transverse section is reniform. It may be compared to the stem of a lance whose blade is represented by the arms. The head is divided into three portions viz.: 1) a wedge-shaped dorsal portion consisting of the skull and the ganglia protected by it (oesophageal and optic ganglia); 2) a similar but more acutely wedge-shaped ventral portion consisting of an oval pharynx or "buccal bulb" enclosed by the muscular sheath formed by the interwoven muscle fibres at the base of the arms; 3) an hourglass-shaped central portion formed by the two hemispherical eyes whose convex inner surfaces almost meet at the center of the head and so separate the skull and ganglia behind from the pharynx and arms below. 'The majority of the muscle fibres which attach the arms and pharyngeal sheath to the skull arise from the cephalic and pedal processes of the skull and pass to the arms through the triangular spaces above and below the eyes. 'The pharyngeal sheath formed largely by these fibres is conical or tentshaped and is attached to the lateral ligaments as well as to the ventral processes of the skull. 'The oesophagus passes back from the pharynx through a venous canal which also holds a pair of arteries and the salivary duct, and which is a dorsal continuation of the cavity between the sheath and the pharynx. Each eye with its ganglion is enclosed by an unsymmetrical, helmet-shaped capsule formed of skin and muscle and attached to the margin of the optic cup. Beginning at the cephalic process, the line of attachment of the capsule to the skull can be traced outward along the upper edge of the skull, then downward along its outer edge, inward along its lower edge as far as the pedal process, and finally upward along the ventral edge of the lateral ligament. 'The outer wall of the capsule forms the cornea and almost the entire lateral surface of the head while the inner wall separates the eye from the sac for the peduncle of the tentacle. At the junction of the outer and the inner walls of the capsule, the membrane which connects the third and fifth arms is attached to the capsule so that to a superficial observer the arms seem to be attached to the eye. The carity of this capsule is the outer chamber of the eye and is in communication with the exterior by means of the "aquiferous pore", a tubular ciliated canal situated at the ventral edge of the cornea. 
Just behind the eye and forming the dorsal portion of the side of the head is a sinuous crest, the olfactory crest, which projects outward and backward toward the collar so that water entering the mantle chamber passes over it. 'The crest forms the dorsal boundary of two concavities, in the lower of which is a pit lined by a sensory epithelium in which the "olfactory nerve" ends.

'I'He paLLAL ChaMber, the visceral MASS, AND THE PALLIAI COMPLEx.

The mantle is essentially a fold which arises from the dorsal and anterior surface of the risceral dome and extends forward around the sides of the body, thus enclosing a space, the mantle chamber, which is largest below. The anterior and dorsal limits of the space are determined by the attachment of the mantle to the risceral mass. Anteriorly, the mantle chamber reaches up to the dorsal end of the nuchal cartilage. Thence, the antero-dorsal boundary of the cavity follows the edge of the pen to the dorsal point of the mantle, thus passing obliquely across the side of the visceral mass. The cavity is lined by a sheet of integument which covers the inner side of the mantle and is reflected orer the visceral mass. 'This integument forms a median mesentery which divides the dorsal part of the cavity and supports the median mantle artery.

The visceral mass or body is attached to the lower surface of the pen and is also loosely attached to the collar by means of the sliding joints between the pallial and siphonal cartilages and between the nuchal cartilage and the pen. It is divided obliquely by the siphonal retractors into a dorsal and a ventral portion. Its ventral portion lies above and in front of the siphon and siphonal retractors. It consists of the liver and the liver case which, as described above, is formed by the cephalic and nuchal retractors and the postcephalic and nuchal cartilages. 'The liver case is conical, its broad ventral end being attached to the skull and its somewhat flattened dorsal end being attached to the middle of the pen between the insertions of the siphonal retractors. The siphon is attached to the lower surface, and the lateral siphonal valves to the sides of the liver case behind the neck. The siphonal retractors are attached to the case by loose connective tissue and by the overlying integument.

The dorsal portion of the body contains all the visceral organs except the liver. It is corered above by the pen and below by the body wall which is thin and transparent and is formed by the integument and the peritoneum.

The organs of the pallial complex are glouped upon the lower surface and sides of the visceral mass near the bases of the siphonal retractors which not only separate the liver from the other viscera, but also divide the fore half of the mantle chamber into a median cloacal, and a pair of lateral respiratory 
chambers. Wach respintory chamber extends along the side of the liver case from the slit between the lateral are of the collar and the lateral siphonal valve which, it will be remembered, lies on the side of the liver case at short distance behind the head and forms the hind boundary of the neck, - to the long, longitudinal slit between the mantle and the body and siphonal retractor. Each gill arises from the side of the body at the level of the origin of the siphonal retractors and, passing outside this muscle, extends forward in the respiratory chamber to the lateral siphonal valve. A fold of integument forms a mesentery which attaches the gill along its whole length to the mantle. Water entering the mantle passes between the lateral siphonal valves and the mantle, over and through the gills, and then enters the cloacal chamber which extends from the right and left compartments of the hind end of the chamber, forward to the imner opening of the siphon, through which the water escapes to the exterior.

The rectum emerges from the lower surface of the body at the level of the base of the gill, and extends forward to the proximal opening of the siphon. A nephridial pore opens through the rounded lower wall of the viscera at a point midway between the base of the rectum and the corresponding portion of the siphonal retractor. In the female, the openings of the nidamental and accessory nidamental glands lie a short distance behind the nephridial pore. The oviduct passes under the base of the gill and emerges from the visceral mass into the cloacal chamber between the rectum and the left siphonal retractor. It ends a short distance behind the tip of the rectum. In the male, the penis occupies a corresponding position. The genital sac, which Narchaxd believes to be homologous with the nidamental gland of the female, opens into the mantle chamber on the outer side of the penis beneath the base of the gill. 


\section{'IHE AIIMENTART CANAI。}

'The alimentary canal (Plate I, Fig. 7) arises from a stomadaeum which forms the epithelium of the pharynx, esophagus, and probably of the stomach, and from a second anlage which forms the caecum, intestine, rectum, inksac, liver and pancreas and whose origin has been a mooted point. 'This anlage is first clearly' seen as a small epithelial cap whose edges rest upon the yolk mass and whose cavity is bounded below by the yolk. WATASE believes this to be a proctodaeum but it now seems quite clear that a proctodaeum is not formed. Apart from his view, it is generally agreed that the cells forming this cap migrate singly from the ectoderm as do all the entodermal, mesodermal (and yolk?) cells of the embryo and later arrange themselves in an epithelium. Hence we believe that the whole discussion is a essentially a matter of names. To BobretzkT: it is mesodermal: to FAussek and Teichman, it is mesentodemal and becomes the definitive entoderm; while to Vialletor and Korschetr, it is entodermal.

The glands of the gut are a median and a pair of lateral salivary glands, a pair of compound glands which form the pancreas and liver, and the inksac.

The Pharrxx. The mouth (Plate III, Fig. 17) is surrounded by the buccal and peristomial membranes. The former is a thin circular sheet attached to the bases of the arms and extending forward around the latter. The buccal membrane is supported by seven muscular columns which form the projecting points of the scalloped free edge of the membrane. The inner surface of each column bears ten or twelve stalked suckers arranged in two rows. The columns are attached to the muscular ring at the bases of the arms as follows; - a median column between the bases of the first pair of arms, one between each first and second arm, one between each third and fifth arm and two side by side between the fifth arms.

The buccal membrane of the female has a horseshoe-shaped depression on its inner surface below the mouth. The spermatophores are closely packed on end in this depression and they form a white spot which, when present, is a convenient and positive mark of the female.

The peristomial membrane is a tubular fold of integument, arising in the angle between the base of the buccal membrane and the pharyn and containing 
in strong sphincter muscle and in thin sheet of longitudinal fibres which arise from the equator of the pharynx and end among the circular fibres. The free edge of the membrane forms a circular lip. The contraction of the sphincter transforms the peristomial tube into a cone, thus practically closing the mouth and throwing the otherwise smooth or slightly wrinkled surface into folds.

The pharynx is armed with a pair of powerful chitinous jaws to which a number of strong muscles are attached. The mandibles and muscles together enclose the pharyngeal cavity and form a large oval mass, the pharynx or buccal bulb, which is enclosed in the muscular case (described in connection with the foot) formed by the bases of the arms. A pair of salivary glands and the infrabuccal ganglion are attached to the dorsal end of the pharynx and the oesophagus is attached near but a little above them.

The space between the pharynx and its case is an extensive but incapacious blood sinus which is divided into two cavities, the outer, and the inner buccal sinus, by a thin-walled conical muscular tube which is attached to the equator of the pharynx and extends backward to the dorsal end of the pharyngeal case. This tube or tubular muscle is the retractor of the pharynx. Its uniform contraction draws back the pharynx into the sheath while the contraction of one or more segments of the muscle tilts the pharynx in the corresponding direction. The outer buccal sinus contains three small pharyngeal muscles. One muscle, the levator mandibuh, which seems to be a specialized portion of the pharyngeal retractor, arises just outside it from the upper portion of the pharyngeal case, and passes forward (ventrad) in the median line to its insertion on the upper mandible. The other two muscles are a pair of thin bands which arise near together from the upper. side of the dorsal end of the pharyngeal case and, passing downward around the pharynx, are inserted upon its lower surface. 'These muscles rotate the pharynx on its long axis. The pharynx is easily movable so that it can be thrown forward more than half its own length, apparently being squeezed out by the contraction of the muscles of the pharyngeal case, and can be retracted or rotated by the muscles described above. The inner buccal sinus contains the infrabuccal and suprabuccal ganglia, the pharyngeal arteries, the duct of the median salivary gland, and the nesophagus. It is prolonged backwald as a canal thru the oesophageal nerve ring. The buccal sinuses are lined by the vascular endothelium.

The mandibles, or jaws (Text figure 11 ) resemble a parrot's beak inverted. 'The upper mandible is longer, straighter, and more compressed than the lower' which is strongly convex and closes outside the upper jaw. Each mandible is formed of two boat-shaped lamellae which unite at an acute angle and make the 
cutting edge of the jaw. 'This edge is drawn up into a strong median tocth which is tlanked by a pair of small notches. 'The pharyngeal muscles are attached to the adjacent surfaces of the lamellae of each jaw and fill the narrow space between them. The jaws grow constantly by additions to their margins and to their unexposed surfaces. 'They are marlied by two sets of fine striae, the lines of growth, one set concentric with the point of the jaw and one set ladiating from it. The jaws are brownish-black on the cutting edges, amber colored near those edges, and colorless at the fiee margins.

'The upper mandible is almost as long as the pharyns and is shaped like the prow of a very deep and narrow boat. Its inner lamella, to the dorsal end of which the oesophagus is attached, forms the greater portion of the lining of the oral cavity. The outer lamella is more strongly curved and is not half as large as the inner. The lexator manciburi is attached to its dorsal end.

The lower mandible is about half as long as

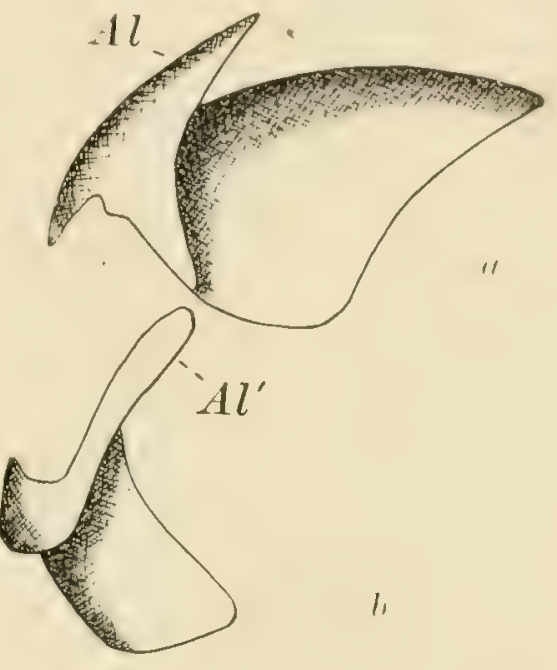
the upper but is less compressed and more curved so that it fits orer the distal end of the inner mandible. The inner lamella has much the same shape and size as the outer lamella of the upper jaw; the outer lamella of this jaw, is a long, broad band which extends backward parallel to the edge of the jaw and forms a pair of prominent wings, the alae. The upper' jaw is comparatively fixed while the lower rotates thru an angle of $45^{\circ}$ about an axis which passes almost thru the middle of each side of the inner lamella of the upper jaw. 'The muscular

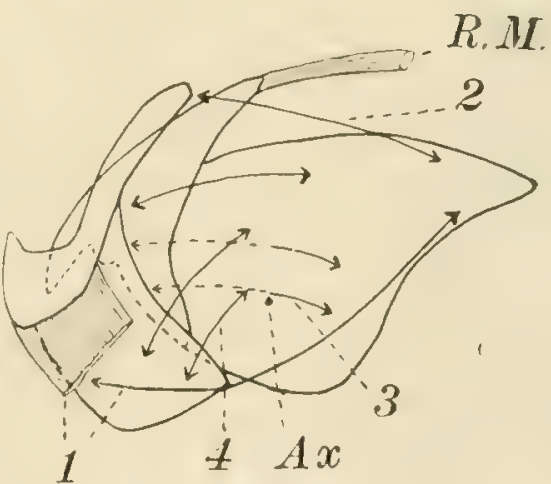

Fị. 11. fibres (Text figure 11, c) which move the jaws arise from the inner lamella of the upper jaw and take a spiral course around this axis. The fibres 13 in the figure) from the lower portion of the middle of the inner lamella of the upper jaw pass directly outward and are inserted in a strong, superficial fascia which is attached to the outer lamella of the lower jaw and which covers the lower half of the pharynx. These fibres form a central column around which 
the other fibres are wound and around which the lower jaw moves. Other fibres (2) which arise from the dorsal end of the same lamella pass outward and forward to the inner sufface of the ala of the lower jaw. Fibres (4) which arise from the forward part of the inner lamella of the upper jaw pass outward and downward over the edge of the inner lamella of the lower jaw and are inserted mpon its outer surface. 'The contraction of these muscles, causing the jaw to rotate around the axis $(\mathrm{Ax})$, draws the lower jaw like a visor over the upper jaw. A pail of superficial muscles (1) which arise from the back end of the upper jaw, pass forward and slightly downward to the middle of the outer lamella of the lower jaw and open the mouth by drawing the lower jaw backward and downward. The jaws are sufficiently powerful to cut and break the bones of small fish or the pen of a quite large squid.

The mouth contains the two palatine lobes and the odontophore. Each palatine lobe is a muscular curtain which is attached to the hind and lower edge of the inner lamella of the upper jaw and lies upon the inner surface of the same lamella. The upper edges of the palatine folds are thickened (especially near the distal end) and project into the mouth, meeting in the median line. The outer surface of each fold is covered by a columnar mucous-secreting epithelium and the inner surface by a columnar epithelium that secretes a thin sheet of chitin which is covered with small backwardly directed teeth. The odontophore is attached to the lower part of the hinder end of the upper jaw and projects forward into the mouth cavity, lying below and partially between the palatine lobes. The lower part of the odontophore is quite distinct from the rest and is called (by Livon) the tongue: the upper part consists of the radula and its appendages. The tongue has a muscular frame work, formed by an upper and a lower pair of longitudinal bands which arise from the posterior edge of the upper jaw and which are bound together by connective tissue and transverse muscle fibres. The upper surface and the tip of the tongue are covered by a thin sheet of chitin, but the sides and lower surface are covered by a palisadal mucous epithelium which forms a large number of sparingly branched tubular glands that occupy the spaces between and around the muscles of the tongue.

The radula is secreted by a deep cylindrical sac which extends backward from the middle of the pharynx to its dorsal end, describing a slight curve, convex beneath. The sac is lined by a chitin-secreting, cubical or palisadal epithelium which, upon all sides except the upper, is raised into small papillae upon. which the teeth are secreted. The epithelium of the upper surface of the sac forms irregular folds covered by a thin sheet of chitin which project into the lumen and occupy the spaces between the teeth. The teeth and this sheet 
of chitin are supported by a tough sheet of connective tissue, known as the subradular membrane. At the ventral end of the radular sac the tooth bearing portion of this membrane is reflected downward over the lower surface of the odontophore between it and the tongue, while the toothless portion of the membrane is reflected backward over the sides and top of the odontophore. The teeth ('Text figure 12) are arranged in seven longitudinal and an indefinite number of transverse rows. Each transverse row consists of a central tooth flanked by three pairs of lateral teeth and has, at each end, a flat oval plate of chitin. The central tooth has a strong middle point and a pair of lesser lateral points. The tooth at either side of the center consists of a large inner and a smaller outer point. The teeth of the second and third rows from the center are strong, long, curved spikes. New teeth are constantly produced at the base of the radula and gradually push outward until they reach the mouth of the sac where they are drawn downward and then backward over the end of the odontophore. While in the radular sac, the points of the teeth project toward its base (backward) but as they are drawn over the end of the odontophore the teeth point first upward and then forward so that they rasp

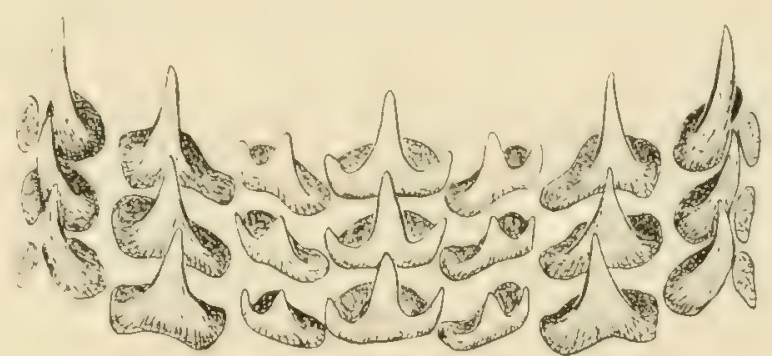

Fig. 1․ food only as the radula is drawn into its sac.

Two pairs of muscles, the radular retractors and protractors, draw the radula in and out over the apposed ends of the two radular cartilages which support it. These cartilages lie at the side of the radular sac and are slightly curved uprard at each end. 'The dorsal ends of the rod-shaped cartilages are fastened to the lower part of the dorsal end of the upper jaw by means of muscle fibres which radiate backward, inward and forward from the jaw to the cartilage. The upper, i. e. the concave, side of each cartilage is covered, except at the end, by a transverse muscle which is several times as thick as the cartilage. 'The fibres of this muscle are sufficiently curved to be concentric with the cartilage and arise from, and are attached to, a fiscia which extends from one end of the fibres downward under the cartilage and up on the opposite side to the other end of the same fibres. The only action which I can assign to this peculiar muscle is that the thickening of its fibres during contraction, presses downward the ends of the raduar cartilage, straightens it and thereby forces the radular forward. 'The radular cartilages are connected by a sheet of muscle which stretches beneath the radular retractors. A similar but thicker and narrower sheet of muscle 
between the cartilages above the radula and radular retractors forms with the lower muscle an oblipuely conical tulne which contains the radular sac and over whose apex the radular membrane is reflected.

The radular retractor's arise from the dorsal end of the radular cartilages and extending forward parallel to the radula are inserted near the ventral ends of the cartilages upon the subradular membrane.

'lhe protractors of the radula arise from the lower edge of the upper jaw and passing forward and inward are inserted upon the reflected distal end of the subradular membrane. A small portion of the protractor is inserted upon the toothless portion of the same membrane which, it will be remembered, covers the sides and top of the odontophore. 'I'he alternate contraction of the retractor's and protractors draws the radula back and forth orer the ventral end of the radular cartilages. The teeth act only during retraction hence the retractors are much more powerful than the protractors.

'The mouth, the oesophagus, the radular sac, the median and the paired salivary glands and probably the stomach also arise from the stomadaeum.

'The salivary glands are relatively simple compound-tubular glands. The lumina are large and are surrounded by palisadal cells whose large nuclei are situated next the supporting membrane and whose distal halves are filled by large secretion vicuoles. 'The secretion in the lumina is usually precipitated by fixatives. An incomplete series of tests showed that aqueous and glycerine extracts of the median gland are not oleolytic or amylolytic, and that they are probably protenlytic. FArLolse finds this to be the case. 'The glands also secrete mucin.

Henze confirms the observations of Lo Braxco, Krause, and Livon \& Briot, that the secretion of the posterior salivary glands of various cephalopods injected into the circulation of crustaceans, eren in small quantities, is quickly fatal. Henze finds that the poison is an organic base (alkaloid) similar to the poison of bees and of the skin of salamanders. 'The gland contains also two nitrogenous substances; one of these, taurin, is rery abundant in the muscles of cephalopods, and since von FurTu has found very little nitrogen in the secretion of the nephridium, Hanze suggests that the gland is, at least in part, excretory.

'The paired or buccal salivary glands are partially imbedded in the muscles upon the dorsal surface of the pharymx between the radula and the oesophagus. The duct of each gland passes through the palatine lobe and opens into the mouth on the inner side of the lobe near its ventral end. 'I'he median salivary gland is a small oval body imbedded in the ventral end of the liver. It lies in a small venous sinus situated beneath the oesophagus and between the diverging risceral and pallial nerves. Its duct accompanies the oesophagus through the 
oesophageal and inner buccal sinuses and entering the lower side of the pharynx opens into the mouth at the tip of the tongue.

'Ine Oesophagus. 'The oesophagus extends from the pharynx through the skull, the oesophageal nerve ring and the liver to the stomach. It passes directly backward in the oesophageal sinus until it has passed under the cerebral ganglion, then it turns slightly upward and passes thru the fascia that closes the large foramen of the skull. 'Lhis finscia separates the liver from the oesophageal nerve ring, covers the visceral ganglion, and closes the dorsal end of the inner buccal sinus. Having left the head, the oesophagus passes obliquely upward and backward thru a very deep groove (apparently a canal) in the liver to its upper surface. It continues backward in a shallow groove on this surfice until some distance beyond the middle of the liver. At this point it passes obliquely downward thru the liver and emerges on its lower surfice between the hepatic ducts. 'I'he oesophagus atter leaving the liver, passes between it and the nephridial sac, and being deflected slightly to the right enters the ventral end of the stomach near the middle of the visceral mass. 'The wall of the oesophagus is formed by a thick outer layer of circular muscle fibres, a thin inner layer of longitudinal muscle fibres and a columnar epithelium which secretes a thin chitinous cuticle. This cuticle is continuous with that which covers the surface of the odontophore and the inner sides of the palatine lobes and with the lining of the stomach.

The Stomach. 'The stomach and caecum are oval muscular sacs which lie on the right and left side respectively and project into the coelom from its ventral end. 'The nephridia and the branchial and systemic hearts are below these organs; the dorsal end of the liver is above them; and the gonad lies above and behind them. 'The stomach and the caecum are very distensible and may occupy only the ventral third of the coelom or may extend nearly to its dorsal end.

'The stomach is a thick-walled, muscular, oval sac, whose inner or left surface is adherent to the inner surface of the caecum. Its wall is formed by five layels viz. 1) the peritoneum, a sheet of ciliated pavement epithelium;2) a thin outer layer of oblique muscle tibres; 3 ) a thick middle layer of circular muscle fibres; 4) a thin inner sheet of oblique muscular fibres; 5) a palisadal epithelium that secretes a chitinous cuticle which lines the stomach. 'There are no mucous or other secretory glands in the walls of the stomach and oesophagus

'I're Caecux. 'The caecum has a very thin wall. It is largel than the stomach and is closely connected with it. The openings (which will be more fully described below) connecting the caecum with the stomach, intestine, and liver are close together at the ventral end of the caecum. 'They lie in the crest of a 
broild. horizontal ridge that passes from the stomach to the left side of the caccum between two large lobes of the caecum which project forward above and below the intestine and stomach so as nearly to encircle the ventral end of the latter. 'The caecum is seldom or never' empty but is usually partially distended so that it extends about to the middle of the coelom and when in this condition it is pear shaped, the smaller end being dorsal. A small circular band of muscle fibres divides the smaller end from the main portion of the sac. 'This band may be strongly contracted so as to produce a diaphragm-like curtain perforated by a large central hole or it may relax so completely that the caecum becomes narrowly oval. A number of folds are formed from the lining of the outer wall of the ventral end of the caecum and of the adjacent portions of the upper and lower walls. The folds are blade-like and radiate from the outer end of the crest that separates the two ventral lobes of the caecum. 'The folds vary in size and are arranged like the mesenteries of a sea anemone: that is, the largest folds are equidistant from one another, smaller folds are placed midway between these, still smaller folds are placed midway between each large and small fold, and so on until the smallest folds are mere ridges. Each fold is corrugated by a series of ridges which are parallel to the free edge of the fold and which alternate on the opposite sides of the fold. Henr finds that the secretion of the caecal folds assists pancreatic digestion.

The wall of the caecum is formed of three coats; viz. the outer pavemental epithelium of the peritoneum, a middle coat of muscle fibres, and a lining or secretory epithelium. 'The latter presents three chief types which are connected by transitional forms. 1) 'The epithelium covering the caecal folds and the adjacent region is thick, densely ciliated, and palisadal. The nuclei lie at the base of the cells and the distal portion of the cells is often filled with granular protoplasm.2) The epithelium of the greater part of the remainder of the ventral portion of the caecum is exceedingly irregular but the characteristic cells are columnar or club-shaped and usually occur in groups of three or more. The nucleus often lies at the distal end of the cell, while in other cases the distal end of the cell is vacuolated and the nucleus is at the base. 'The cells are sparingly ciliated. 3) 'T'he epithelium of the dorsal end of the caecum is cubical or pavemental and ciliated. It is possible that tension may change the epithelium from one type to another but this is improbable because the three types often occur close together in a portion of the ivall which is apparently under uniform strain.

The communication (Plate I Fig. 2) between the caecum and the neighboring cavities of the gut is by means of a very remarkable five-way valve whose lumen may be roughly compared to a letter M. The two upper points of the M-shaped 
lumen open into the stomach and caecum. 'The right arm of the lumen leads to the oesophagus, the left to the hepatic duct and the central point to the intestine. The three angles included between the four arms of the lumen are formed by the walls which separate (1) the oesophagus and the intestine, (2) the stomach from the caecum, and (3) the intestine from the hepatic duct. The openings from the oesophagus and from the stomach are circular and are controlled by sphincters. 'The openings between the caecum and the intestine, and between the hepatic duct and the caecum have in addition to sphincters, three adjustable valves. One valve which we may call the gastric valve, is a high, hooked ridge which is situated upon the upper side of the opening from the caecum to the stomach. Its concave side is directed toward the right i.e. toward the stomach. A second, the intestinal valve, is formed by a high ridge which arises on the upper wall of the intestine, passes backward to the opening between the caecum and intestine, and then curves upward around the edge of this opening forming here a quite high tubercle that projects into the caecum. A ridge arises on the left of the intestinal valve and passes backward through the caeco-intestinal opening and then outward along the edge of the large partition between the upper and lower lobes of the caecum. 'This ridge ends in a large, spoon-shaped valve, the hepatic valve, which lies just behind and above the opening of the hepatic duct. The concave surface of this valve is turned toward the opening and the valve can be turned downward so as to cover the opening and form a deep groove that, by being pressed against the adjacent wall, is converted into a canal which leads from the hepatic duct to the intestine. By the contraction of the caecal opening and the turning downward of the hepatic valve, the caecum can probably be occluded from the rest of the gut while a passage may remain open from the hepatic duct to the intestine and through it to the stomach.

The action of the muscles and ralves above described is somervhat conjectural since it is impossible to observe their normal action. However, a careful study of all the data at hand leads to the inference that the following adjustments probably occur. 1) 'The oesophagus opens into the stomach. The food is prevented from passing out of the stomach by the contraction of the sphincter between the stomach and the caecum. The gastric valve may possibly be drawn into the opening to serve as a plug. 2) 'The oesophagus may open into the caecum. This adjustment may be effected by the contraction of the sphincters around the ventral end of the stomach and around the intestine accompanied by the relaxation of those around the oesophagus and caecum. 3) The stomach opens into the caecurn. This is accomplished by the relaxation of the sphincters around the 
stomaln and caccum and the contraction of those around the oesophagus and intestine. 4) 'The stomach may open into the intestine. 'The relaxation of the sphincters around the gastric and intestinal openings and the contraction of those around the oesophageal and caecal openings may produce this connection. a) 'The caecum opens into the intestine. (i) The hepatic duct opens directly into the caecum. 7) The shape and position of the hepatic valve suggest two possibilities: lirst, that the valve may close over the hepatic duct and prevent the regurgitation of fluids from the caecum; second, that the valve may be apposed to the caecal wall so as to form a canal which leads, even when the openirg from the caecum to the intestine is closed, from the hepatic duct to the intestine so that the digestive fluids which ordinarily pass directly from the hepatic duct to the caecum may be diverted to the intestine and through it to the stomach. 'This second possibility is strongly suggested by the form and position of the valve but there is great doubt whether this ever occurs. The explanation of this remarkable connection between the portions of the gut is to be found in the great difference in structure and in function between the stomach and caecum. The stomach, oesophagus, and mouth (that is the entire gut as far as the opening from the stomach to the caecum) are lined with chitin and, with the exception of the glandular epithelium upon the unexposed surfaces of the tongue and palatine lobes, is nonglandular. 'The three salivary glands are connected with the mouth but they are so small that they can scarcely have a predominant digestive function and, unless they do produce a remarkably effective digestive fluid, the tood in the stomach is not digested by fluids produced by the anterior portion of the alimentary canal. Nevertheless, the examination of the contents of the stomach of a large number of squid shows that digestion does take place in the stomach for the ingested food is found in the stomach in all stages of digestion from large angular pieces wholly undigested to a mass of bones and bits of chitin from which all flesh has been removed. The caecum and intestine, on the other hand, are lined by a ciliated secretory epithelium and receive the secretion from the immense digestive glands, the liver and pancreas. The structure of the stomach and caecum naturally leads to the supposition that the stomach is merely a crop for storing food until it can be passed into the caecum for digestion but in the large number of individuals examined, bones, chitin, or pieces of undigested food were never found in the caecum while, as has been stated, partially digested food and indigestible substances are found in the stomach. Hence it seems clear that the first stages of digestion, at least, occur in the stomach. All these facts lead us to the following conclusion which agrees with that of Bourouelot who reached the result from a study of the physiology of 
digestion; that the food is comminuted and partially digested in the stomach by the digestive fluids introduced from the caecum or from the pancreas and liver: that the partially digested food then passes into the caecum for complete digestion and absorption while the bones and indigestible residue are ejected from the stomach through the intestine to the exterior. It is probable that the fluids from the liver and pancreas pass into the caecum and from it to the stomach but it is possible, as suggested above, that these secretions may flow directly into the intestine and thence to the stomach.

'The Liver and Pancreas. These glands arise from two long tubular evaginations from the caecal portion of the mesenteron. 'These tubes extend outward to the risceral wall and then forward as far as the skull. 'They are flattened laterally between the yolk mass and the visceral wall. At first the wall of each tube is formed by a plain cubical or palisadal epithelium but later each tube becomes differentiated into three portions. 'The distal portion becomes a large racemose gland which fuses with its mate to form a conical gland, the liver. The middle portion of each forms a short hepatic duct. 'The proximal portion of the evagination forms one side of the pancreas. The two evaginations, originally independent, are carried out by another evagination of the caecal wall, so that they finally open together into the caecum. This secondary evagination becomes the common hepatic duct and its walls becoming glandular, form the unpaired portion of the pancreas. 'The fact that the liver and pancreas are originally paired structures accounts for the passage of the oesophagus thru the liver and of the intestine between the lobes of the pancreas.

The liver is conical. Its broad ventral end rests upon the skull and its pointed dorsal end lies beneath the middle of the pen. The ventral end of the liver is irregular because the median salivary gland is imbedded in it and because the visceral and pallial nerves, and the oesophagus and aorta pass obliquely through it in deep grooves or in canals. 'The groove for the oesophagus and aorta continues backward to the middle of the upper surface of the liver. At this point, it opens into a canal which passes obliquely downward and backward to the lower side of the liver, ending between the hepatic ducts at a point about one third the length of the liver from its dorsal end. The two hepatic ducts emerge from the liver, one on each side of the oesophagus and aorta, and pass immediately into a space between the siphonal retractors, and above the anterior vena cava. After a short course in this space. they enter the pancreas which lies in the nephridial cavity. 'The hepatic ducts and the liver are attached to surrounding tissues by means of loose connective tissue.

The liver is a compound tubular gland of light yellowish-brown color. 'The 
colls of the standular epithelium of the tubules are cubical or columnar and certain of them are longer than others and project into the lumen making the inner surfice of the tubule very irlegular. 'The large round nucleus lies at the base of the cell and the protoplasm at the distal end of the cell is granular and often vacuolated. 'The epithelium is supported by a connective tissue frame work which carries the veins and arteries. 'The secretion of the liver is proteolytic.

'The hepatic ducts are simple, thin-walled, muscular tubes lying side by side and leading from the livel to the pancreas. 'The lumen of each duct is continuous with those of the corresponding lobes of the liver and of the pancreas.

The pancreas is a whitish, slightly lobulated gland surrounded by the nephridial sac. As a whole it is U-shaped. The two arms begin at the points where the hepatic ducts enter the ventral end of the nephridial sac and pass backward, one on each side of the intestine. They unite behind it just before the duct enters the caecum. 'The dorsal part of the pancreas lies between, and is partially adherent to, the two ventral lobes of the caecum. 'The wall of the pancreas separates the lumina of the pancreas (the hepatico-pancreatic duct) and of the nephridium and contains numerous evaginations from both cavities. 'The external surface of the gland is covered by a palisadal epithelium which is the reflected epithelium of the nephridal cavity. 'The nuclei of the cells of this epithelium are arranged in a regular layer near the outer ends of the cells. 'The epithelium forming the walls of the tubules of the gland is pavemental or cubical. The extract of the pancreas is proteolytic, amylolytic, and oleolytic but it is possible that the proteolytic enzymes are derived from the liver for it is impracticable to remove the hepatic secretion from the lumen of the pancreas.

Falloise finds that the hepatico-pancreatic secretion is continous but is much more copious during digestion. The fluid is acid, colorless to brown or yellow, is rich in proteids, contains a proteolytic ferment, amylase, lipase and erepsin. Invertin is absent.

The gut distal to the caecum passes obliquely downward to the lower surface of the visceral mass and then passes forward some distance. It is usually divided, for purposes of description, into two portions viz: the intestine which is a short wide tube extending from the caecum to the lower surface of the visceral mass, and the rectum which is a long conical tube attached to the lower surface of the visceral mass.

The intestine passes forward from the caecum between the caecal lobes, and between the oesophagus on the right and the pancreas on the left. 'Then it turns sharply downward, passing between the right and left lobes of the pancreas and between the two arms of the $V$-shaped nephridial sinus 
and in front of the heart which lies between the nephridium and the pancreas.

The rectum lies just beneath the skin of the lower surface of the visceral mass. Its upper surface is next to the ventral part of the nephridium and to the ink sac which separates it from the anterior vena cava. 'The rectum is about half as long as the liver and it extends from the level of the hinder end of the liver to the middle of the same. 'The forward end of the rectum is attached to the liver case by a mesentery-like fold of skin. It ends in a small anal chamber from which it is separated by an anal sphincter. 'The ink sac opens into the anal chamber and the chamber opens into the mantle cavity through the transversely oval anus which is

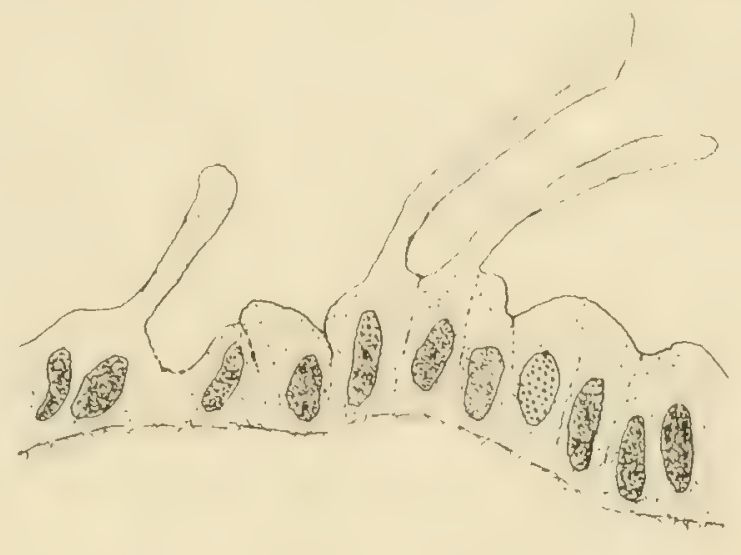
bounded by an upper and a lower lip. A pair of ovate leaf-like processes, the rectal valves, supported on short round stalks are attached at each side of the anus.

The wall of the intestine and rectum has the usual circular and longitudiual muscles and, with the exception of the distal part of the rectum, is lined by a ciliated columnar epithelium in which are scattered go-

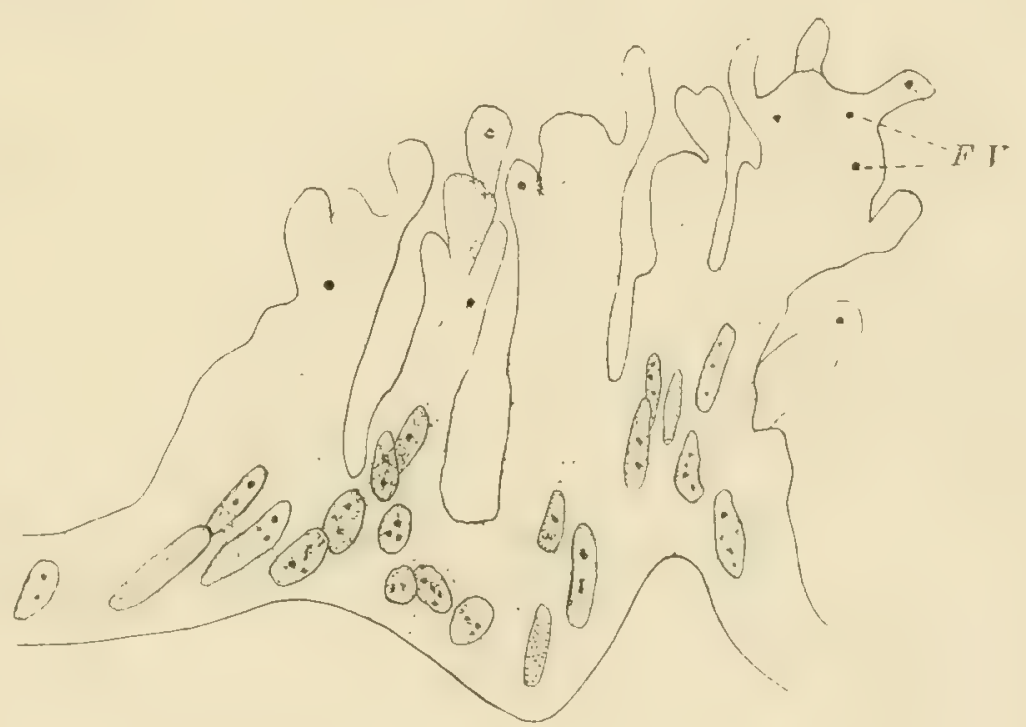

Fig. 13. blet cells. The epithelium of the middle of the rectum is non-ciliated and contains a large number of goblet cells while that of the ventral end is palisadal, nonciliated, and contains a large number of characteristic cells ('T'ext figure 13). Each of these cells has a single process from one to four times as long as the cell and one half or less the breadth of the cell. 'The majority of the processes are blunt, but some of them taper out into fine points while a few are knobbed or contain a vacuole in the free end. 'The processes vary in size from mere 
Imotuberances on the free surfices of the cells to long tentacle-like processes. This variation leads to the supposition that the processes are capable of being cxtended and withdrawn. In young squid the processes retain their independence but in the adult the processes of several adjacent cells fuse and form an irregular corill-like mass. 'These masses often contain bodies which appear to be food grimules and racuoles.

In transparent young, 5 or $4 \mathrm{~mm}$. long, the l'ectal valves can be seen beating downward into the anus and as they descend the anal lips open; as they rise, the anal lips close. This action drives water into the rectum and in an experiment particles of carmine in the water were carried into the rectum. Contractions of the rectum drove the water out through the anus while the carmine was retained, probably being screened out by the processes, and was then carried by cilia as far as the proximal end of the intestine. The appearance of the rectal cells in the adult leads us to suppose that the processes are truly pseudopodial and that the granules in them are food particles undergoing intracellular digestion. Intestinal pseudopodia and intra-cellular digestion have not, we believe, been described in any molluse and it will be surprising if it is proven that structures and habits commonly associated with much simpler animals occur in the highest of the mollusca.

The INK SAC. The ink sac is a large pear-shaped organ situated above the rectum, below the anterior rena cava and the liver, and in front of the nephridium whose median portion separates it from the intestine. The ink sac arises from an evagination of the upper side of the distal end of the rectum and becomes differentiated into three portions: a dorsal glandular portion, a large conical reservoir. and a short duct which leads forward from the small end of the reservoir to the anal chamber. The glandular portion is oval and consists of a series of connected chambers lined by a cubical glandular epithelium which secretes the jet black ink. The size of the chambers increases rapidly from the small dorsal chamber to the large ventral chamber which occupies the greater part of the ventral half of the glandular portion and opens into the reservoir thru a small opening in the iniddle of its convex ventral surface. 'The dorsa] half of the glandular portion is attached to the wall of the sac but the ventral half projects freely into the reservoir in which the ink is stored. 'The reservoir' is a conical chamber whose large dorsal end is formed by the glandular portion of the ink sac and whose narrow ventral end is continuous with the duct from which it is separated by a sphincter. This chamber is homologous with the reservoir and the long tubular portion of the duct of Sepia while the duct of Loligo is homologous with the small terminal chamber or "ampulle" of Sepia 
(Grrop). The duct opens into the anal chamber and its distal end is surrounded by a sphincter. The wall of the ink sac is formed of an outer sheet of connective tissue, a middle sheet of circular and longitudinal muscle fibres, and an inner sheet of pavemental epithelium. 'The reservoir has an additional layer situated between the epithelium and the muscular layer. 'This layer is about as thick as the other layers combined and is formed of iridiocysts whose fibres reflect light and give the ink sac its beautiful silvery luster. The jet black ink, as is well known, is discharged into the water and produces a black cloud under cover of which the squid may escape an enemy. Such a provision is very useful to an animal which has neither protective skeleton, efficient defensive organs, nor the porver of sustained rapid motion. 'The ink of Sepia is composed of melanin, which is produced by the action of a ferment, tyrosinase (von FürTh) and which is accompanied by laccase (GESSARD).

In conclusion it may be well to describe the very interesting manner in which the squid captures and eats its prey. While stalking the prey, the squid swims lazily forward and backward in a zig-zag line, gradually approaching the animal which is to be captured. This motion is produced by jets of water ejected through the siphon which is turned forward to drive the squid backward, and backward to drive it forward. The fins keep up a slow undulating motion by means of which the back end of the body is guided in the proper direction. At the same time the arms are pressed together to form a lance-shaped fin which is generally bent upward while the siphon is turned forward, and the squid is going backward: and is bent downward while the siphon is directed backward and the squid is moving forward. 'The squid having come sufficiently near, turns its head toward the prey and by a powerful contraction of the mantle, drives a jet of water backward through the siphon and shoots forward like an arrow. Just as it reaches its prey, the sessile arms spread outward like the rays of a clirysanthemum and the tentacles are driven forward so that they are pressed against the prey which is quickly drawn back to the mouth and grasped by the sessile arms. Sometimes a fish is wary and repeatedly escapes the attack so that the squid appears to give up the chase. Squid are often kept in the aquaria of the United States Fish Commission at Woods Hole and fed upon mummichogs and other small fish. At one time we noticed among the mummichogs, one that was especially wary and agile so that it successfully avoided the attacks of several squid for some time after the other fish had been captured. One of the squid dropped to the bottom and grasping the gravel with its suckers anchored itself and at the same time adjusted its chromatophores so that it was as inconspicuous as possible. The squid lay thus upon the bottom until the mum- 
michog came within reach and then by a sudden dart captured it. Once caught the fish is usually killed by a single bite through the spinal cord or head but occasionally the tail of the fish is turned toward the mouth and the squid while trying to tum the fish ol to bite effectively lets it escape unharmed or slightly injured. 'I'he fish is thrust end on into the mouth by the arms and the buecal membranes, and the jaws work rapidly, biting out large pieces which are swallowed at once without further mastication. 'The food is swallowed so quickly that there is no time for the use of the radula, nor does the food show any trace of its action. It is possible, however, that the radula is used upon resistant objects. If so, it is evident that the object to be comminuted is held by the palatine lobes against the upper jaw while the radula is drawn back and forth over the end of the odontophore which is pressed against the food. 'The secretion of the median salivary gland which opens at the tip of the tongue and from the lateral glands which open near the ends of the palatine lobes is poured upon the food as it is being comminuted. The food usually reaches the stomach in pieces so large that one can scarcely explain how they were able to pass through the oesophagus and the skull. There the digestible portions are partially dissolved probably by the action of the fluids from the caecum, intestine, and liver. 'The partially digested food passes into the caecum and thence into the intestine and rectum for complete digestion and absorption. The indigestible portion of the food is voided through the intestine and rectum.

\section{T'HE REPRODUCTYE SYSTEM.}

In both male and female animals, the sexual gland is median and is suspended from the upper wall of the posterior part of the coelom. The genital duct is an unpaired, more or less convoluted and glandular tube lying in the left wall of the body and extending from the level of the middle of the gonad nearly to the inner opening of the fumnel.

A. MalE. 'The male reproductive organs are the testis, the complex spermduct, and possibly the hectocotylized left fifth arm.

The testis is oval transversely and elliptical longitudinally and is attached to the upper median line of the coelomic wall by a mesentery formed by the peritoneum which is reflected over the organ. 'The testis consists of a multitude of tubes placed approximately perpendicular to its surface and, on the lower side of the testis, opening into a small lumen which in turn opens by a narrow longitudinal slit into the coelom. The testis has a porcelain-white color that, in bright sunlight, is clearly visible through the mantle and pen of the living squid. 
The spermduct is formed of fire portions: the vas deferens, the spermatophoric gland, the vas efferens, the spermatophoric sac and the penis. The spermatophoric sac forms the proximal, the penis the distal end of a fusiform longitudinal tube which is parallel both to the vas deferens and the vas efferens, and the spermatophoric gland connects the distal end of the former with the proximal end of the latter. 'The vas deferens (Plate II, Figs. 10-12) begins in a ciliated funnel which is placed posteriorly near the median line at the level of the opening of the testis. The funnel leads from the coelom to a small bulbular enlargement and this in turn opens into the main portion of the vas deferens which seems convoluted, since a number of folds, the remnants of a primary convolution, project like vavilae comiventes into its lumen. Otherwise the vessel is straight and gradually increases in diameter distally. It opens into the spermatophoric gland near the middle of its inner surface.

The spermatophoric gland, an oval and slightly flattened organ, is a specialized portion of the sperm duct which forms two bights in the gland; the first directed outward and backward, the second inward and forward. The former, the vesicula seminatis is formed of three portions and is much larger than the latter, the appendix. ${ }^{1}$ ) The proximal (upper) limb of the seminal vesicle is very thick (about one half as broad as longi and the sperm rope passes thru it in a small sigmoid canal, "the sperm canal", into which open three large glandular blind sacs or pouches. The first of these (Plate II, Fig. 12, V.1.) is a huge backwardly directed, bean shaped sac, which lies upon the upper and inner surface of the gland. Its lower wall, which rests upon the second portion of the seminal vesicle, is formed of a very thick columnar epithelium $(320-340$ : $)$ which differs markedly from the epithelium of the rest of the gland. The remainder of the wall of the gland forms a branched tabular gland of the type shown in text figure 14. The lumen of this gland is approximately trough-shaped and opens into the upper side of the proximal part of the sperm canal. 'The second pouch ( $V .1^{\prime}$ in the figures) is biscuit-shaped and lies upon the outer surface of the gland. It opens into the sperm canal just behind the opening of the first gland. These two glands, with the corresponding portion of the sperm canal, form Marchand's first portion of the spermatophoric gland. The third gland is about as large as the first and lies inside above and below the sperm canal with which it communi-

1) We follow the nomenclature used by MARCHAND in his excellent work upon the male reproductive system of cephalopods, with a slight modification, viz. - the spermatophoric gland is the entire organ concerned in the formation of the spermatophore, i. e. the vesicula seminalis, the prostata and the appendis; the vas efferens (Brock) is the distal portion of sperm duct which connects the spermatophoric gland and the spermatophoric sac and is, therefore, MARCHAND's "the distal portion of the vas deferens" 
cartes by a long, slightly crescentic slit. 'Ihe forward portion (about one half of the whole) of this gland is represented in text figure $14, A$ and $B$.

'Ihe sperm canal passes across the outer surface of the gland from above downward and backward in the concavity which is readily seen in text figure $1+$. A, passing fiom right to left. (A small portion only of the sperm canal has been modelled). 'The sperm canal is connected with the gland by a long, narrow, slit-like lumen a portion of which is shown in the figures. The chief lumen becomes larger toward the hind end of the gland and forms as a whole a deep spoon-shaped cavity whose outer edge is connected with the sperm canal while its other edges and both upper and lower surfaces communicate with numerous flattened lumina.

In the vertical section of the gland represented in text figure 14, B, it will be seen that the majority of the lumina at the left of the chief lumen are united by a common lumen which opens into the chief lumen a short distance beyond the last section modelled. A similar but smaller set of cavities is shown in the upper right hand section of the photograph. These two systems are also clearly shown upon the outer surface of the gland. Thus we see in the photographs, a large series of brinching frond-like lumina opening into the forward edge and partly into the inner edge of the chief lumen, and two similar but smaller series which are converging to the upper and lower sides of the chief lumen. The most marked flattening of the lumina and of the enclosing cellular plates is in the longitudinal plane and I believe that the whole structure can be correctly pictured if one imagines that an extensive elongation accompanies and modifies the formation of a gland of the compound tubular type. A rapid elongation of the canal at the time of the formation of the primary evagination would draw it out into a long narrow pit and we will find that the prostata is formed of a large series of such simple, or slightly branched pits. 'The elongation would affect the secondary evaginations in a less degrees and the tertiary evaginations in a still smaller measure. But three primary evaginations of the seminal vesicle would seem to be formed whereas in the prostata a large number have been formed and are but slightly developed.

'The term "simple tabular gland" seems applicable to the type of structure characteristic of the prostata. The nidamental and oviducal glands of the female are of similar structure but in them the flattened pits are placed at right angles to, instead of parallel to the main duct as in the prostata. The glands of the seminal vesicle are twice or thrice compound tabular glands.

The third portion of the seminal vesicle is a large tube into whose lumen there projects from its outer and upper side a large, outwardly concave ridge 


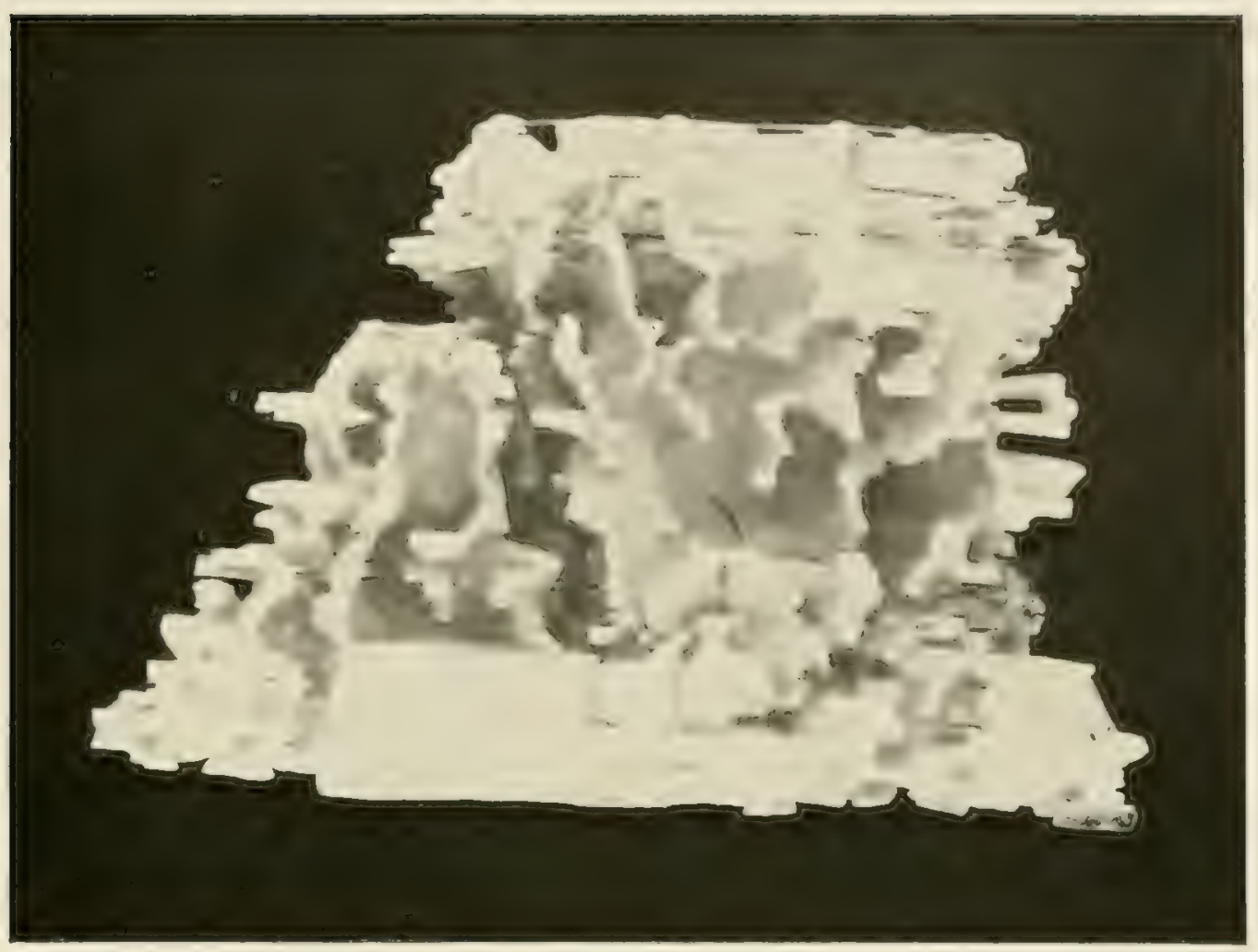

B

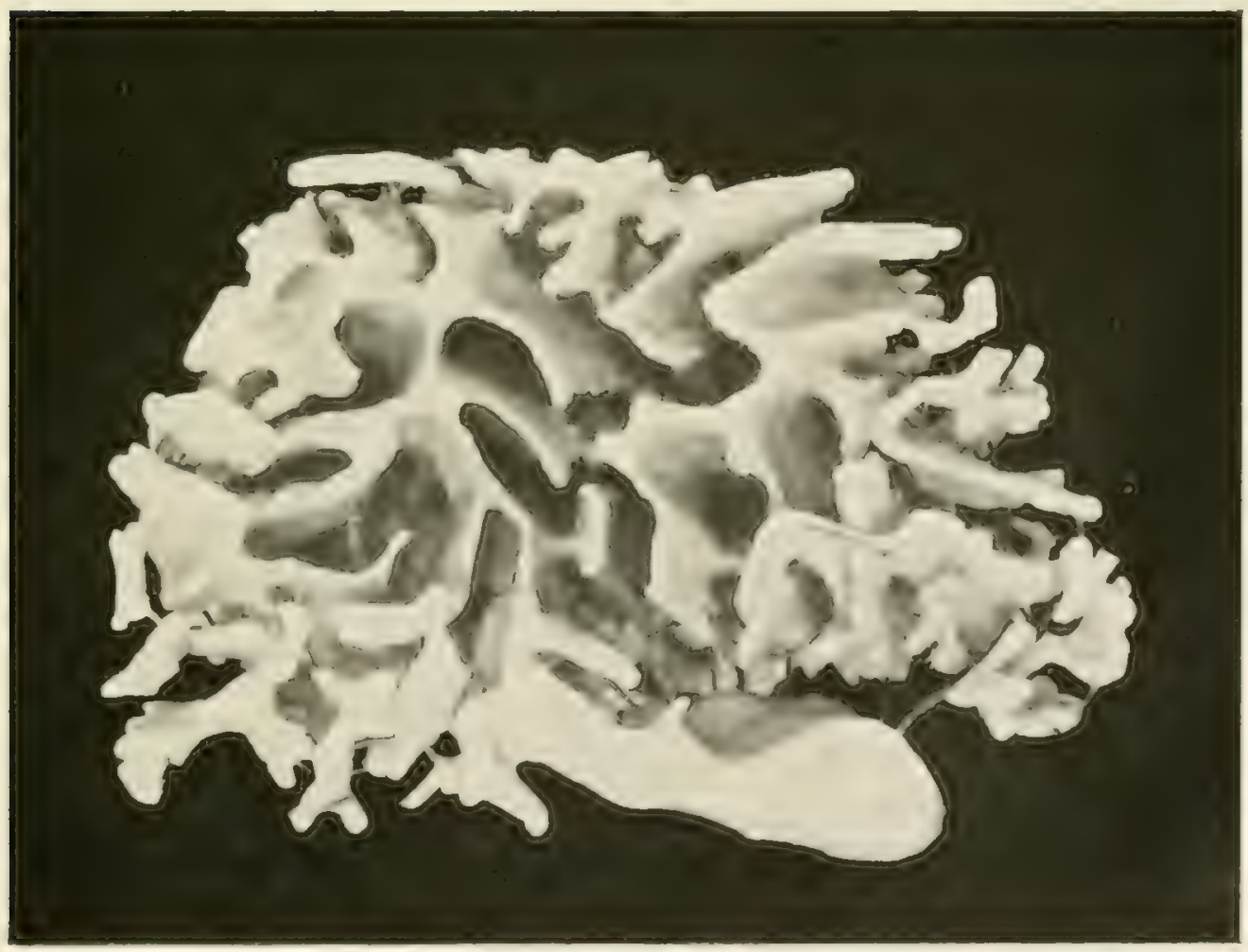

Fig. 14.

Model of the lumen of a portion of the seminal vesicle. A Outer surface with ventral end uppermost. B Dorsal surface. 

which is divided into two portions: a large and broad proximal portion, lying in the sharp curve at the beginning of the third portion of the seminal vesicle; and a small and narrower, but much longer distal portion. 'The ciliated canal (Ci. C.), recently discovered by Crius, opens into the distal end of the third portion of the seminal vesicle.

The appendix forms the small auricular fore lobe of the spermatophoric gland. Its wall is plain, except that the epithelium of the small, widely.open upper diverticulum forms a series of low longitudinal ridges. 'The distal end of the appendix leads to the vas efferens, which extends from a point slightly in front of the distal end of the vas deferens, nearly to its proximal end. 'l'he prostate or accessory gland is a large, flattened, broadly elliptical organ which extends from the appendix nearly to the hind end of the gland, and lies inside and below the resicula seminalis. Its wall forms a series of narrow longitudinal ridges which separate a series of deep, long and narrow pits, so that the gland is of the simple tabular type. Its central lumen is quite large, and surrounds the proximal part of its long tubular duct which opens into the appendix.

The appendicular gland (Di), a slender and relatively short blind tube formed of columnar epithelium, is nearly one half as long as the entire gland and extends backward inside the prostata from the distal end of the appendix.

The ciliated canal (Plate II, Fig. 12, Ci.C.) is a small and long ciliated tube whose wall, in prepared sections, is thrown into a few low longitudinal folds. It begins near the hind end of the gland in a broad ciliated funnel whose two divergent halves rest upon the adjacent surfaces of the accessory gland and the third portion of the seminal vesicle, and it opens into or from the genital sac, whose wall covers the gland. The canal extends forward between the accessory gland and the third portion of the resicula seminalis to the distal end of the latter, which it enters obliquely. The function and morphological meaning of the ciliated canal are alike doubtful. Marchani) finds that its cilia beat away from the sac and toward the gland. but its broad flaring funnel and its oblique opening into the gland seem to indicate that they must carry fluid into the gland. MIARchaxd believes, however, that it is the distal portion of a second sexual duct, whose proximal portion has been fused with the vas deferens, and that it corresponds morphologically to the portion of the internal oviduct which is buried in the wall of the oviducal gland, the latter being the homologue of the genital pouch, whereas the nidamental gland corresponds to the vas efferens, penis and spermatophoric gland, and has lost its primitive connection with the proximally fused genital ducts. Bourse finds, in Sepia, that the ciliated canal leads from the coelom to the spermatophoric gland, and this seems to faror 
MAnchasn's view, for he would doubtless say that this is the proximal end of the second and aborted sexual duct, whose distal end is fused with the functional duct. Until the embryological history of the organs has been followed, these are merely vague surmises.

The spermatophoric gland is suspended by the vas deferens and vas efferens and the connective tissue surrounding them in an ovate sac, the genital sac, which was described first by BRock and later, and more correctly, by CHUN. In Hlex the sac opens widely into the mantle cavity; in Loligo vulgaris and $L$. marmorae it is a closed sac: but in our species it is prolonged forward into a small tube which, at the base of the gill, opens into the mantle cavity. The sac extends upward between the vas efferens and spermatophoric sac for some distance.

'The vas efferens is a small, somewhat flattened tube, lined by a ciliated epithelium which is slightly folded longitudinally. Extending backward from the spermatophoric gland, it enters obliquely the lower surface of the proximal end of the spermatophoric sac.

The spermatophoric sac, or NeEnhax's sac, is a thin-walled, broad tube which lies at the side of the visceral mass, above the spermatophoric gland and outside the caecum. It extends forward from near the beginning of the vas deferens to the branchial heart, and merges distally into the small and more muscular tube, the penis. 'The wall of the sac bears a large number of longitudinal folds, which divide its cavity into a number of tubular spaces in which the spermatophores are stored in small bundles.

The penis passes thru the space between the branchial heart, the caecum and the base of the gill, from which it is separated by a narrow prolongation of the pallial cavity. It lies, for the greater part, in the mantle cavity between the gill and rectum and beiow the siphonal retractor, and terminates near the anus.

The spermatophoric gland secretes very complex cases in which the spermatozoa are transferred to the female. These packets of sperm, the spermatophores, (Plate I, Fig. 5) are stored in large numbers in the spermatophoric sac. The spermatophore consists of a double walled case which encloses a sperm rope, at one end of which is the so-called ejaculatory or flask apparatus. The case is a slightly curved, slender cylinder (eighteen or twenty times as long as broad) rounded at the ends and somewhat smaller at one end. 'The smaller end contains the "ejaculatory apparatus" and bears a long tubular filament. 'This smaller, filament bearing end, we will call the distal end of the spermatophore and not with MARCHAND, the oral end, for it is turned away from the mouth when it is in its final - shall we say functional? - position in the buccal pit of the female. In the spermatophoric gland this end turns about twice, so that a term 
applying to its final position is more applicable. The outer wall of the case is a thick cylinder of chitin-like material, marked by distinct striations parallel to its surface. It is perforated at its distal end for the passage of the filament. 'The inner wall of the case is thin. Between these two walls is a granular fluid which separates them widely at the proximal end of the case, but which is scanty at the distal end where the walls are close together and are connected by a few fibres. About one ninth of the length of the case from its distal end.a number of apparently contractile fibres encircle the inner wall of the case and press it upon the flask apparatus. The spermatophoric case encloses a transparent fluid in which lies the sperm rope, occupying its middle two fourths and the flask apparatus filling its distal fourth; the greater portion of the fluid which often contains a few spermatozoa being gathered at the proximal end of the case. The sperm are twisted into a rope which forms a closely coiled, oblique spiral plate and which is enclosed by a delicate membrane. The proximal end of the rope bears a knob-like protuberance consisting of some sticky substance, by means of which it is attached to the buccal membrane of the female after the discharge of the spermatophore. The flask apparatus consists of a flaskshaped sac which is prolonged into the filament and which is partly enclosed by an outer tube. 'The latter', the outer flask tube, is apparently continuous with the inner wall of the case. It contains the proximal portion of the filament and is attached to the shoulder of the flask. The proximal portion of the outer flask tube is double walled, the space between the walls being filled with a slightly opaque fluid. Just beyond the constricted portion of the inner wall of the case, the walls of the outer flask tube diverge so as to enclose a ringshaped carity beyond which the two walls fuse. The single walled portion of this tube is somewhat convoluted. The flask is attached to the sperm rope by a slender tube which seems to be continuous both with the flask's wall and with the sheath of the sperm rope. The flask is filled with a dense fluid which does not seem to contain sperm, and it tapers into a neck-like portion which is separated from the filament by a slight constriction, where a break usually occurs as the spermatophore is discharged. The filament is a continuation of the flask and passes thru the outer flask tube to the exterior. The inner wall of the proximal portion of the filament bears a dextrose spiral thickening, the "spring", which extends from the base of the filament to a point somerwhat beyond the enlargement of the outer flask tube. The filament beyond the spring is smaller, and, after a few convolutions, passes out of the case of the spermatophore. The free portion of the filament is as long as, or longer than the spermatophore, but since it remains attached to the penis, or to the spermatophoric sac, it is 
usually broken off near the case. 'The cavity of the filament is continuous with that of the flask and seems to contain the same opaque fluid. 'The cavity around the filament is apparently continuous with the cavity between the outer and imner walls of the case, but it contains a transparent fluid, not the granular fluid which fills the space between the walls of the case.

The measurements of the appended table were taken during July, and are typical, excepting the last.

\begin{tabular}{c|c|c}
\hline $\begin{array}{c}\text { Length of squid. } \\
\text { (mantle) }\end{array}$ & $\begin{array}{c}\text { Length of spermato- } \\
\text { phore. }\end{array}$ & $\begin{array}{c}\text { Length of sperm } \\
\text { rope. }\end{array}$ \\
\hline $115 \mathrm{~mm}$. & $8.5 \mathrm{~mm}$. & $5.5 \mathrm{~mm}$. \\
$115 \mathrm{~mm}$. & $7.0 \mathrm{~mm}$. & $3.5 \mathrm{~mm}$. \\
$100 \mathrm{~mm}$. & $6.5 \mathrm{~mm}$. & $3.5 \mathrm{~mm}$. \\
$150 \mathrm{~mm}$. & $6.5 \mathrm{~mm}$. (few present) & $4.5 \mathrm{~mm}$.
\end{tabular}

This table shows that in general the size of the spermatophore varies with the size of the squid. The relative length of the sperm rope varies in different individuals, but the spermatophores present in the sac at any time are essentially alike. The largest squid had probably passed the period of sexual activity.

The process of formation, transference, and discharge of the spermatophores is not well known. The sperm are packed into a solid thick colum in the vas deferens, and seem to pass into the vesicula seminalis in a small stream or column, for in its second portion they are arranged in a regular, spirally oblique plate, which forms the sperm rope. A sheath, probably the sheath of the sperm rope, is acquired in the first or second portion of the seminal vesicle, and MARCHAND finds that the third section of the vesicle secretes the outer case of the spermatophore and that in this portion of the gland its proximal (oral) end is foremost. This end of the spermatophore enter's the duct of the prostata first thru the appendix and vas efferens. Upon entering the spermatophoric sac, the spermatophore turns again, and its proximal end is foremost in the sac and emerges first from the penis. The sperm ropes, enclosed in their sheaths, and with the flasks attached are deposited in a closely packed cluster in the depression of the buccal membrane of the female. One can scarcely believe that the penis can be extended to such a length that it protrudes from the mantle and deposits the spermatophores in the buccal pit, and one is tempted to believe that they are deposited with the aid of the hectocotylus. 'The mechanism of the discharge and the function of the parts of the spermatophore are not understood. 'The discharged sperma- 
tophores in the buccal pit consist of the sperm rope, enclosed in its membrane, and the flask, with a small portion of the neck and tube. The anterior end of the rope is attached, probably by means of a sticky substance upon the knoblike process above mentioned, to the buccal membrane. 'The spermatozoa escape gradually through the flask. The spermatophores taken from the penis usually discharge and attach themselves to the walls of the mantle chamber, or to the receptacle in which they are placed. By observing fresh spermatophores in a watch glass, the discharge can be seen, but it is so rapid that one can only record the result. The discharges obtained in this way, vary considerably and may not be normal. Usually the case breaks at or near the distal end and the sperm rope with the flask apparatus escapes. The proximal end of the sperm rope turns away from the case and fixes itself to a neighboring object, while the flask tube remains attached for a time to the case. The expansion of the spring is chiefly radial, serving to evert the filament so that the thickening becomes external. The flask tube breaks not far from the flask and the sperm escape as rapidly as they can free themselves from the rope. The use of the filament and the complex telescoped tubes, and the stimulus which causes the spermatophore to discharge are unknown. The force necessary for the discharge of the spermatophore is furnished by the elasticity of its capsule.

B. The female reproductive system.

The female organs of reproduction are the ovary, the oviduct with its glandular portion, the oviducal gland, a pair of nidamental and of accessory nidamental glands, and the buccal pit, or "copulatory pocket".

The ovary, like the testis, is a median organ, but it is considerably larger than the testis. Each ovum is carried in an oval follicle upon a slender stalk formed mainly by the blood ressels of the follicle, and these stalks are clustered upon the larger bloodvessels as grapes upon the stem. BERGMann has shown that the ova of Cephalopods arise from cells of the coelomic epithelium, each of which migrates into the underlying connective tissue, carrying with it one or more epithelial cells which divide rapidly and form the follicular epithelium. Each ovum increasing in size by growth and by the addition of yolk, is forced out of the ovarian stroma into the coelom, and carries with it a peritoneal and a connective tissue sheath. The blood vessels of the follicle form a complex capillary network around the orum and the larger vessels form ridges which project into the surface of the ovum. The chorion appears first in the form of isolated granules which finally unite to form a firm sheet. 'The micropyle lies at the end of the ovum opposite the stalk and, as the connective tissue sheath is much thinner around the micropyle, the free end of the orum seems to 
projoct out of a cup-like follicle. 'I'he egg is oval, telolecithal, and the protoplasm, which forms a cap under the micropyle, extends further downward on one side of the egg than on the opposite side which is somewhat flattened. 'I'he flattened side of the egg becomes the posterior, the side opposite becomes the anterior, surfice of the embryo.

The oviduct, (Plate II Figs. 13, 14) like the sperm duct, lies upon the left side of the body. It consists of three portions, the internal oviduct, the oviducal gland and the external oviduct. The first is a broad, flattened, thin walled and slightly muscular tube which passes forward from the ciliated funnel, its internal opening, to the oviducal gland, doubles upon itself in a large dorsal loop, and then enters the oviducal gland obliquely from its outer side. The entire internal oviduct is peristaltically contractile; its proximal portion and probably the entire duct is ciliated. The three segments of the internal oviduct lie side by side and partially overlap one another.

The oviducal gland is merely a glandular enlargement of the oviduct. It is large, oval, flattened, and is prolonged into the flaring external oviduct. Its large vertical lenticulal cavity extends nearly to the outer wall of the gland and divides it somewhat obliquely into a short outer and dorsal segment and a longer inner and ventral segment which is continuous with the external oviduct. The outer segment is perforated near its middle by the internal oviduct, and the cavity of the external oviduct extends forward from the middle of the inner segment. The thick wall of the gland is formed of a vast number of thin curtain-like septa which extend directly inward from the exterior to the lumen of the gland. They form in each segment a single series which extends from the fore end of the segment around the opening of the internal or external oviduct to the opposite side of the same end of the same segment, and since the septa are nearly perpendicular to the cavity of the gland and of the oviducts, they are transversely placed ventrally and radiate from the oviducts dorsally. Each lamella is corered with a columnar epithelium which secretes the mucin or pseudomucin of the egg capsule and probably part of that of the egg case. The free edges and probably the entire surface of the lamellae are ciliated.

The external oviduct is a muscular tube whose distal end is oblique, flaring and more or less folded.

The nidamental glands cover the lower surface of the viscera from the base of the rectum to the end of the posterior aorta. Their structure is similar to that of the oviducal gland except that their lumina are longitudinal and their lamellae transverse. The glands together form an elliptical flattened mass. Each gland is linear except that its outer angles are quite rounded. In transverse 
section each gland is triangular. Its inner surface is adherent to the corresponding surface of the other gland; its upper surface is attached to the visceral mass and its lower surface finces the mantle cavity. 'The flattened longitudinal lumen extends from the lower inner angle of each gland to its upper surface near its outer angle and divides each gland into two approximately equal and similar segments.

The accessory nidamental glands are small, oval, light-brown masses mottled with brick red, which lie on each side of the base of the rectum in front of the nidamental glands. 'The function of these glands is unknown, but it is believed that they contribute to the formation of the egg cases.

The ova are probably fertilized within the cavity of the oviducal gland, the sperm having entered the mantle cavity with the respiratory water. VIALLEToN, however, believes that the sperm enter the egg case as, emerging from the siphon, it passes between the bases of the fifth arms and over the buccal pit.

The eggs are deposited in elongated gelatinous cases which contain from 50 to 200 eggs, each invested by a spherical capsule. The material of the cases has been found by von FürTh to be similar to the pseudomucins found in ovarian cysts. Each case is attached by a moderately short stalk, which is prolonged into the body of the case as a tapering core and which is also continuous with the sheath of the case. 'The stalk and core are formed of a sheet of mucin which is wound in a left-handed spiral. Its outer edge is more loosely wound and stretches obliquely from the core to the sheath of the case, enclosing between its successive turns a single row of eggs. The eggs of this closely wound spiral are separated at irregular distances at the base of the case, but towards its middle they are spaced at regular intervals so that they almost form longitudinal as well as oblique rows. There are seven or eight eggs in each of the 15 to 20 turns of the row, there being in all 150 to 200 eggs in a well developed case. The core ends about one fourth the length of the case from its distal end and consequently the eggs beyond this point are irregularly crowded together at the end of the case. The extent and perfection of the spiral core varies considerably even in the cases of a single cluster and its existence has not, we believe, been noticed previously.

'The structure of the egg case suggests something of its manner of formation which has not been understood. 'The unfertilized eggs enter the lenticular cavity of the oviduct from the middle of its outel side. and. if the secretion of the gland commences some time before they begin to enter this cavity and if the cilia upon the edges of the lamellae of the gland strike outward and to the left, the secretion would be rolled into a solid strand. Furthermore. if after such a

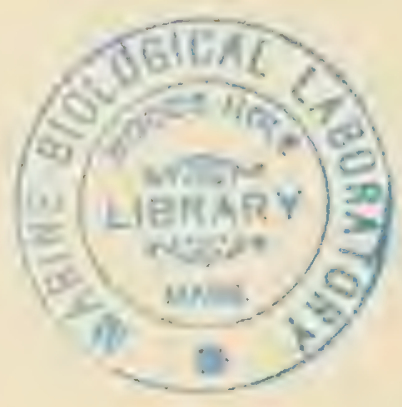


strind had begun to form, the eggs emerge from the middle of the wall of the glind, they would be caught between the successive layers of the continuously forming sleet and would be carried away in a spiral row. Finally, if we suppose that eggs continue to emerge into the cavity of the oviducal gland for some time after the cessation of its greatest activity, they would not be enclosed between the folds of the completed core, but would lie free in a cavity containing the less dense mucin produced by the gland at the end of the period of activity; and as the core of the case, with the eggs partially buried in its surface, passes the mouth of the nidamental glands, it probably receives the sheet of mucin which forms the sheath of the case. The capsule of each egg is probably produced by the oviducal gland. The egg cases are attached in clusters to fixed objects on the bottom and, since a single cluster may contain as many as 175 cases and approximately 26,000 eggs, it is probable that several females contribute to the formation of each cluster. The appended table records the size of and number of eggs in three typical egg cases.

\begin{tabular}{|c|c|c|c|c|c|c|c|c|c|c|c|c|}
\hline Length of case, & $\mathrm{m} . \mathrm{m}$. & . & . & . & • & . & - & & & . 85 & 70 & 90 \\
\hline .. stalk & $"$ & . & . & . & . & . & . & - & & 15 & 10 & 26 \\
\hline Diameter of case & 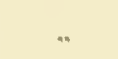 & 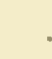 & . & . & . & . & . & & & 15 & 7 & \\
\hline .. $\quad$ stalk & $"$ & . & . & . & . & . & . & & . & 3 & 3.5 & \\
\hline Number of eggs & . . & . & . & . & . & . & . & & & . 173 & 164 & 158 \\
\hline Length of eggs & m.m. & . & . & . & . & . & . & & & 1. & -1.6 & \\
\hline Diameter & $\because$ & . & . & . & . & . & . & & & - & -1.2 & \\
\hline ength of egg capsule & e & . & . & . & . & . & . & • & & 1. & $5-1.9$ & \\
\hline iameter $\quad "$ & , & . & . & . & . & . & . & & & . & -1.7 & \\
\hline
\end{tabular}

'I'he Vascular System. (Plate I, Fig. 6; Plate II, Figs. 8, 9.)

'The vascular system of the squid is double, closed, and almost perfectly symmetrical. The arterial blood goes out from the systemic heart by either of three aortae, - the anterior (I) the posterior (II) and the genital (III); from these it flows into paired arteries, capillaries and veins. The venous blood from the systemic veins may flow entirely in lateral vessels or for a short time in the median anterior vena cava (VI) or the genital vein $\left(3^{5}\right)$. It finally flows from the lateral nephridial vessel (V) into the right and left branchial hearts. The blood from the branchial heart flows through the branchial artery (VIII) to the capillaries of the gill and from them the blood, now arterial, passes thru the branchial vein (IV) to the systemic heart. 


\section{'T'He Systemic Circuiation.}

'Trie Heart. The heart is a lozenge-shaped, one-chambered, muscular sac, which lies mesially in the coelom behind the intestine, below the stomach and caecum, and above the nephridium. Five vessels communicate with it. They are: the two large branchial veins which enter its rounded lateral angles; two large median ressels, the anterior and posterior aortae, which leave the conical anterior and posterior projections of the heart; and the small genital aorta which arises from the ventral edge of the heart. The heart is not quite symmetrical; its ventral portion and the anterior aorta which arises from it being displaced toward the right by the intestine. The exterior of the heart is covered by the peritoneum or coelomic epithelium. Its interior is probably lined by an endothelium and its wall is formed by interlacing muscle fibres between which the bloud penetrates some distance. The venous blood is collected from the tissues of the heart by two or three veins which are probably connected with capillaries. The muscle fibres have the character of smooth muscle except that they exhibit a faint striation. MARCEAU, in his beautiful work upon the structure of the heart of molluscs, shows that the muscle fibres of the heart of Cephalopods are long, cylindrical and branched. The branches of each fibre anastimose with those of other fibres forming a complex mesh. The fibres, like those of the mantle, consist of a sheath of fibrillae separated by sarcoplasm and a core of cytoplasm containing the nucleus, but the fibrillae of the cardiac muscles are parallel to the fibres and are not homogeneous since the striation is transverse, not oblique and is due to the differentiation of the fibrillae into the structures which in transverse rows form the light (isotropic) band divided by KRAUSE's membrane and the dark (anisotropic) band divided by Hensen's line. The heart has four valves: a pair of semilunar flaps at the end of each branchial vein prevent the return of blood into the gill; a single semilunar valve at the origin of each of the large aortae checks the re-flow of blood to the heart.

T'He Anterior AoRTA. The anterior aorta arises just inside the visceral wall a little in front of the base of the gill. At first it lies in the right nephridial wall, then having been joined by the oesophagus, it pierces the liver obliquely between the hepatic ducts and emerges in a shallow groove on the upper surface of the liver. 'The aorta with the oesophagus passes forward in this groove until it ends near the skull in two terminal branches. Near its origin the aorta gives off an artery $\left(1^{\prime}\right)$ which divides into four branches and 
supplies the pancreas, stomach, and caccum; one branch (d) enters the pancreas; (n) (a) crosses the lower surfice of the lower caecal lobe, passing close to the splanchnic ganglion, and then ramifies over the outer side of the stomach: another (b) supplies the adherent inner walls of the stomach and carecum; and the last (c) pisses to the outel side of the caecum and supplies the caecal folds. A pair of important arteries arises from the aorta as it emerges on the anterior surfice of the liver. Each of these immediately divides into several branches: two or three enter the liver (5'); two or more supply the nuchal and siphonal retractors (4'); one branch (3') passes through the supporting membrane of the gill to the branchial gland and the gill; another branch ( $\varkappa^{\prime}$ ), passes through a canal in the mantle with the nerves of the fin, to an arterial plexus $\left(9^{2}\right)$ on the upper surface near the dorsal end of the mantle. 'The latter artery has a remarkable length compared to its size and has a theoretical interest which will be discussed later. One of its branches anastomoses with the arteries of the ventral end of the fin, and other branches go to the mantle. The arteries of the siphonal retractors enter these muscles near the middle of their length and each divides into a dorsil and a ventral branch. These two branches form a longitudinal trunk from which small arteries radiate to the fibres of the muscle. Near the dorsal end of the nuchal cartilage a median artery $\left(6^{\prime}\right)$ arises from the aorta. It immediately bifurcates and each branch, after giving off small branches to the nuchal retractor, passes through that muscle at the edge of the cartilage and enters the mantle under the stellate ganglion to supply the upper ventral portion of the mantle. Several small and inconstant arteries arise from the aorta along its course and supply such adjacent structures as muscles, oesophagus, or liver.

The aorta forks near the skull and the branches passing around the oesophagus unite behind it, forming an oesophageal arterial ring. Ten vessels arise from this ring: four pairs; muscular, optic, pharyngeal, and siphonal; a median, the pedal; and an azygos artery, the salivary. 'The upper part of the ring lies in the liver case and the lower part in the skull. Just before each terminal branch of the aorta enters the skull it bears a "peripheral heart", which will be discussed later. The origin of the first pair of arteries of the ring the muscular $\left(7^{\prime}\right)$ is quite variable, sometimes the arteries arise at the bifurcation of the aorta and sometimes just distal to the peripheral heart. The arteries suppliy parts of the liver and the cephalic retractors. The savilary artery $\left(8^{\prime}\right)$ arises from the left vessel at the distal end of the peripheral heart and passes back to the salivary gland. Just beyond the peripheral heart each terminal branch of the aorta enters the skull by passing through the fascia which 
closes the great foramen, and immediately gives off two branches: one, the optic $\left(9^{1}\right)$, passes with the optic tract through the lateral formen of the skull and forms an arterial ring around the pupil under the iris supplying the eye and the white-bodies; the second, the pharyngeal $\left(11^{1}\right)$, occupies the venous canal with the oesophagus and salivary duct and supplies the pharynx. After the artery of the ling has given off these branches it passes downward between the pleural and visceral ganglia and enters the fascia between the pedal and visceral ganglia and having given off the siphonal artery $\left(10^{1}\right)$ which passes with the siphonal nerves to the muscles and glands of the funnel, it turns forward beneath the pedal ganglion to meet its mate and form the pedal artery. This artery $\left(12^{1}\right)$ lies upon the upper surface of the posterior process of the skull beneath the pedal and pro pedal ganglia. Near the latter, the following branches are distributed: an artery to the propedal ganglia; a pair of arteries to the muscles of the pharynx, and a median vessel to the tentacular sac. At the ventral end of the propedal ganglion the pedal artery forks and the branches pass forward as far as the middle of the pharynx and then each terminates in three branches: one enters the fifth arm; another enters the fourth arm: and the last passes upward around the pharynx to supply the third, second, and first arms. 'The small arteries of the arms radiate from the brachial artery which lies in the central canal with, and on the outer side of the brachial nerve. The distribution of the branches of the pedal artery is parallel to the distribution of the nelves from the pedal ganglion and so adds evidence that the arms are a part of the foot.

I'He Grattal AORTa. 'The genital aorta arises from the middle of the ventral surface of the heart and, having given small branches to the pancreas and peritoneum, it runs downward and backward between the adherent walls of the stomach and caecum. The position of this vessel is constant in the Oigopsida and Myopsida but in the former it arises from the posterior aorta. The aorta passes backward along the upper surface of the testis or ovary to which it gives off pinnately arranged branches.

'T'HF Posterior Aorta. 'The posterior aorta is about as long as the heart and lies in the partition between the dorsal lobes of the nephridial sac. In the male it is separated from the pallial chamber by the body wall alone but in the female the large nidamental glands also lie between it and the pallial chamber. Four or fire small vessels arise from the aorta. 'Two branches arise together near its origin: one $\left(1^{2}\right)$ passes thru the nephridio-coelomic wall to the ink-sac and to the nephridia, being deflected to the left to pass the intestine; the other $\left(2^{2}\right)$ takes a parallel course in the lower nephridial wall and supplies the 
rectum. In the female the latter also supplies the nidamental and accessory glands. A pair of vessels $\left(3^{2}\right)$ pass to the branchial hearts and their pericardia. An unpaired artery $\left(4^{2}\right)$ arises from the left side of the arta or from the left vessel of the preceding pair to supply the organs of the genital duct, viz. the spermatophoric sic, the vas deferens, the spermatophoric gland, and the penis in the male, or the oviduct and oviducal gland in the female. After giving off these branches the aorta divides into three terminal arteries, the right, left, and median pallial arteries. The median mantle artery $\left(6^{2}\right)$ passes in mesentery-like median fold across the pallial chamber to the lower side of the mantle. It supplies the lower ventral part of the mantle. The lateral pallial artery $\left(5^{2}\right)$ passes obliquely across the visceral mass between the peritoneum and the integument to the edge of the pen near the ventral end of the gonad. Here it leaves the visceral mass and, after giving off two arteries to the mantle $\left(7^{2}\right)$, expands into a peripheral heart as it enters the mantle. One pallial branch passes forward in the tissues of the mantle; the other passes backward giving off many branches to the mantle and passes through it to the arterial plexus at the dorsal end of the mantle $\left(9^{2}\right)$. The trunk $\left(8^{2}\right)$ of the artery passes obliquely through the mantle and enters the middle of the base of the fin. As soon as it enters the fin this vessel divides into two branches which pass beside the cartilage to the dorsal and ventral angles of the fin. Some of the dorsal branches anastomose with the vessels of the plexus $\left(y^{2}\right)$ which covers the anterior dorsal surface of the mantle. This plexus is formed by the anastomosis of these vessels with branches from the lateral mantle arteries $\left(7^{2}\right)$ and from the anterior aorta.

The arteries of all parts of the squid anastomose freely so that an injection from one artery will fill two or three others: for example, an injection from the anterior aorta will fill the median mantle artery and an injection of the right mantle artery will fill the left artery. The walls of the arteries have three coats; an endothelium, a layer of circular muscle fibres, and a sheath of connective tissue. 'The aortae and their larger branches are peristaltically contractile and their muscular fibres are short, fusiform, and distinctly cross-striated. 'The muscle fibres of the smaller arteries and arterioles are plain and those of the latter are irregularly distributed so that theil contraction makes the vessels moniliform. The large veins, readily distinguishable from the arteries because of their thinner walls, are also peristaltically contractile but it has not been determined whether or not the fibres are striated. The arterioles communicate with a complete system of capillaries but there are no blood-spaces or lacunae. The so-called "peripheral hearts" occur upon all the large arteries that leave the mantle i.e. upon the fin vessels and the terminal branches of the anterior aorta. 'The peripheral heart is 
a small oval body formed by the thickening of the circular muscular coat. Its lumen is no larger than that of the artery. An injection mass cannot be driven past these "hearts" when they are contracted. 'I'heir function undoubtedly is to prevent the transmission of an excessive blood pressure to the head and fins, for it is evident that, during the contraction of the mantle, the viscera are subjected to great pressure. If the peripheral hearts contract in a degree coordinate with the contraction of the mantle, the blood pressure in the extrapallial vessels is not disturbed even by the most violent contractions of the mantie.

'IHE Verss. (Plate II fig. 8). The distribution of the smaller veins is in general very similar to that of the corresponding arteries and usually the smaller branches of the arteries, veins, and nerves correspond closely to one another but the larger venous trunks lave an arrangement totally different from that of the arteries. The arterial system is largely median and anterior or antero-dorsal in reference to the alimentary canal; the venous system is largely bilateral and is posterior or postero-ventral to the alimentary canal. Moreover the venous system is characterized by the great size of its vessels which form large sinuses and by the specialization of a portion of its central vessels in connection with the excretory organs, the nephridia. These organs are formed by the modification of the walls of a large sinus which is shaped like the letter $V$ and is enclosed in the nephridial sac. The nephridial sinus receives the median anterior vena cava and five or six paired reins: the posterior vena cava, the anterior pallial veins, the splanchnic, the rectal, and in the female the nidamental veins.

The posterior vena CAVA (VII Plate II figs. 8 and 9) is a large, pear-shaped vessel whose larger end opens into the nephridial sinus, and which is formed near the peripheral heart of the lateral pallial artery by three veins arising from the fin and from the mantle behind and in front of its point of origin. It crosses the lower surface of the visceral mass, on the outer side of the corresponding artery, and enters the corresponding arm of the nephridial sinus near the end of the posterior aorta.

The anterior vena cava and its tributaries. Each arm has two longitudinal veins: one in its central canal with the brachial artery and nerve and one on its inner surface between the two rows of suckers. 'These twenty brachial veins, meet in a large, thin, oval brachial sinus $\left(7^{6}\right)$ below the pharynx. 'This sinus opens near the dorsal end of the pharynx into the outer buccal sinus $\left(9^{6}\right)$ which surrounds the pharynx and extends from the base of the peristomial membrane, from which it receives blood, to the entrance of the skull where it opens into the inner buccal sinus $\left(8^{6}\right)$. It contains the rotators of the pharynx and the retractor mandibuli. The inner sinus $\left(8^{6}\right)$ is separated from the outer by the 
phurygeal retractor which is attached to the equator of the pharynx. It receives blood from the organs of the pharynx and is prolonged dorsally into the canal which transmits the oesophagus through the skull. A sinus, the cephalic $\left(6^{6}\right)$, which surounds the oesophageal nerve ring communicates with this canal but I have not been able to locate the exact opening. 'This canal opens on each side into the optic sinuses through a small foramen just behind the opening of the outer into the inner buccal sinus (Plate III Fig. 17, 28). 'The optic sinus $\left(5^{6}\right)$ encloses the optic ganglion and embraces the inner surface of the eye from which it receives a number of veins. These veins are grouped along the upper and lower margins of the sinus where it is not overlaid by the white-bodies which are wedged in between the eye and the optic ganglion. A large vein $\left(4^{6}\right)$ collects blood from the iris and from the outer portion of the inner coat of the eye and passes over the upper part of the eye with the corresponding artery to enter the optic sinus. A large vein passes from the optic sinus through the lower part of the lateral plate of the skull to meet a vessel from the opposite sinus. 'These two vessels from the optic sinuses form the anterior vena cava and the wall intervening between the vessels bears a pair of vertical folds which form a valve that prevents the return of blood to the head. This valve is necessary in order that the blood in the large venous sinuses under the visceral mass may not be forced into the head by the contraction of the mantle and hence we must associate it functionally with the "peripheral hearts". "The valve is so effective that an injection mass can seldom be forced into the head through the anterior vena cava and for this reason the venous system is best injected through the buccal sinuses.

The anterior vena cava (VI) is a large, contractile median vessel situated under the liver case. The ventral third of the sinus lies between the siphon and the liver, its middle portion lies between the siphonal retractors upon the lower surface of the visceral mass, and its dorsal portion runs above the ink sac to its dorsal end and there opens into the nephridial sinus. In addition to several small veins from the siphon and liver case, the anterior vena cava receives; a pair of veins from the ink sac $\left(1^{6}\right)$, a large median vein from the liver $\left(2^{6}\right)$, and a vein from the salivary sinus $\left(3^{6}\right)$. This sinus surrounds the salivary gland, receives blood from that gland and the neighboring portion of the liver, and opens into the anterior vena cava between the skull and the post-cephalic cartilage. Just behind this opening the anterior vena cava expands into an oval chamber whose size and position correspond to the outline of the cartilage. 'The venous blood from the two-thirds of the liver ventral to the canal for the oesophagus and the aorta is collected by two median veins which run backward on the upper and 
lower surfaces of the liver. 'The upper vein enters the liver with the oesophagus and passes more directly through the liver so that it emerges on the lower surface some distance in front of the exit of the oesophagus and hepatic ducts. The hepatic vein, formed by the union of the upper and lower veins, passes through the liver case and enters the anterior vena cava obliquely so that the lower wall of the vein forms a valve.

The blood from the dorsal third of the liver is collected by a pair of reins $\left(2^{5}\right)$ which arise near its dorsal point and pass forward to the hepatic ducts with which they enter the nephridial sac. One of these ressels is often small or absent while the other is correspondingly large. Within the nephridial sac these veins pass along the outer wall of the pancreas, receiving blood from it, until near its middle where they meet other veins. The right vein unites with the large, median, genital vein $\left(3^{5}\right)$ which passes with the genital aorta between the stomach and caecum, receiving venous blood from the stomach and from the inner wall of the caecum. It empties into the right arm of the nephridial sinus. The left vein unites with a vessel from the caecal folds $\left(5^{5}\right)$ and with a vein from the intestine and then passes out of the pancreas to the left arm of the nephridial sinus.

A pair of small veins $\left(1^{5}\right)$ passes backward from the sides of the rectum and enters the lower side of the nephridial sinus almost opposite the entrance of the preceding vessels.

Three or four small veins $\left(4^{5}\right)$ from the systemic heart empty into the nephridial sinus.

The ventral lateral pallial vein, $\left(6^{5}\right)$ formed by the veins of one side of the ventral portion of the mantle, runs backward parallel to and outside of the supporting membrane of the gill. At the base of the gill it turns abruptly inward and, after receiving two vessels from the gill and passing above the branchial heart, enters the nephridial sinus. One $\left(7^{5}\right)$ of the veins from the gill comes from the nerve and muscle which lie within the gill, the other $\left(8^{5}\right)$ comes from the center of the branchial gland. The left mantle vein as it passes over the branchial heart receives a ventral vein $\left(9^{5}\right)$ from the penis or external oviduct and a dorsal vein from the vas deferens, spermatophoric gland, and spermatophoric sac or from the oviduct and oviducal gland. A rein $\left(11^{5}\right)$ corresponding to a branch of the anterior aorta alises from the venous plexus $\left(9^{2}\right)$ at the back of the mantle and passes through the mantle in a canal with the fin nerve to join the ventral mantle vein.

The Nephridal Sinus. (V). The median portion of the V-shaped nephridial sinus or precava receives the blood from the anterior vena cava and the ends 
of the two ams of the simus are continuous with and receive blood fiom the posterior vena cava. Wach arm opens into the ventro-internal portion of the branchial heart which lies just external to the dorsal third of each arm. 'The median portion of the sinus is bounded below and behind by the angle of the gut formed by the rectum and intestine, in front by the ink sac, and above by the pancreas. 'The remainder of the sinus lies under the pancreas, the heart, the digestive sacs and, in the female, above the nidamental glands, or in the male, just above the pallial chamber. The intestine passes between the two arms of the sinus as they turn inward to unite with each other and with the anterior vena cava. The sinus passes through the nephridial sac and is only attached to the nephridial walls by its ends and by a narrow band of fascia along the upper surface of the arms. Faussek has described a pair of tubular, longitudinal cavities in the mesoderm of the embryo from which the coelom and the nephridium arise. Each tubular cavity soon after its appearance becomes differentiated into a thin-walled dorsal portion which forms the coelom and a narrow thicker walled ventral portion which communicates with the exterior and becomes the nephridium. 'This nephridial tube originally has no connection with its mate or' with the venous system but as the embryo develops each nephridial cavity enlarges so that its walls become moulded over the surface of the pancreas, the intestine, and the veins. The two nephridial cavities become confluent by the absorption of their opposed walls. In the adult the nephridial sac has the shape of a retort whose neck is vertically flattened and is bilobed. 'The body of the flask occupies the greater portion of the visceral mass between the heart and the digestive sacs behind, and the livel and the ink sac in front, and contains the pancreas, the intestine, and a part of the nephridial sinus. 'The neck, - conceiving the retort to be inverted, - is directed backward beneath the heart and digestive sacs, and in the female between them and the nidamental glands. It contains the arms of the nephridial sinus which are separated dorsally by what remains of the original septum between the nephridial cavities. Conical tubular canals lead from the coelom to the nephridium passing obliquely for a short distance in the wall between the sac and the pallial chamber. The canals pass into the nephridium just above the branchial veins and at the junction of the flask with the neck. By this arrangement the inner wall of the canal forms a valve which prevents the escape of fluid from the nephridium into the coelom. The nephridial sac opens unon the lower surface through two papillae, which lie one on either side of the base of the rectum. 'The lining of the nephridial carity is reflected over all the structures within the cavity and, except where it covers the venous vessels, is a ciliated pavement epithelium. Upon the sinus and the veins 
which pass through the sac to the sinus the epithelium is columnar and secretory.

The wall of the nephridial sinus is formed of three coats: the nephridial epithelium; the vascular endothelium; and an intervening sheet of connective tissue which contains arteries and capillaries, the vasa vasorum. This wall is evaginated and invaginated to form a series of short interdigitating tubes. The blood fills the tubes which open into the sinus and the nephridial excretion is discharged into those which open into the nephridial sac. 'The sinus is divided by a number of constrictions, four or six, into several lobes and the veins coming from the pancreas and the rectum form four small additional lobes.

\section{'The Respiratory Circulation.}

Each branchial heart (br. h.) is biscuit-shaped and lies within its pericardium just under the integument and at the level of the dorsal half of the systemic heart. It bears upon its inner edge a small gland, the "pericardial gland", which has a small irregular lumen opening into the pericardium. The epithelium of the lumen and of the surface of the gland is columnar; that of the portion of the heart around the gland is cubical, and that upon the remainder of the heart pavemental. The heart is composed of striated muscle-fibres and spherical or ovate cells which are apparently secretory though their function as well as that of the pericardial gland is unknown. The tissues of the branchial heart are supplied with arterial blood by the posterior aorta. The venous blood from the nephridial sinus enters the ventro-internal portion of the heart through an opening guarded by a pair of semi-lunar valves and passes out into the branchial artery through an opening at the ventro-external edge of the heart. The base of the artery is enlarged and has strong circular muscle-fibres. Four tubercles, each typically as long as the diameter of the artery, project into the lumen in the direction of the current. Although four tubercles are always present, one, less commonly two or rarely three, are small or minute while the others are correspondingly enlarged. The contraction of the circular muscle at the base of the artery presses together these tubercles and closes the vessel preventing the flow of blood in either direction. This valve makes it very difficult to obtain successful injections of the gill. The branchial artery passes through the center of the gill giving off throughout its course small alternating branches.

The Gill. The gill has been the subject of an extended anatomical and embryological paper by Joubin, and we find that his conclusions hold for this species. The gill appears early as a small papilla projecting from the posterior side of the embryo in the area between the mantle folds, the siphonal folds and 
the anus. 'I'his papilla gives off' alternate buds from its tip and each bud soon folms a triamgular sheet whose inner and outer margins are formed by a secondary branchial vein and artery. 'The surface of this sheet grows much more rapidy than the vessels and so it is thrown into folds whose axes are perpendicular to the ressels. A tertiary artery forms in every angle of the folds and a tertiary vein develops in the middle of each fold. The surface continues to grow more lapidly than the ressels and is thrown into a second series of folds whose axes are perpendicular to those of the first fold. 'The capillaries of the gill lie in the folds between the tertiary vessels. 'The blood passes from the secondary artery at the outer edge of the pinna - i. e. the edge towards the mantle - into the tertiary arteries at the edges of the primary folds and from them flows through the capillaries torrard the center of the fold and into the tertiary vein at the middle of each fold.

The gill finally becomes a long pinnate structure which lies beside the liver in the pallial chamber and extends from the heart to the entrance of the siphon. 'The water entering the mantle over" the lateral siphonal ralve passes over and through the gill. The gill proper consists of two longitudinal vessels, the branchial artery and vein, which bear a large number of alternating pinnae. 'T'he latter are moulded over a muscular and glandular core so that the gill is trihedral. 'The two angles towards the mantle are formed by the ends of the two rows of pinnae and the third, formed by the branchial vein, is directed toward the liver. The branchial vein is separated from the untery by a water canal which communicates with the pallial chamber between the pinnae. On the outer side of the artery the branchial nerve cord and a rein of the systemic circulation run the length of the gill. The branchial gland, which is enclosed in a sheath of fascia, lies between the nerve and the mantle. Bands of muscle attached at the base of the gill partly to the mantle and partly to the visceral mass lie above and below the nerve, vein, and gland. 'They form one of the chief connections between the mantle and the viscera. A thin extensile sheet of integument attaches the gill to the mantle. This sheet leaches almost to the tip of the gill and is necessary to hold the gill up against the water rushing into the pallial cavity.

Each pinna is attached to the core of the gill by a triangular sheet of fascia which is fastened to the secondary artery at the lower edge of the pinna. The free edge of this membrane is stiffened by an acicular rod of chitinous nature whose broadened base is attached to the side of the gland and whose apex is fastened to the tip of the pinna. The rod is secreted by a tube of cylindrical cells. Burve finds in Sepia that these rods are formed of typical cartilage.

'The gill grows continuously at the tip and at the ends of the pinnae so 
that the latter become gradually smaller towards the apex of the gill. Each of the alternating branches of the branchial artery (VIII) passes around the canal of the gill and joins a zigzag longitudinal artery $\left(1^{8}\right)$ which is on the same side of the canal with the branchial vein and so opposite the artery. In this way the canal is surrounded by a series of alternating semicircular vessels which unite the longitudinal arteries. Near the middle of each semicircular vessel the larger portion of each branch of the branchial artery passes out at right angles to the canal and forms the outer edge of a pinna.

The branchial artery and vein, the anterior and posterior vena cava, and the larger branches of these vessels are peristaltically contractile.

DHRÉRÉ has found that the oxygen-carrying power of the blood of cephalopods is directly proportional to the amout of copper in the blood. 'The blood coagulates readily and firmly. The blood corpuscles are not numerous in the blood and they resemble the lymphocytes of higher animals. 


\section{PROBIALAA'IC DUC'ILESS GIANDS AND 'THE BODY CAVITIES.}

The branchial or "blood" gland, and the "white bodies" are both isolated masses of tissue and are probably blood glands. 'The former is long and somewhat flattened, and forms the center of the core of the gill. It is composed of large oval or cuneate cells, radially arranged around the blood vessels, from which they seem to be separated by a vascular endothelium. Joubin, however, believes that the gland cells form the entire wall of the blood vessels. The gland has no apparent physiological connection with the gill and is not connected with it except through a branch of the anterior aorta which passes through the gland and anastomoses with the branchial arteries.

The four white bodies (Plate III F'ig. 22, W. B.\& W. B.') are compact and smooth and are wedged in between the optic ganglia and the eyes. One lies above and behind each optic nerve, another below and in front of it. 'The glands are richly vascular and then veins open into the optic sinuses which surround the glands. The cells of the glands are small and are composed of a relatively large nucleus and a small cell body. 'They are very similar to the blood corpuscles and are closely packed without definite order. Mitoses are very common, and there seems little donbt that these glands produce the blood corpuscles. The glands arise from the ectoderm.

\section{The Body Cavities.}

The vascular system of the squid, is lined throughout by an endothelium which is formed of thin flat cells whose edges are irregular or sinuous. 'The muscular and connective-tissue coats of the arteries and veins become gradually thinner as the vessels become smaller until they disappear leaving a vascular wall formed solely by the endothelium. The vessels thus formed branch and anastomose profusely so that they make a complex net-work in the tissues. 'These vessels are the capillaries and may be recognized not only by the simplicity of their walls but by the fact that repeated division does not reduce the size of the vessels. The primary body cavity of molluses consists of the unwalled lacunae and blood-spaces into which the arteries, and from which the veins, open. Such cavities do not exist in the squid unless possibly in the tissues of the hearts. The sinuses are all lined by an endothelium and no tissues except possibly those 
of the hearts are directly bathed by the blood. My most careful preparations have failed to demonstrate an endothelium on the inner surface of the branchial and systemic hearts yet both have intrinsic arteries and veins which are probably connected with capillaries. MARCEAU finds that the walls of the hearts are either covered by an endothelium or by glandular epithelium. 'I'he presence of capillaries in the Dibranchs has been recognized for a long time but it has not been known whether lacunae - i. e. primary body cavities - exist. The accepted belief has been that they are present and are represented in part by the sinuses of the head; but since capillaries are found in every part of the squid and lacunae in none we must believe that the lacunae do not exist. The sinuses cited as examples of lacunae are certainly bounded by an endothelium.

The Coelon. The coelom or secondary body cavity is formed by the union of the dorsal portion of the pair of tubular cavities whose ventral portion forms the nephridial sac (compare p. 39). The coelom occupies the dorsal half of the visceral mass and contains the gonad, the stomach, caecum, intestine, and the systemic and the branchial hearts. It communicates with the exterior through the ciliated tubes which lead to the nephridial sac and it is lined by a ciliated pavement epithelium, the peritoneum, which is reflected over the organs within the cavity. The systemic heart is attached to the lower wall of the coelom by a mesentery which is fastened along the median line of its lower surface and also by the peritoneum reflected over the two branchial veins and the large aortae as they enter the heart. 'The branchial hearts are enclosed in coelomic evaginations, the branchial pericardia, which open into the coelom through narrow oblique slits near the dorsal end of the systemic heart. The genital products are shed into the coelom, from which they are removed by the ciliated funnels of the vas deferens or the oviduct. 'There is apparently nothing to prevent the escape of the genital products from the coelom through the nephridium unless the cilia of the peritoneum drive the ova and sperm toward the opening of the sexual duct. The coelom is not divided, as in some Dibranchs, into a dorsal genital chamber and a ventral pericardium which are united by a narrow tube. The coelom normally holds a small amount of fluid which contains a few amoeboid cells. It is commonly infested by Cestodes which float in a large amount of fluid. 


\section{'THE NERVOUS SYSTEM.}

The nerrous system of the squid (Plates II fig. 15, III fig. 16 and Text Figs. 15 and 16 ) is well centralized and is almost perfectly bilaterally symmetrical. The nerve cells are collected in thirty-one ganglia, all but one of which are paired, as follows:

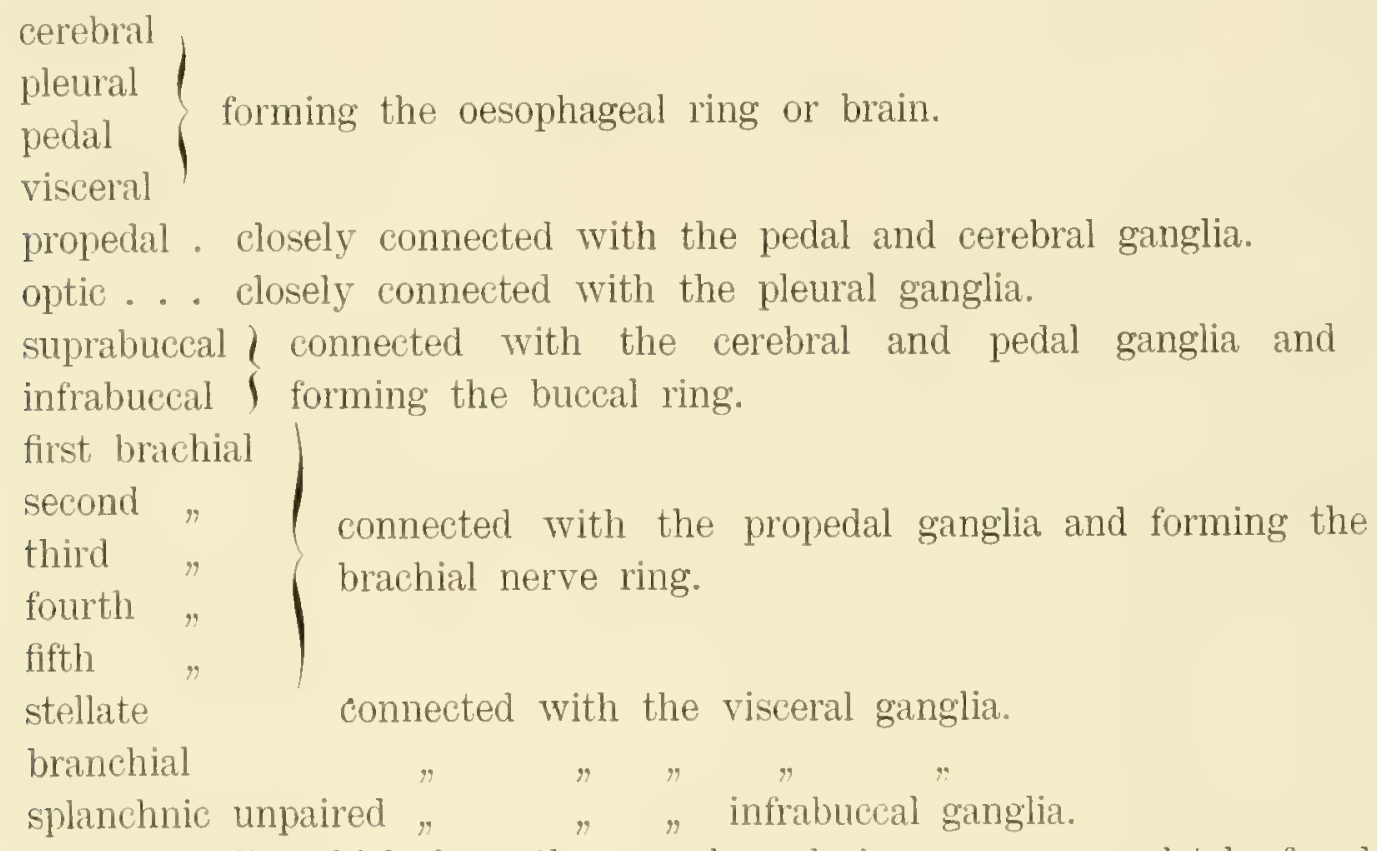

The eight ganglia which form the oesophageal ring are so completely fused that it is almost or quite impossible to determine the bounderies of individual ganglia. Moreover, each member of three pairs of ganglia, the propedal, infrabuccal, and suprabuccal, unites with its fellow in the median line forming a median ganglion. A similar fusion exists in the cerebral, pedal, and visceral ganglia so that each pair of these and of the above mentioned ganglia is indiscriminately termed a ganglion or a pair of ganglia.

The oesophageal ring is enclosed by the skull and surrounds the oesophageal venous sinus and the structures that lie within the sinus. The top of the ring is formed by the cerebral ganglia, the sides by the pleural ganglia, and the bottom by the pedal ganglia in fiont and the visceral ganglia behind. 'The pedal ganglion lies directly below the cerebral and pleural ganglia and in front of the 
statocysts whereas the risceral ganglion lies above the statocysts and behind the rest of the ring, blocking the oesophageal canal so that the oesophagus makes a sharp turn upward to pass above this ganglion. 'The upper and posterior surfaces of the risceral ganglion are covered by a fascia which extends from the edges of the large foramen of the skull to the oesophagus and so separates the brain and the oesophageal canal from the liver.

The cerebral ganglion gives off two pairs of connectives, the cerebropedal and the cerebro-buccal. 'The former pass downward and forward around the oesophagus to the propedal ganglion, the latter pass forward above the oesophagus to the suprabuccal ganglion. This ganglion also receives a connective from the propedal ganglion (propedo-buccal connective) and gives off a connective which passes around the oesophagus to the infrabuccal ganglion. A long pair of connectives passes from the infrabuccal ganglion to the splanchnic ganglion.

A short large bundle of fibres passes from the pedal to the propedal ganglion, which also receives the above mentioned connectives (cerebro-propedal and propedobuccal connectives) and gives off five pairs of connectives to the five pairs of brachial ganglia. Connectives unite the first and second, the second and third, the third and fifth brachial ganglia, and with the commissures between the ganglia of the first pair and the fifth pair

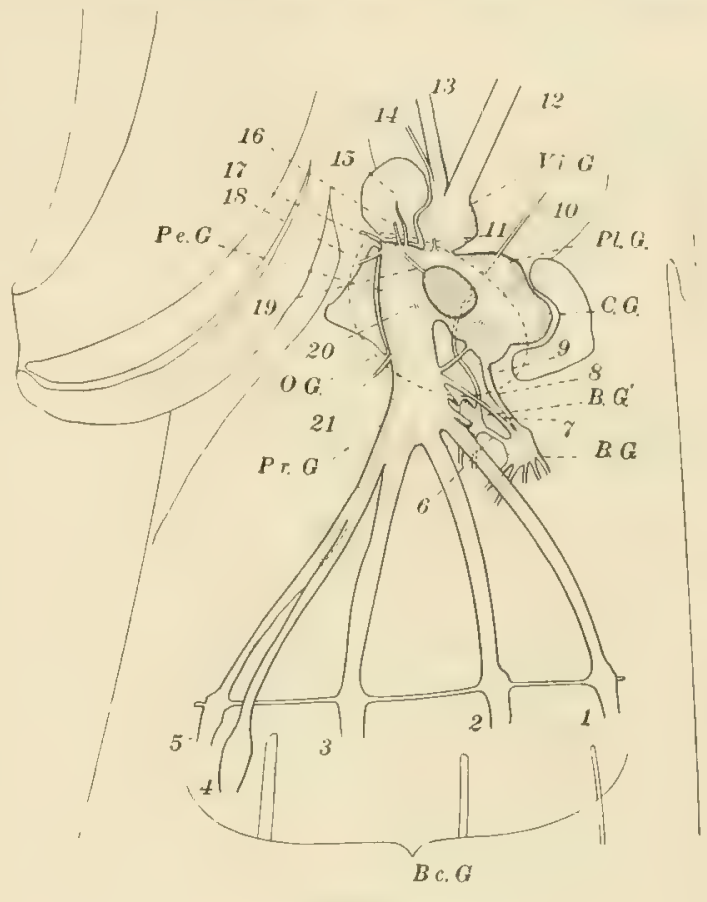

Fjor. 15 form the branchial nerve-ring. Careful search has failed to reveal any connection betreen the ganglia of the fourth arms (tentacles) and this ring.

The pleural ganglion, viewed externally, is well marked and is readily distinguished from the cerebral ganglion on one hand and from the pedal and visceral ganglia on the other, but a study of the minute anatomy of the so called ganglion shows that there is very little ground for calling the mass of fibres in which a few nerve cells are scattered a ganglion. It is really a mass of nerve tracts passing, a) between the optic lobes through the base of the cerebral ganglion, $b$ ) from the optic ganglion to the cerebral and pedal ganglia, and c) from the cerebral to the pedal and visceral ganglia. Nevertheless, it is 
convenient to retain the term, ganglion, as a name for this region of the oesophliageal ring.

'The pleural and cerebral ganglia (with a slight exception mentioned below) consist of small cells whose nuclei vary in diameter between 4 and 7 micra and whose cytoplasm is scarcely discernable, the tissue having a granular appearance under a low power of the microscope. A small lobe of the cerebral ganglion, forming the lower part of its front end and surrounding the tracts which pass out into the cerebro-buccal and cerebro-propedal connectives, differs from the rest of the ganglion in that the cells are larger. The nuclei are from 5 to 13 micra in diameter and the diameter of the cytoplasm is twice or three times that of the nucleus. In contrast to these ganglia, all the other ganglia of the squid have a greater or less proportion of large cells whose nuclei vary from 18 to 20 micra in diametel and whose cytoplasm has a diameter two or three times as large as that of the nucleus.

The optic ganglia have relatively few large cells while all other ganglia have a fail, though varying proportion of them. 'The difference in the size of the cells is very marked and clearly distinguishes the cerebral and pleural and. in a large measure, the optic ganglia from all other ganglia.

The nerve cells are external and the fibre tracts internal ir all ganglia, though the boundary between them is often very irregular.

The cerebral ganglion is the largest ganglion of the squid with the exception of the optic ganglia. It fills up the concavity of the cerebral process of the skull. The ganglion is rounded except that a small lobe from which the cerebro-buccal and cerebro-propedal connectives arise, projects forward from its ventral side. No nerves arise from it, it is very closely connected with the so-called pleural "ganglia" thru which it sends fibres to, or receives them from, the optic, pedal, and visceral ganglia. The lower part of the cerebral ganglion is formed partially by a large tract which connects the two optic lobes and appears to have nothing to do with the ganglion thru which it passes. 'The fibres which form the cerebrobuccal and cerebro-propedal connectives can be traced in the cerebral ganglion some distance. One tract is at first distinguishable near the dorsal end of the ganglion and as it passes forward it joins the other tract which arises in the neighborhood of the pleural ganglion. 'The fibres of the tract thus formed, at least partially, cross to the opposite side and as they leave the ganglion the fibres form two bundles, the connectives.

The pleural ganglion is quite continuous with and inseparable from the cerebral ganglion above and is hardly distinguishable from the pedal and visceral ganglia below. Its inner surface rests against the wall of the oesophageal canal 
and its outer surface rests against the skull and the lateral ligaments of the skull, and gives off the large optic tract which enters the optic ganglion at once.

The optic ganglia lie in the concavities of the lateral processes of the skull, and behind and inside the eyes. Each ganglion is bean-shaped and is attached to the pleural ganglion by the optic tract which enters the concave side or hilum of the ganglion. The opposite (ventro-external) side rests upon the dorso-internal surface of the eye. 'The longest axis of the ganglion is directed obliquely upward and forward, and the gaps above and below between the ganglion and the eye are filled by the white bodies. The artery which supplies the ganglion enters thru the optic tract. 'The veins of the ganglion open into the optic sinus.

'The numerous fibres of the optic nerve arise from the retinal cells and, forming small bundles, pass thiu the foramina in the sclera and, converging, pass thru the narrow slit between the white bodies. They then diverge and, passing over the surface of the ganglion for some distance, finally enter it. Almost the entire surface of the ganglion, except the hilum, is covered by the fibres of the optic nerve.

The optic ganglion is formed of a stratified cortex and a coarsely reticular medulla. The cortex covers the convex surface of the ganglion and the concave hilum is covered largely by the entrance of the optic tract. 'The structure of the optic ganglion of Cephalopods has been thoroughly studied by LexHossek, whose work we summarize here.

The cortex of the ganglion is composed of an outer granular layer; a plexiform layer and the inner granular layer. 'The plexiform layer contains two zones, the inner and the outer plexus, having a preponderance of horizontal fibres, which separate three zones having a larger proportion of vertical fibres. In a small adult of Loligo pealii the outer granular layer is 72 micra, the plexiform layer 170 to 180 , and the inner granular layer, 180 micra thick. The outer granular layer contains unipolar cells of three types: - numerous small cells which lie near the inner surface of the layer, intermediate cells located near its middle, and large cells lying at or near its outer surface. 'The largest cells are about 40 micra long, their nuclei are about 13 micra in diameter and the nuclei of the small cells are about 5 micra in diameter. 'The cell process of each of the small inner cells passes thru the outer clear zone and ends in a brush in the outer horizontal plexus. The processes of the large cells are sparingly branched and terminate in the horizontal plexuses and the middle zone. The processes of the intermediate cells are like those of the large cells except that they bear irregular brushes in the outer horizontal plexus. 'The plexiform layer is formed by the interlocking processes of the ganglion and of the retinal cells together 
with the fibres of the neuroglia cells, which are located upon the outer surface of the inner granular layer. The tibres of the optic nerve pass inward vertically to the inner plexus, and in the outer plexus each bears a brush of short straight processes.

'The medulla contains multipolar, or bipolar cells of four types: - "giant", intermediate, small centripetal and small centrifugal cells. The dendrites of the centrifugal and of the small and intermediate centripetal cells are distributed in the medulla: those of the giant centripetal cells are unusually irregular (knobbed), and are distributed to all parts of the ganglion, but are more numerous in the inner plexus. 'The neurites of the centripetal cells pass toward, and probably into, the optic tract, while those of the centrifugal cells go outward to the outer and inner plexuses.

A small ganglion, somewhat larger than a pin-head, is situated on the anterior and dorsal side of the optic tract. 'This is the "ganglion pedunculi" and seems to be connected with the pleural ganglion alone and only by a few fibres. All its cells are small and their nuclei are separated from one another only by a distance equal to the diameter of a single nucleus.

The pedal ganglion lies in the concavity of the pedal process of the skull below the oesophagus and above the pedal artery. Its upper surface on each side of the oesophagus is continuous with the pleural ganglion and is separated from the visceral ganglion by a septum thru which a large number of fibres pass. The pedo-propedal connectives arise from the ventral end of the pedal ganglion and pass forward a short distance to the propedal ganglion.

The following nerves arise from the pedal ganglia. --

A. Nerves of special sense.

1. Two cristic nerves. Each arises from the back end of the pedal ganglion and, as it enters the cartilage of the skull, divides into two branches, one of which innervates the ventral transverse portion of the crista, and the other the remainder of the crista. The fibres of this nerve are unusually large and stain differentially so that they can be readily traced for some distance in the ganglion. 'The fibres pass along the surface of the ganglion for perhaps half its length and then turn inward and form at least a partial chiasma. 'The fibres have not been traced beyond the chiasma.

2. A pair of macular nerves. Each arises from the back end of the ganglion some distance inward from the roots of the preceding nerve. It passes immediately into the cartilage and, as it passes thru it to the statocyst, 
divides into several small branches which radiate under the macula and end in it. 'The fibres of this nerve are much smaller than those of the cristic nerve and since they do not stain differentially they cannot be traced as readily as those of the cristic nerve. 'The fibres seem to originate in the ganglion some distance behind those of the preceding nerve.

3. A pair of olfactory (?) nerves. Each nerve passes from the side of the pedal ganglion thru the lateral foramen of the skull with, and below, the optic tract. It then passes thru the optic cup below and behind the optic ganglion to the edge of the lateral process of the skull which it pierces or passes over and ends in the columnar epithelium of the olfactory pit. Within the brain the fibres can be followed from the point of their exit, obliquely upward to a point near the pleural ganglion.

B. Other nerves.

4. A pair of nerves arises from the back end of the ganglion some distance above the origin of the statocystic nerves, in fact, at the extreme upper edge of the ganglion. Each nerve pierces the septum that separates the pedal and visceral ganglia and passing over the outer surface of the latter enters the cartilage. In the cartilage the nerve divides and, leaving the skull, ends in the cephalic and nuchal retractors.

5. Two nerves arise on each side from the same part of the ganglion and are perhaps one with the preceding nerve. One of these passes thru the lateral foramen of the skull and probably innervates the upper and posterior muscles of the eye. 'The other passes upward thru a foramen to the upper part of the cephalic retractor.

6. A pair of small nerves arises from the pedal ganglion a short distance in front of the last mentioned nerves and each nerve passes forward and upward around the oesophagus and then outward to the ventro-anterior muscles of the eye.

7. A pair of siphonal nerves arises from the posterior part of the lower surface of the ganglion and each nerve passes at once thru a foramen in the pedal process to the siphon. While in the foramen the nerve gives off' a branch which enters the optic capsule.

8. Immediately in front of the siphonal nerves there arises a median nerve which goes thru the pedal process and is distributed to the muscles of the lower side of the head.

9. A pair of nerves arises from the sides of the front end of the ganglion. Each nerve passes outward and forward above the pedal process and the 
capsule of the eye and below the optic ganglion. 'They supply the muscles and capsule of the eye.

10. A pail of nerves arises from the front end of the ganglion and passes forwind with and under the pedo-propedal connectives. At the dorsal end of the propedal ganglion each nerve turns sharpely downward over the point of the pedal process and between the bases of the preorbital car. tilages. It supplies the muscles at the base of the arms.

A pair of cells, (Text Fig. 16) the two largest and most remarkable cells of the body are situated in the pedal ganglion. They lie near the median line a short distance in front of the statocyst. Each cell is fusiform and is vertically placed. The nucleus is large, round, and central. The cytoplasm is granular and, like the very large nerve process arising from it, stains difterentially with haemalum, taking a very distinct blue gray color, which is in marked contrast to the other unstained fibres and cell bodies. The nerve fibre arises from the backwardly curved upper end of the cell and passes backward, upward and inward to the center of the visceral ganglion, where it crosses the median line, forming a chiasma with the process of the other cell. Beyond the chiasma the fibre passes into the viscero-stellate connective of the side opposite its origin and, entering the stellate ganglion, divides into at least four and probably five or even more branches, one of which enters each of the larger nerves which arise from that ganglion, and thus the fibre branches pass to various parts of the mantle.

I have been unable to discover the ultimate distribution of the fibres or to make out the central connections of the cell. 'These fibres, not previously described in any mollusc, resemble closely the fibres of Nauthner in vertebrates which are also unique in the nervous system of the animal, there being but one pair of cells which are marked off both by the size of the cells and of their fibres and by some chemical constituent which makes them stain differentially from nearly all other fibres. These cells appear in the embryo and persist throughout life. The very size of the nerve processes has prevented their discovery, since it is well-nigh impossible to believe that such a large structure can be a nerve fibre.

The propedal ganglion lies directly ventral to the pedal ganglion and betreen the oesophageal canal and the muscles that are attached to the pedal process. The connective which it receives from the pedal ganglion, is incompletely divided into a central, and six pairs of lateral bundles. 'The ganglion is also connected with the cerebral ganglion by the cerebro-propedal connective and with the suprabuccal ganglion by the bucco-propedal connective. The former passes 

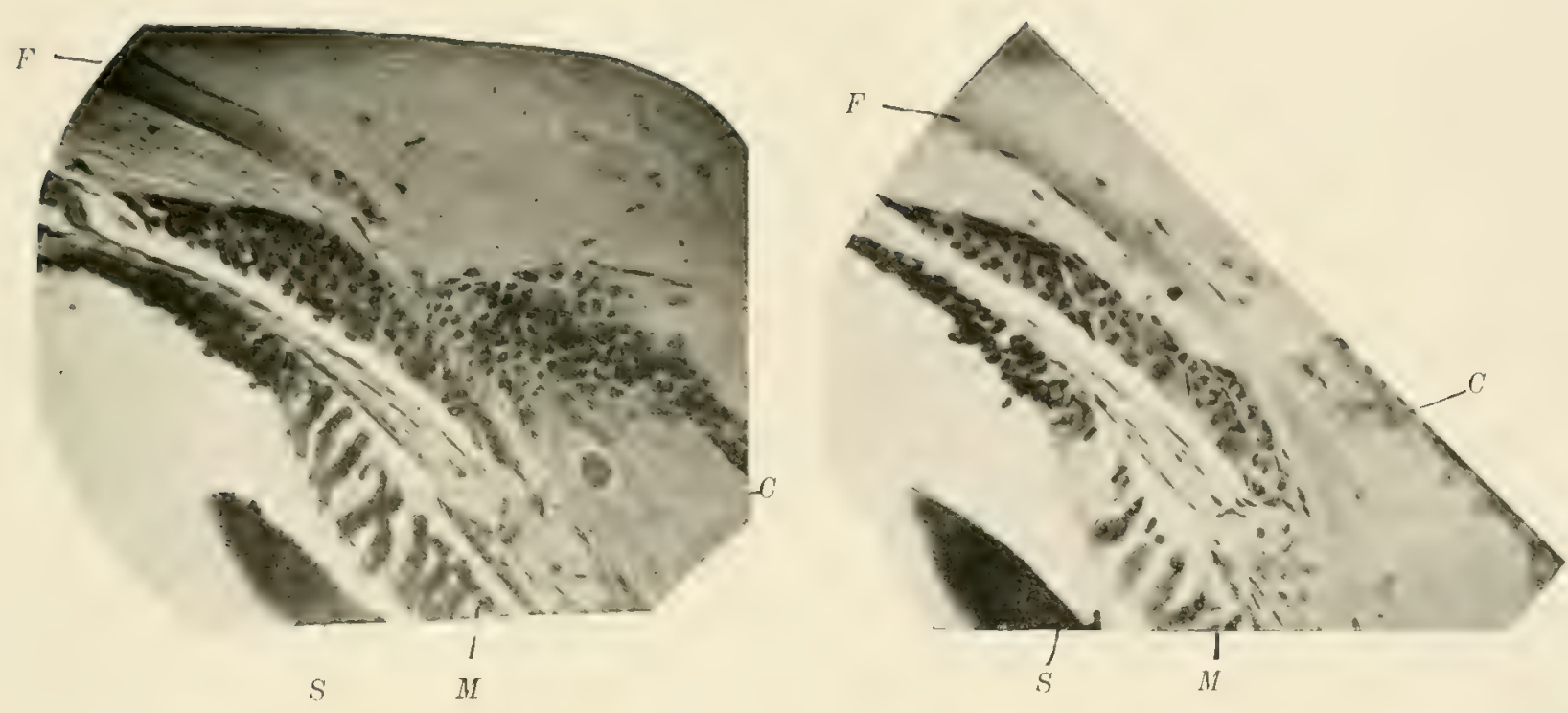

C

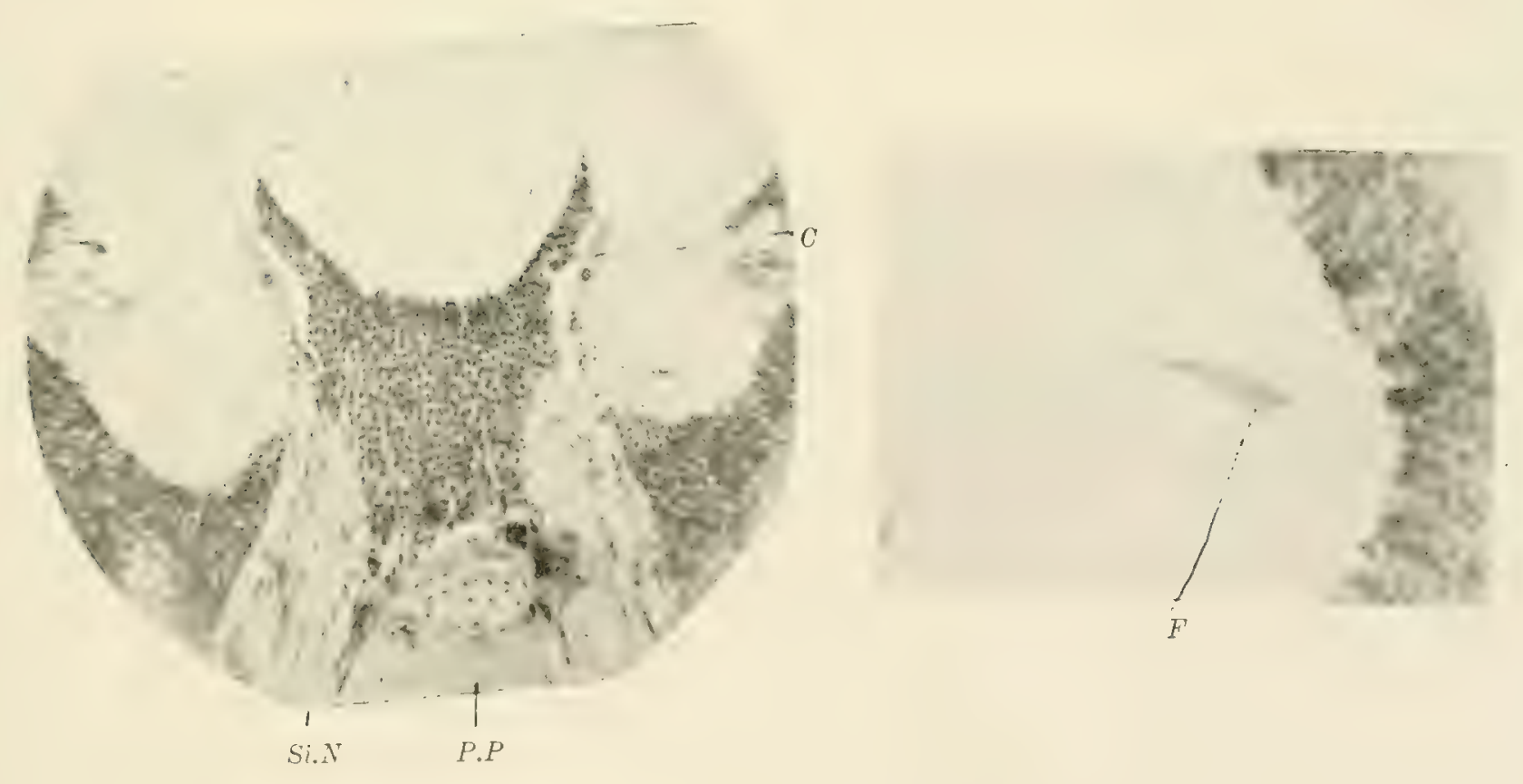

Fig. 16 . 

upward and backward around the oesophageal canal to the ventral end of the cerebral ganglion. 'The latter arises from the back end of the ganglion together with the former and turns forward and upward around the oesophagus and ends in the supra-buccal ganglion. Several small nerves arise from the edges of the upper surface of the ganglion. The fibres of these nerves radiate backward, upward and forward, and innervate the muscles between the skull and the base of the arms. Five pairs of nerves or connectives come from the edge of the ventral surface of the ganglion and diverge from one another as they pass forward around the pharynx from which they are separated by the buccal sinuses. These ten nerves enter ten brachial ganglia which lie in the corresponding arms, and which are more properly called nerve-cords. Each ganglion or cord extends from the base to the apex of the arm and taper's regularly from its large base to a minute point. The bases of the ganglia are connected by slender nerve tracts which with the ganglia form at the bases of the arms a nerve-ring, the brachial ring. It is not certain, but probable, that the ganglia of the fourth pair of arms are connected with this ring.

The buccal nerve ring is formed by the suprabuccal and infrabuccal ganglia, and encircles the oesophagus just back of the pharynx. 'The suprabuccal ganglion is attached to the inner surface of the septum that separates the two buccal sinuses. Its dorsal surface receives two pairs of connectives, the cerebrobuccal and the propedo-buccal, from the cerebral and propedal ganglia respectively. From the ventral end of the ganglion arise four or five pairs of nerves which pass to the muscles of the pharynx, and from the sides arise two connectives which pass downward around the oesophagus to the infrabuccal ganglion.

The infrabuccal ganglion is attached to the dorsal surface of the pharynx between the lateral salivary glands. Two pairs of nerves from this ganglion innervate the odontophore and a pair of connectives arises from its dorsal end and passes backward along the entire length of the oesophagus. 'These connectives, the bucco-splanchnic, enter the splanchnic, "gastric", or "abdominal" ganglion which lies on the upper surface of the dorsal end of the intestine between the oesophagus and the caecum.

The splanchnic ganglion gives off five large and two or more small nerves. The largest nerve passes to the left between the caecum and the pancreas and, entering the ridge from which the caecal folds arise, supplies them. 'Two large nerves arise from the dorsal end of the ganglion and go between the stomach and caecum, supplying the inner sides of both organs. One large and two small nerves from the right side of the ganglion pass under the oesophagus to the upper (anterior) caecal lobe. From the ventral end of the ganglion arise the 
bucco-splanchnic connectives and a large nerve which supplies the liver, the pancreals, and perhaps the intestine. The innervation of the systemic heart has not been discovered but there is little doubt that the splanchnic ganglion also sipplies it.

'The visceral ganglion is the most dorsal of the oesophageal ganglia and fits into a shallow depression in the skull above the statocysts. It is bound down to the cartilage by a tent-shaped sheet of fascia whose top is attached to the oesophagus and to the anterior half of the great foramen of the skull and whose edges are attached to the rim of the depression that lodges the ganglion. The rentral portion of this sheet is perforated laterally by openings for the visceropedal and viscero-pleural connectives. These connectives arise together in the ganglion and diverge as they pass backward, the pedal turning downward, and the pleural outward. Four pairs of nerves arise from this ganglion. 'Two arise from the dorso-external region of the ganglion: one passes directly outward to the lateral siphonal valve; and one downward over the dorsal surface of the skull close to the attachment of the cephalic retractor, then thru this muscle into the upper surface of the siphon. From the dorsal surface of the visceral ganglion arise two pairs of nerves which are united to two pairs of connectives: the visceral nerve with the viscero-branchial connective, and the pleural nerve with the viscero-stellate connective. The pleural nerves and the associated connectives arise from the sides of the dorsal surface of the ganglion. Each bundle of fibres passes obliquely outward and backward thru a deep groove in the liver to the dorso-lateral edge of the nuchal cartilage, turns over this edge, and passes thru the nuchal retractor which is attached to it. As the bundle emerges from this muscle it divides; the pleural nerve passes backward and the viscero-stellate connective at once enters the stellate ganglion. The pleural nerve gives off a small branch to the nuchal retractor as it leaves that muscle and forms the greater part of the nerve which innervates the fin.

The two stellate ganglia are oval and flattened and lie under the skin of the inner surface of the mantle near the dorsal end of the nuchal cartilage and close to the shaft of the pen. Each ganglion sends off eight or ten nerves which radiate from its ventral edge. The dorsal part of the ganglion projects backward like the tail of a comma and contains the majority of the large nerve cells of the ganglion. The stellate ganglia are connected by a small commissure which leaves each ganglion with the viscero-stellate connective and which passes under the dorsal end of the nuchal cartilage. All but two of the nerves arising from the stellate ganglion enter the mantle within five or six millimeters of the ganglion and pass at once to the middle of its wall and are distributed to all parts 
of the mantle. One of the two nerves which do not enter the mantle at once joins the fin branch of the pleural nerve, and the fin nerve thus formed passes thru the mantle in a long oblique canal and enters the ventral angle of the fin. The nerve breaks up into a number of branches which cross the upper surface of the fin cartilage and ramify in the middle fascia to all parts of the fin. 'The other nerre enters the canal thru which the fin nerve passes but leaves the canal near its middle and supplies the mantle.

'The two visceral nerves arise separately in the visceral ganglion and, uniting as they leave the ganglion, form a median nerve which with the associated viscero-branchial connective passes obliquely downward and backward thru the liver to the posterior wall of the liver-case. The nerves then separate and enter the cephalic retractor, at a point one third or one fourth the length of the liver from its ventral end. Each nerve then passes obliquely thru the muscle and runs backward beside the anterior vena cava to its termination in the nephridial sac. 'The nerve passes from that point across the outer wall of the sac, and finally above the branchial artery and vein to the branchial ganglion. Before entering the cephalic retractol, the visceral nerve gives off a branch to that muscle and as it emerges it gives off two branches: one passes outward to the siphonal retractor; the other turns downward around the anterior vena cava and joins its mate from the other side. The median trunk thus formed divides at once: one branch passes thru the mesentery-like sheet of muscle and fascia which fastens the rectum to the visceral mass and enters the rectum near the distal end of the duct of the ink-sac; the other branch passes back and enters the upper surface of the ink-sac. A branch arises from the left visceral nerve near the end of the anterior vena cava; in the male it innervates the vas deferens, the spermatophoric gland, the spermatophoric sac, and the penis; in the female it supplies the oviduct and the oviducal gland. A small bundle of nerve fibres passes under the back end of the anterior vena cava and connects the two visceral nerves. The majority of the fibres seem to come from the branchial ganglion but a few appear to come from the visceral ganglion hence we are led to believe that at least a part of this bundle is the branchial commissure.

The branchial ganglia are situated in the gills and are very similar to the brachial ganglia. Each is small and oval and lies at the base of the gill just dorsal to the branchial artery. From the anterior end of the ganglion there arises a nerve cord which seems to be a continuation of the ganglion. 'This cord tapers gradually from the base to the apex of the gill. It is surrounded by the longitudinal muscles of the gill, the "blood gland," and the branchial artery. A nerve which seems to arise from the branchial ganglion, passes forward with 
the viscero-branchial connective a very short distance and then enters the branchial heart. It is possible that this nerve arises from the visceral ganglion, not from the branchial, and it is also possible that this nerve, not one from the splanchnic ganglion, supplies the systemic heart.

\section{The Sense Organs.}

The organs of special sense are the statocysts, the eyes, and the organ which is probably olfactory in function. The last is an area of colummar epithelium situated in the concavity at the lower end of the "olfactory crest" and innervated by a nerve from the pedal ganglion.

\section{The Statocysts.}

The statocysts of the Cephalopoda have been described by HamLrs.HARRIS and, although he did not have this species before him, his description of the statocysts of Loligo vulgaris holds true for this species. The statocysts lie in the skull below the visceral, and behind the pedal ganglion. The cavity of each is 2 or $^{\circ} 3 \mathrm{~mm}$. in diameter and 3 or more mm. in length. They are side by side and are separated by a thin cartilaginous septum. Twelve papillae project into the statocystic cavity. These are situated as follows, passing backward from the first, near the front end, to the last, near the back end of the cavity:

The first postero-median papilla.

second "
$"$ first median
$" \quad$ antero-median
$"$ first posterior
$" \quad$ " anterior
$" \quad$ second median
$" \quad$ posterior
$"$ first external
$"$ second "
third posterior

\section{"}

" The first anterior, the second median

$"$ and the second posterior papillae are

$" \quad$ included in the same cross section.

These papillae are side by side and " $\quad$ the first which is bent uprard is poste" Crior to the second which is erect. $\because$

$"$

behind the preceding. above the preceding.
This begins as a ridge on the thickened posterior part of the septum, runs outward and backward, and ends in a posterior papilla. 
'The second anterior papilla. This is slightly inside the center of the anterior surface.

In addition to these papillae, there is a prominent ridge which is horizontal and lies on the ventral (front) end of the extemal surface.

'The statocystic cavity is lined by a pavement epithelium except in the region of the macula statica and crista statica. The former is an area of colummnar, ciliated, sensory epithelium covering the ventral or front end of the cavity. The statolith, a club shaped concretion rests upon the macula. The nerve fibres arising from the macula form a number of small bundles and these converging, form two large bundles of fibres which pass out thru the cartilage and then unite. 'The macular nerve thus formed enters the pedal ganglion and curving outward is lost in the ganglion just outside the roots of the siphonal nerve. 'The fibres of this nerve do not stain differentially and are small so that it is not easy to follow them far into the ganglion.

The crista statica is a ridge of ciliated epithelium which winds over the walls of the statocyst. This ridge begins at the foot of the first postero-median papilla runs outward across the floor of the cavity to the front end of the external horizontal ridge, passes backward above this ridge between the first and second external papillae (passing beneath the overhanging part of the first) then turns inward across the floor to the back side of the third posterior papilla, again turns and passes upward to the base of the second anterior papilla where it ends. The crista is formed by three or more rows of columnar, ciliated cells with supporting cells. The cells of the central row are markedly larger than those of the two or four lateral rows. 'The distal ends of the lateral cells incline towards the central cells so that a ridge is formed which in section has approximately the outline of an isosceles triangle. The nerve fibres arising from the anterior transverse portion of the crista form a bundle which enters the cartilage near, but separate from, a larger bundle arising from the remainder of the crista. The latter bundle begins at the dorsal (back) end of the crista and, constantly receiving fibres from it, passes along its upper (anterior) edge. The two bundles pass out of the statocystic cavity at its ventroexternal angle and, uniting in the cartilage, enter the pedal ganglion. The fibres pass along the outer surface of the ganglion until beyond the roots of the siphonal nerves and then bend inward forming at least a partial chiasma. The fibres have not been traced beyond the chiasma but are lost in the neuropile of the ganglion. They are traceable so long a distance because they are unusually large and stain differentially with haemalum or haematoxylin. The fact that the macular and cristic nerves are markedly different does not seem to have been noted by other observers. 'These two nerves 
differ in staining property, size of fibres, course in the brain and the skull, and in origin.

The statocyst arises from an invagination of the ectoderm which forms laterally on the posterior side of the embryo. 'The bottom of the invagination becomes large and rounded and projects inward until it reaches the middle of the posterior part of the head and is separated from its mate by a thin septum only. The cavity of the statocyst remains for some time in communication with the surface by a long, narow duct which is attached like the neck of a retort, to the side of the cavity and leads to the posterior surface of the embryo. In the adult the outer opening seems to be closed but the canal remains as a slender ciliated duct which is named from its discoverer, Koelliker's duct. It leads thru the skull from its inner opening at the front end of the statocystic cavity just above the crista, downward and slightly backward to the lower surface of the skull. Here the duct seems to end but it is possible that it leads to the surface.

The Ere. (Plate III figs. 20-2̌). The eye of the higher Cephalopoda is very similar to the vertebrate eye; in fact the two structures furnish a most remarkable case of convergent development, for while differing essentially both in the origin of their parts and in structure, the eyes are so similar that a large part of the terminology of the vertebrate eye is applicable to the Cephalopod eye. In the young embryo of the squid an oval area of ectoderm at each side of the embryo becomes differentiated from the surrounding flat or cubical epithelium and forms the anlage of the retina. The cells of the anlage become greatly elongated and the nuclei take up different positions at the middle or at each end of the cells so that, although remaining one layered the epithelium appears to be several layered. The cubical epithelium at the margin of each retinal plate forms a circular ridge which gradually becomes a fold surrounding a pit and finally the outer wall of a vesicle, the inner chamber of the eye. From the walls of the optic vesicle the retina, the lens, and the inner portion of the ciliary body are formed. The outer wall of the vesicle consists of two sheets of ectoderm separated by a small amount of mesodermal tissue. The mesodermal tissue forms the sclerotic coat and the suspensory ligament of the lens, and the ectoderm produces the lens which consists of two segments, one formed in the inner chamber by the inner layer of the ectoderm and one formed in the outer chamber by the external sheet of ectoderm. Two circular folds also containing both ectoderm and mesoderm arise around the optic vesicle. The inner fold grows over the optic vesicle and forms the iris. The outer fold also grows over the vesicle and enclosing the outer chamber forms the cornea and the capsule of the eye. 'The outer' 
chamber is extensive but incapacious and completely separates the eyeball, which is formed by the optic vesicle and the iris, from the capsule of the eye. 'The chamber communicates with the exterior thru a small canal, the "aquiferous pore", which is surrounded by a sphincter muscle and which has at its inner end a ciliated funnel composed of columnar cells. This pore lies at the ventral edge of the eye just in front of the cornea. 'The capsule is helmet-shaped and is attached to the margin of the optic cup of the skull. It is composed of connective tissue, muscle and skin. 'The outer wall of the capsule covers almost all of the side of the true head and contains the cornea, a circular, transparent, slightly convex membrane whose margin is supported by a ring of stiff connective tissue. The inner wall of the capsule separates the outer chamber of the eye from the sac which contains the peduncle of the tentacle. 'The capsule is lined by a pavemental epithelium except in the neighborhood of the aquiferous pore and is reflected over the iris, forming the only connection between the capsule and the eyeball.

The iris is a thick, opaque, iridescent curtain which projects from the margin of the sclerotic cup into the outer chamber of the eye. A small visor-like fold of the iris projects into the pupil from its upper margin and by a contraction in faint, and extension in strong light, alters the shape of the pupil from a circular to a cresentic form and so adjusts the illumination of the retina. The iris has four layers: - an outer epithelium, a thick argentea, a muscular layer, and an inner epithelium. The outer epithelium is pavemental and is continuous with that lining the capsule. 'The argentea is a thick, opaque coat and extends beyond the iris over all the eyeball except the dorso-internal surface which is in contact with the optic ganglion. The opacity and iridescence of the argentea are due to a vast number of rods and fibres which interfere with and reflect light. The cells which produce these rods and fibres are similar to the iridiocysts of the skin. 'The protoplasm of each cell produces a large number of rods or fibres, as the case may be, there being left barely enough untransformed material to hold the rods or fibres together. All the rods or fibres produced by a cell are parallel but the fibres of different cells are inclined to one another at various angles. The cells immediately beneath the outer epithelium produce short rods that are perpendicular to it. The fibres of the underlying cells tend to lie parallel to the epithelium or to form acute angles with it. The importance of the argentea is evident since all the tissues of the living squid except this and the iridiocysts are very translucent, almost transparent, and without the argentea the posterior chamber of the eye would be penetrable by light rays from all directions. The muscular layer of the iris is formed of circular 
and ritial fibres. 'The former cncircle the pupil and are inserted in the visor' like fold of the iris. 'The latter arise from the margin of the sclerotic cup and interweave with the circular fibres. The contraction of the circular fibres narrows the pupil and draws the visol down into it, while the contraction of the radial fibres dilates the pupil and draws up the risor. 'The inner epithelium is continnous at the inner edge of the iris with the outer epithelium and at its periphery with the outer layer of the ciliary body. Its cells are cubical and are filled with black pigment.

The eyeball is held in place by nine muscles and by a somewhat cylindrical fascia which stretches from the equator of the eye to the margins of the optic cup of the skull and so, with the eye, encloses the optic ganglion and the white bodies. The imner side of this fascia is supported by the preorbital cartilage which projects from the pedal process of the skull forward and slightly downward between the outer chamber and the eyeball. The nine orbital muscles, however, form the chief attachment of the eye. They lie in the orbital fascia and are attached with it to the eyeball. The muscles arise from three points and so naturally fall into three groups viz. 1) two that arise from the cerebral process of the skull; 2) three that arise from the lower part of the outer edge of the skull: and 3) four that arise from the pedal process and the preorbital bar. One of the two arising from the cerebral process passes outward and downward to the dorsal surface of the eye. The other passes downward between the muscles of this third group and the eye, then outward to its lower surface. Of the three that arise from the outer edge of the skull; one, a slender band, passes upward and is inserted upon the upper part of the dorsal surface of the eye; another, a small short muscle, reaches directly forward to the lower part of the dorsal surface of the eye; the third, a strong muscle, goes forward to the lower surface of the eye. The four remaining muscles arise from the pedal process or from the preorbital bar. One passes from the former outward and downward to the lower surface of the eye. A second arises from the same process and is inserted upon the lower edge of the preorbital cartilage. A third muscle, apparently a continuation of the last, arises from the opposite edge of the cartilage and from the pedal process near the base of the preorbital cartilage and is inserted upon the ventral surface of the eye. The remaining muscle is a peculiar digastric muscle which extends from eye to eye passing through a pulley at the rentral end of the pedal process. From this pulley which may be considered the origin of the muscle a slender tendon passes outward and forward upon each preorbital bar and then ends in a small triangular muscular belly that is attached by a broad fascia to the ventral surface of the eye. It is not probable that this 
extensive musculature produces any considerable movement of the eyeball - it is too firmly attached to the immovable optic cup - but the muscles probably adjust the eye to the displacements produced by the flexures of the arms and head.

The sclera is a hemispherical cup of cartilage whose margin is thickened and slightly incurved. 'This cartilage consists of a single layer of flattened cells lying between two sheets of matrix. 'loward the lim of the cup the cells become cubical, then columnar and in the thickest part of the rim, they form two or three layers of angular cells. The portions of the sclera that are not covered or are only partially covered by the argentea of the iris are coated externally by an argentea similar to that of the iris whose fibres, however, are sinuous, longer and finer.

The white bodies (see p. 65) are two irregular masses of problematical tissue which are wedged in between the optic ganglion and the eye. 'I'he upper white body lies upon the anterodorsal surface of the eye while the lower lies upon the postero-internal surface so that they are upon opposite sides of the bundle of nerve fibres which passes between the eye and the optic ganglion. A falciform bar of cartilage, attached by a fascia to the pedal process, lies between the upper white body and the eye, and helps both to support the eye and to protect the optic ganglion. The foramina in the sclera through which the nerve fibres pass out from the retina are small, quite near together and are situated in an elliptical area on the dorso-internal surface of the eye. 'The longer axis of this area extends obliquely downward and forward.

A sheet of connective tissue, the suspensory ligament of the lens, stretches across the top of the sclerotic cup and supports both the ciliary body and the lens. The peripheral portion of this ligament has attached to its inner surface the fibres of a radial muscle, the ciliary muscle (of LANGER) which arises from the rim of the sclera. The intermediate zone of this ligament supports the inner and outer portions of the "ciliary body" or "corpus epitheliale" which produce the inner and outer portions of the lens, respectively. The two portions of the ciliary body (Plate III, Fig. 20) arise from the inner and outer sheets of ectoderm that form the outer wall of the optic vescicle while the suspensory ligament and cilary muscle arise from the mesoderm enclosed between the ectodermal sheets. The cells of these sheets are at first cubical but those at the center of the inner sheet soon prodice small, finger-like processes, one for each cell, which extend into the posterior chamber and, uniting, form a small clubshaped body, the lens. The cells of the zone immediately around the center, produce similar but longer processes which, extending toward the lens, unite with one another and form one of the concentric laminae of the lens. 'The 
laminie, thus produced, are added constantly to the lens until it becomes a spherical mass attached to the inner portion of the ciliary body by means of the stalks of the processes. As soon as the lens has become spherical, the outer part of the ciliary body begins to contribute to its growth, for further growth by additions from the inner portion of the ciliary body necessarily produces a lens flattened on the side in contact with the suspensory ligament. Hence, to maintain the spherical form of the lens, a plano-convex segment is produced by the outer portion of the ciliary body. Those cells of the ciliary body which are enclosed between the two segments of the lens degenerate and are absorbed, leaving only the suspensory ligament between the two segments. The constant growth of the lens and of the ciliary body necessitates the existence of three zones in the latter viz. an inner zone of degenerating cells, a middle zone of mature cells, and a marginal zone of immature cells. The lensforming processes of the immature cells are relatively larger and more conspicuous than those of the mature cells and form a prominent layer between the ciliary body and the adjacent chamber of the eye. The large size and conspicuous position of the processes have led some writers (FAUSSEK '96) to ascribe to them the formation of the entire lens and to assert that the large mature cells of the ciliary body have some unknown physiological function. The mature cells of the ciliary body are oval, cubical or columnar and are attached by their bases to the suspensory ligament. The free end of each cell is drawn out into a long, slender process which is so small compared with the cell and the corresponding portion of the lamina, that it probably serves as a duct which carries the secretion of the cell to the lamina. When isolated these cells are so similar in general appearance to unipolar nerve cells that the writer who has given the best description of them (Hoffinan) believed them to be nerve cells. The cell body is large and stains deeply with nuclear stains. The nucleus is large and the nucleolus conspicuous. While attaining their mature condition, the cells of the inner portion of the ciliary body grow so much that the epithelium formed by them is thrown into radial folds. The inner furrows of these folds are filled by the cell processes while the outer furrows are filled by ridges of the suspensory ligament. 'Thus this outer layer remains a simple palisadal epithelium which, however, in section appear's several cells thick. The outer layer of the ciliary body is less folded or remains plane. A pigmented membrane, the continuation of the supporting layer of the retina, lies upon the inner surface of the ciliary body, and, as HofFun has shown, the cells of the inner part of the ciliary body may be distinguished from those of the outer part by the presence of pigment granules in or between the cells. 
The retina has been shown by Granacher to be a one-layered colummar epithelium but, owing to the specialization of portions of its cells, it seems formed of several layers. 'The apparent layers are: an internal limiting membrane, an inner pigment layer, a layer of rods, an outer pigment layer together with an inner nuclear layer, the basement or outer limiting membrane, a clear zone and the outer nuclear layer. The retina arises from the ectoderm of the center of the first optic invagination and remains continuous with the epithelium of the peripheral portion of the pit, from which arises the pigmented epithelium (choroidea) which lines the outer wall of the inner chamber of the eye. The retinal epithelium rapidly becomes very thick, certain of its cells elongate more rapidly than the others and, pushing their nucleated proximal ends through the basement membrane, extend some distance into the surrounding connective tissue. These are the sensory or rod cells, which become differentiated into three regions, a long and slender distal "rod", a short intermediate rod-stalk ("Sockel") and the projecting nuclear portion. The remaining cells become the supporting cells. They form a honeycomb-like frame work (apparently a syncytium) which surrounds the rods and stalks. The nuclei of these cells, with a small amount of the cytoplasm, lie close to the basement membrane. Slender cytoplasmic processes extend inward in the spaces between four or more adjacent rods to the internal limiting membrane and serve to bind together both the rods and the limiting membranes. Each rod secretes a pair of thick trough-shaped or semicylindrical cuticular plates which invest it except at its ends; the outer of which forms a small bulb whereas the inner is continuous with a short fusiform expansion, the rod stalk which lies between the rod and the internal limiting membrane and laterally between the nuclei of the supporting cells.

The rods are closely packed in regular longitudinal and transverse rows, and the cleft between the semicylinders of each rod is inclined at an angle of $45^{\circ}$ to both rows and at right angles to the corresponding clefts of the four adjacent rods. This arrangement brings together the half cylinders of every alternate group of four rods in the form of a Maltese cross whose center is made by a strand of the cytoplasm of the supporting syncytium and whose ends are each bound by a similar strand to the arms of three other crosses. Grenacher, regarding these pretty crosses as units, called them rhabdomes, but there is no adequate reason for regarding them either as morphological or physiological units.

The stalks and the intervening portions of the supporting cells are filled with granular pigment which forms a thick pigment layer, the external pigment layer, within the basement membrane. The nuclear portion of the sensory cell extends inward from the basement membrane and forms about one third of the 
length of the entire cell. 'The nuclear' segments are supported by richly vascular' commective tissue. The proximal portions of these segments contain the nuclei, which are arranged at various levels so that they seemingly form two or three layers.

The above description is generally accepted, but the essential part of the sensory cell, - the percipient structure - has been, and perhaps still is, little understood. HEsse (1900) finds that the neurofibrillae which form the fibers of the optic nerve, and which seem to him the percipient structures, arise near the distal end of the rods and extend the entire length of the sensory cells. MERTON (1905), however, finds that the neuro-fibril, entering the nuclear segment, broadens into an irregular and often split lamella which extends to the base of the rod stalk; and that the rod contains a cytoplasmic network mistaken by Hesse for the continuation of the neurofibril - which is the path of migration of the pigment.

The pigment migration has been extensively studied by RAwitz, Hesse and Hess, who have shown that the retina of a Cephalopod which has been long in the dark contains a single layer of pigment, - the external pigment layer, and that in the light the pigment granules migrate inward from this layer and, massing in the expanded inner ends of the rods, form the inner pigment layer which lies beneath the internal limiting membrane and which is connected with the external pigment layer by a small amount of pigment scattered along the rods.

Hess finds that the fresh retina always appears dark brown or black and that a red hue tends to predominate in the upper, a brown shade in the lower half of the eye. On the contrary, a retina preserved after remaining long in the dark, appears gray; after exposure to light, dark brown or black; while after an exposure for one hour to changing light, there appears a horizontal gray band about $4 \mathrm{~mm}$. broad between the darker upper and lower halves of the retina. With increased light this band becomes narrower and finally dissappears.

The dark color of the fresh retina is due to its transparence, which allows the pigment to be seen at any depth, while the opaqueness of the preserved retina does not allow the pigment to be seen unless it lies near the surface.

The retardation of the migration of pigment to the distal part of the rods of the horizontal band seems to indicate that the cells of this region are less sensitive to an excess of light.

In addition to this merely protective pigment, Hess finds that the Cephalopod retina contains a purple pigment which is very similar to, perhaps identical with, visual purple. 
BeER has described the mechanism of accomodation and has shown that it is much the same as in the eyes of 'Teleosts, although there are important differences. In both cases the eye is myopic, the convexity of the lens is unchangeable, and accomodation is effected by drawing the lens toward the retina. In fish the falciform process, or musculus retractor lentis, draws the lens toward the retina, but in the Cephalopod eye, the ciliary muscle accomplishes this. 'The outer surface of the ere is convex and the contraction of the ciliary muscle flattens the outer wall of the eye and draws the lens toward the retina. Moreover, the more violent contraction of one segment of the ciliary muscle turns the lens so that a ray, which otherwise would not reach the retina, strikes it. Thus, by turning the lens, a moving body may be watched without turning the eye or the head. 



\section{B I B L IOGR A P H Y.}

Babuchin, A. Vergleichend-histologische Studien. Ueber den Bau der Cephalopodenretina. Würzhurger naturw. Zuit. 5, 1864, p. 127-140.

Ballowitz. Ueber den feineren Bau der Muskelsubstanzen der Cephalopoden. Aruh. f. mikr. Anat. 39, 1892 , p. $291-324$, pl. XIII-XIV.

BeEr, TH. Die Accommodation des Cephalopodenaugen. Pflueger Arch. f. d. g. Phys. 67, 1897, p. 541586 , pl. I.

BergManN, W. Untersuchungen über die Eibildung bei Anneliden und Cephalopoden. Zeit. f. wiss. Zool. $73,1902-1903$, p. 278-301, pl. XVII-XIX.

- Ueber den Bau des Ovariums bei Cephalopoden und einiger Nachträge zur Eibildung derselben. Aich. Naturg. 69,1903, p. 227-236, pl. XI.

Bobretzry, N. Recherches sur le développement des Cẻphalopodes. Mém. de la Soc. imp. des Amis d'Histoire Nat. 24, 1877, 74 pages $10 \mathrm{pl}$.

Bolı, E. Beitrag zur vergl. Histologie des Molluskentypus. Arch. f. mikr. Anat. 5 Suppl. 1869, p. 1-111, pl. I-IV.

Bourquelot, M. E. Recherches sur les phẻnomènes de la digestion chez les mollusques céphalopodes. Arch. Zool, exp. ge̊n. VIII, (2 ser.), 1885, p.1-73, pl. I-III.

- - Recherches expérimentales sur l'action des sucs digestives des Céphalopodes. Arch. Zool. exp. et gén. 10,1588 , p. $356-419$.

Brock, J. Ueber die Geschlechtsorgane der Cephalopoden. Zeit. f. wiss. Zool. 32. 1879, p. I-116, pl. I-IV.

- - Versuch einer Phylogenie der dibranchiaten Cephalopoden. Morph. Jahrb. 6. 1880, p. 185-296.

-_. Zur Anatomie und Systematik der Cephalopoden. Zeit. f. wiss. Zool. 36, 1882, p 543-606.

- Uebel das sogenannte Verrillsche Organ der Cephalopoden. Nachr. d. Koen. Ges. d. Wiss. z. Goettingen, N. 17, 1888 , p. $476-478$.

Brooks, W. K., The Development of the Squid (Loligo pealii). Ann. Mem. Boston Soc. Nat. His. 1880. 23 pags. $3 \mathrm{pl}$.

- The Development of the Cephalopoda and the Homology of the Cephalopod Foot. Am. Jour. Sc. 1880, p. $288-291$.

Bruce, A. T. Segmentation of the egg and formation of the germ layers of the Squid. Jolins Hopkins Univ. Circ. 6, No. 54, 1886, p. 45-46.

BURne, R. H. On some points in the Anatomy of Sepia officinalis. Proc. Malac. Soc. London 3, 1898, p. $53-56$.

Chéron, Jules. Recherches pour servir a l'histoire du système nerveux des Céphalopodes dibranchiaux. Ann. des Sc. Naturelles, Zool. V, 1866, p. 1-122, pl. I-V.

Crun, C. Ueber die Chromatophoren der Cephalopoden. Ver. d. D. Zool. Ges. 1902, p. 162-182.

- Ueber einen unbekannt gebliobenen Flimmertrichter bei Cephalopoden. Zool. Anz. 28, 1905, p. 644654 , fig. $1-8$.

_- Ueber die Geschlechtsverhältnisse der Cephalopoden. Zool. Anz. 29, 1906, p. 743-753. 5 figs.

Clarke, L. On the Structure of the Optic. Lobes of the Cuttlefish. Phil. Trans. 157. 1867, p. 155-159, pl. X. Deflandre, C. Rôle de la fonction adipogénique du foie chez Invertébrés. C. R. Ac. Sc. 135, 1902, p. 762.

DHÉRÉ, Cr. Le Cuivre hématique des invertébrés et la capacité respiratoire de l'hémocyanine. C. R. Soc. Biol. 52,1900 , p. 458-459.

- Quelques nouveaux documents concernant le cuivre hématique des invertébrés et la capacité respiratoire de l'hémocyanine. C. R. Soc. Biol. 55, 1903 p. 1161-1162.

Engeliann, T. W. Uebel die Function der Otolithen. Zool. Anz. 10, 1887, p. 439-444.

Faliorse, A. Contribution à la physiologie de la digestion. Arch. Internat. Pliys. Liège 3, 1906, p. $282-305$. 
FAUsseK, V. Uobor don sogenannte "woisson Körpor” sowie über die embryonalo Entwickelung dessolben, der Cerobralganglion und dos Knorpols boi Cophalopoden. Mém. Ac. Pétersbourg. Sér. 7, 41, 1893, №. $9,27 \mathrm{pp}, 3 \mathrm{pl}$.

- Zur Coplatopodenentwickelung. Zool. Anz. 19, 1896, p. 496-500.

_- Untorsuchungon über die Entwickolung der Cophalopoden. Mitt. a. d. Zool. Sta. Neapel, 14, 1900, p. 83-337.

For, H. Note sur le développement des Mollusques Ptéropods et Céphalopodes. Arch. Zool, exp. et gén. III, 1874.

Frönцcri, A. Studion über Statocysten. 1. Versuche an Cephalopoden und Einschlägiges aus der menschlichen Pathologio. Arch. ges. Physiol. 102, 1904, p. 415-472.

Von Funri, O. Vergl. chemische Physiologie der niederen Tiere. Jena, 1903, 670 pp.

Gessard, M. C. Sur les oxydases des Seiches. C. R. Ac. Sc. 136, 1903, p. 631-632.

Grrod, P. Recherches sur la poche du noir des Céphalopodes des côtes de France. Arch. de Zool. exp. et gén. 'I'. 10, 188:, p. 1-100, pl. I-V.

- - Recherches sur la peau des Céphalopodes. Arch. Zool. exp.' gén. 2 sér. Vol. 1, 1883, p. 225-266, pl. XIV,

Grenacher, H. Zur Entwickelungsgeschichte der Cephalopoden. Zeit. f. wiss. Zool. 24, 1874, p. 419-498.

- - Abhandlungen zur vergleichenden Anatomie des Auges. I. Die Retina der Cephalopoden. Abhandl. d. Naturf. Geselisch. zu Halle. Bu. 16, 1886, p. 207-256, pl. XVI.

—- Ueber die Retina der Cephalopoden. Zool. Anz. 18, 1895, p. 280-281.

Grobben, C. Morphologische Studien über den Harn und Geslechtsapparat sowio die Leibeshöhle der Cophalopoden. Arb. Zool. Inst. Wien. V, 1884, p. 179-252, pl. XVII-XIX.

- Zur Kenntniss der Morphologie und del Verwandschaftsverhäitnisse der Cephalopoden. Arb. Zool. Inst. Wien, VII, 1886 , p. $61-82$.

Hamlyn-Harris, R. Die Statocysten der Cephalopoden. Zool. Jahrb. 18, Anat. 1903, p. 325-355, pl. XXX-XXXIV.

Heinrich, H. Ueber der Schlundkopf einiger dibranchiaten Cephalopoden. Zeit. Naturw. 77, p. 1-40, pl. 2.

HeNRI, V. Étude des ferments digestifs chez quelques Invertébrés. C. R. Soc. Biol. 55, 1903, p. 1316-1318.

Hensen, v. Ueber das Auge einiger Cephalopoden. Zeit. f. wiss. Zool. 15, 1865, p. 155-242, pl. XII-XXI.

Henze, M. Chemisch-physiologische Studien an den Speicheldrüsen der Cephalopoden. Centralbl. f. Phys. 19, $1905-6$, p. $986-990$.

Huss, C. Ueber das Vorkommen von Sehrpurpur bei Cephalopoden. Centralbl. f. Physiol. 16, 1902, 1). $11-19$.

- - Beiträge zur Physiologie und Anatomie des Cephalopodenauges. Arch. ges. Physiol. 109, 1905, p. 393-439, pl. V-VIII.

Hesse R. Untersuchungen über die Organe der Lichtempfindung boi niederen Thieren. VI. Die Augen einiger Mcllusken. Zeit. f. wiss. zool. 68, 1900, p. 379-477, pl. XXV-XXXII.

Hoffuann, C. K. Ueber die pars ciliaris Retinae und das corpus epitheliale. Selenka's Niederlaend. Arch. f. Zool. 1, 1872, p. 187-193.

HoyLe, W. E. Cephalopoda. Challenger Report, 16, p. 1-246, pl. I-XXXIII.

- - On a tract of modified epithelium in the embryo of Sepia. Ploc. R. Phys. Soc. Edinburg, 10, 188889 , p. $58-60,4$ figs.

- - A Catalogue of Recent Cephalopoda. Proc. R. Phys. Soc. Edinburg, 9, 1886, p. 205-257. Also Supplement 1887-1896. Ibid. 13, 1897, p. 363-375.

JAtra, G. Sopra l'organo dell'imbuto nei Cefalopodi. Boll. Soc. Natural. Napoli, 7, 1893, p. 45一-60, pl. $1 \mathrm{~V}$.

_- IjCefalopodi viventi nel Golfo di Napoli. Fauna and Flora, Neapel, Mon. 23, 1896, 268 pp. Atlas 31 pl.

Jherrng, H. VoN. Ueber die Verwandtschaftsbeziehungen der Cephalopoden. Zeit. f. wiss. Zool. 35, 1881, p. $1-22$.

Joubin, L. Sur la structure ot le développement de la branchie de quelques Céphalopodes des côtes de France. Arch. Zool. exp. gén. 3 (2 sér.) 1855, p. 75-150, pl. IV-VI.

- - Sur l'anatomio et l'histologie des glandes salivaires chez les Céphalopodes. C. R. Ac. Sc. 105, 18s7, p. 177-179. Review J. R. Micr. Soc. 1887.

-_. Recherches sur la morphologie comparée des glandes salivaires des Céphalopodes. Arch. Zool. exp. et gén. 5 (2 sér.) Suppl. 1887-90. Mém. No. 3, 60 pp., 3 pl. 
Joubin, L. Recherches sur la cololation du tégument chez les céphalopodes. Inid. 10 (2 sér.) 1892-93, p. $277-303, \mathrm{pl} . \mathrm{X}-\mathrm{X} I 1$.

KELLER, C. Boiträge zur feineren anatomie der Cephalopodon. Boricht u. d. Thaot. der naturw. Gesell. Zürich, 187:-3.

Kxol, PH. Zur Lehre von den doppelt schrïggestreiften Muskelfasern. Sitzb. Kais. Ak. Wiss. Wien, Math.-natulw. Classe. 101, abth. II, 1892, p. 498-514, pl. I \& II.

Koflurker, A. Entwickelungsgeschichte der Cephalopoden. Zürich 1844, 180 pp., 6 pl.

Korscn, F. Mittheilungen über das Ganglion opticum der Cophalopoden. Internat. monats. f. Anat. u. Physiol. 16, 1899, p. 33-54, pl. IV, V.

Kolsscheli, L. Beitrïge zur Entwickelungsgeschichte der Cephalopoden. Festsch. 70 geburtstage Leukarts. Leipzig 1892.

-_ Beiträge zur Entwickelungspreschichte der Cephalopoden. Verh. D. Zool. (Yos. 1892, p. 347-373, pl. XXXVI, XXXVII.

Krause, R. Ueber Bau und Funktion der hinteren Speicheldrüsen der Octopoder. Sitzb. K. Akad. Wiss. Berlin 1897, p. 1085-1098.

Kronx. Beiträge zur näheren Kenntniss des Auges der Cephalopoden. N. acta Acad. Leop. Carol. 1835.

Krukenberg. Ueber das conchiolin und das Vorkommen des Chitins bei Cephalopoden. Br. d. deutschen chem. Gesellsch. 18, 1885, p. 989-993.

Lacaze-Duthiers, H. DE. Otocystes ou capsules Auditives des Mollusques. Arch. Zool. exp. et gén. 1, 1872, p. $97-168$.

LaMARCK, Syst. Anim. sans vert. 1801, p. 60.

LANGer, C. Ueber einen Binnen-Muskel des Cephalopodenauges. Sitzb. d. Kais. Ak. der Wiss. Wien, 5, 1850 , p. $324-326$.

LANkESTER, E. R. Observations on the development of the Cephalopoda. Q. J. Micr. Soc. N. S. 15, 1875, p. $37-47$.

Laurie, M. The organ of Verrill in Loligo. Ibid. 29, 1888-9, p. 97, 99, pl. X.

LeNHosséK, M. von. Zur Kenntniss der Netzhaut der Ceplaalopoden. Zeit. f. wiss. Zool. 58, 1894, p. 636-660.

- Histologische Untersuchungen am Sehlappen der Cephalopoden. Arch. f. mikr. Anat. 47, 1896, p. $45-120$, pl. VI-VIII.

Lrasuedr. Jour. Acad. Nat. Sc. Philadelphia, 2, 1821, p. S6-101, pl. VI-IX.

Livon, CH. Recherches sur la structure des organes digestives des poulpes. Jour. de l'anatomie et de la pliysiologie par Robin \& Pouchet 17,1881 , Paris.

Mac Munn, P. A. On the gastric gland of Mollusca and decapod Crustacea. Proc. R. Soc. 64, 1899, p. 436.

Marceau, F. Sur la structure des muscles du manteau des Céphalopodes en rapport avec leur mode do contraction. C. R. Acrtd. Sc. 141, 1905, p. 279-280.

- - Recherches sur la structure du coeur chez les Mollusques suivie d'une étude spéciale des coeurs branchiaux et de leurs appendices glandulaires chez Céphalopodes. Arch. anat. Micr. 7, 1905, p. 495588 , pl. XX-XXVI, Paris.

-_- Recherches sur la structure des muscles du manteau des Céphalopodes en rapport avec leur modo du contraction. Trav. Lab. Soc. Sc. Arcachon. Ann. 8, 1905, p. 48-65, 2 pl.

Marchand, W. Beitrag zur: verglejchenden Anatomie des männlichen Geschlechtsapparat dor Cephalopoden. Zool. Anz. 29, 1906, p. 758-758, ? figs.

- - Der männliche Leitungsapparat der Dibranchiaten. Zeit. f. w. Zool., 86, 1907, p. 311-415, 66 figs.

MerToN, H. Ueber die Retina von Nautilus und einigen dibranchiaten Cephalopoden. Zeit. f. wiss. Zool., 79, 1905 , p. 325-396, pl. XVII-XIX.

Nueller, H. Bau der Cephalopoden. Zeit. f. wiss. Zool. 4, 1853, p. 337-358.

Muskens, L. J. J. Ueber eine eigentümliche compensatorische Augenbewegung der Octopoden mit Bemerkungen über dereı Zwangsbervegungen. Arch. Anat. u. Physiol. Leipzig, 1904, (49-56). Physiol. Abth. D’ORBIGNY, ALC. Céphalopodes acétabulifères. Paris, 1835-1848.

OwsJannikow und Rowalewsky. Ueber das Centralnervensystem und das Gehörorgan der Cephalopoden. Mém. Ac. Sc. St.Pètershourg (sér. 7) 11, No. 3, 1868.

Pelsenefr, P. Sur la valeur morphologique des bras el la composition du système nerveux central des Céphalopodes. Arch. de Biol. 8, 1888, p. 723-756, pl. XXXVII-XXXVIII.

-_. Sur la nature pédieuse des bras des Céphalopodes. Ann. Soc. Roy. Malacolog. de Belgique, 24, 1889, p. $382-384$. 
Prysalix, C. Notrvellos recherchos sur los chromatophores des Céphalopodos. Arch. Physiol. Paris, (5), T. 6,1894, p. $92-100$.

RABL, H. Uober Bau und Entwickolung der Chromatophoron der Cophalopoden, nebst allgemeinen Bomerkungen übor dio Haut diesel Thiore. Sitzb. d. Kais. Akad. Wion, 109, Abth. 3, 1900, p. 341-404.

RacovitzA, E. Notes des Biologio II. Moeurs et fécondation do la Rossia macrosoma. Arch. d. Zool. exp. et gén. (3) 2, 1894, p. 491-539, pl. XX-XXI.

Ravitz, B. Zur Physiologio der Cophalopodenretina. Arch. fo. Anat. u. Physiol. Phys. Abth., 1891,p. 367-372.

- Ueber den feineren Bau der Speicheldrüsen der Cephalopoden. Arch. f. mikr. Anat. 39, 1892, p. 596-611, pl. XXVII.

Richiard. Sul occhio dei Cefalopodi. Comm. Soc. Tosc. d. scienc. natur. Pisa, 1879.

Rottmann, G. Uober dio Enbryonalentwicklung der Radula bei den Mollusken. I. Dio Entwicklung der Radula boi den Cephalopoden. Zeit. f. wiss. Zool. 70, 1901, p. 236-262, 2 pls., 4 figs.

Saint-Hilaire, K. Ueber die Innervation der Chromatophoren bei Cephalopoden. Sitz. nat. Gesell. Dorpat, 15,1906 , p. $60-66$.

Scrimkewitsch, W. Note sur le développement des Céphalopodes. Zool. Anz. 9, 1886, p. 205-207.

Scrofbl. Ueber die Blutgefässe des Auges der Cephalopoden. Sitz. d. k. Boehm. Gesellsch. d. Wiss. Prag, 1878 , p. $41-46$.

- - Ueber die Blutgefässe des Auges der Cephalopoden. Arch. f. mikr. Anat. 15, 1878, p. 215-243, pl. XII-XIII.

Scrultze, M. Die Stäbchen in der retina der Cephalopoden und Heteropoden. Arch. f. mikr. Anat. 5 , 1869 , p. 1-24, pl. I-II.

SchweIkfRT, G. Beitrïge zur morphologie und genese der Eihüllen der Cephalopoden und Chitonen. Zool. Jahrb. Suppl. VI. Fauna Chiliensis, 3, h. 2, p. 353-406, pl. XXIII-XXVI.

Solger, B. Zur Kenntniss der Chromatophoren der Cephalopoden und ihrer Adnexa. Arch. mikr. Anat. 53, 1898, p $1-19$.

- - Ueber die chromatophoren der Cephalopoden. Ver. Ges. D. Naturf. und Aerzte 69, p. 237.

Sternach, E. Studion über die Hautfärbung und über den Farbenwechsel der Cephalopoden. Arch. f. g. Physiol. 87, 1901, p. 1-37.

Stieda, L. Studien über den Bau der Cephalopoden. Zeit. f. wiss. Zool. 24, 1874, p. 84-112, pl. XIII.

Sturges, M. Polymorphic nuclei in embryonic germ cells. Science, 9, 1899, p. 183.

Teicrmann, E. Die frühe Entwickelung der Cephalopoden. Verh. d. deutch. Zool. Ges. 13, 1903, p. 42-52.

Thesing, Curt. Beiträge zur Spermatogensis der Cephalopoden. Zeit. f. wiss. Zool. Leipzig, 76, 1904, p. $91-136$.

Verrili, A. E. Cephalopods of the Northeastern Coast of North America. U.S. Fish Commission, Report fol 1879 , p. $211-455$, pl. I-XLVI.

- - The Cephalopoda of the Northeastern Coast of America. Trans. Conn. Acad. o, 1882, p. $177-446$.

--. Amer. Jour. Sc. (4) 3, p. 135-136, 1897.

Vialieton, L. Sur la fécondation chez les Céphalopodes. C. R. Ac. Sc. 101, 1885, p. 619-621.

- - Recherches sur les premières phases du développement de la Seiche. Ann. Sc. Nat. (7) 6, 1888, p. $165-280$, pl. VII-XIV.

Vigelius, W. J. Ueber das Excretionssystem der Cephalopoden. Niederl. Arch. Zool. 5, 1880, p. 115-184, pl. $\mathrm{X}$-XII.

-_. Vergleichend-anatomische Untersuchungen über das sogenannte Pankreas der Cephalopoden. Verh. K. Akad. Wetensch. Amsterdam, 22, 1883, p. 1-30, pl. I-IV.

VIGIER, P. \& VLES, F. Structure histologique des éléments musculaires du coeur chez les Mcllusques. Bull. Soc. Zool. France, 29, p. 2:1-229.

Watasé, S. Observations upon the development of Cephalopods: Homology of the germ layer's. Studies Biol. Lab. Johns Hopkins Univ. Vol. 4, 1888, p. 163-183. XVI-XVII.

- - Studies on Cephalopods: Cleavage of the ovum. Jour. Morph. 4, 1891, p. 247-296, pl. IX-XII.

WeIss, E. On some Oigopsid Cuttle Fishes, Quart. Jour. Micr. Sc. 29, 1888, p. 75_96, pl. 8-10.

Willer, V. Résumé de nos connaissances sur la physiologio des Céphalopodes. Bull. Scient. France Belgique 31,1898 , p. $31-54$.

Williams, L. W. The Vascular System of the Common Squid: Loligo pealii. Am. Nat. 36, 1902, p. 787-794. 
LW: Williams, Amutsmy of the Common Squid.

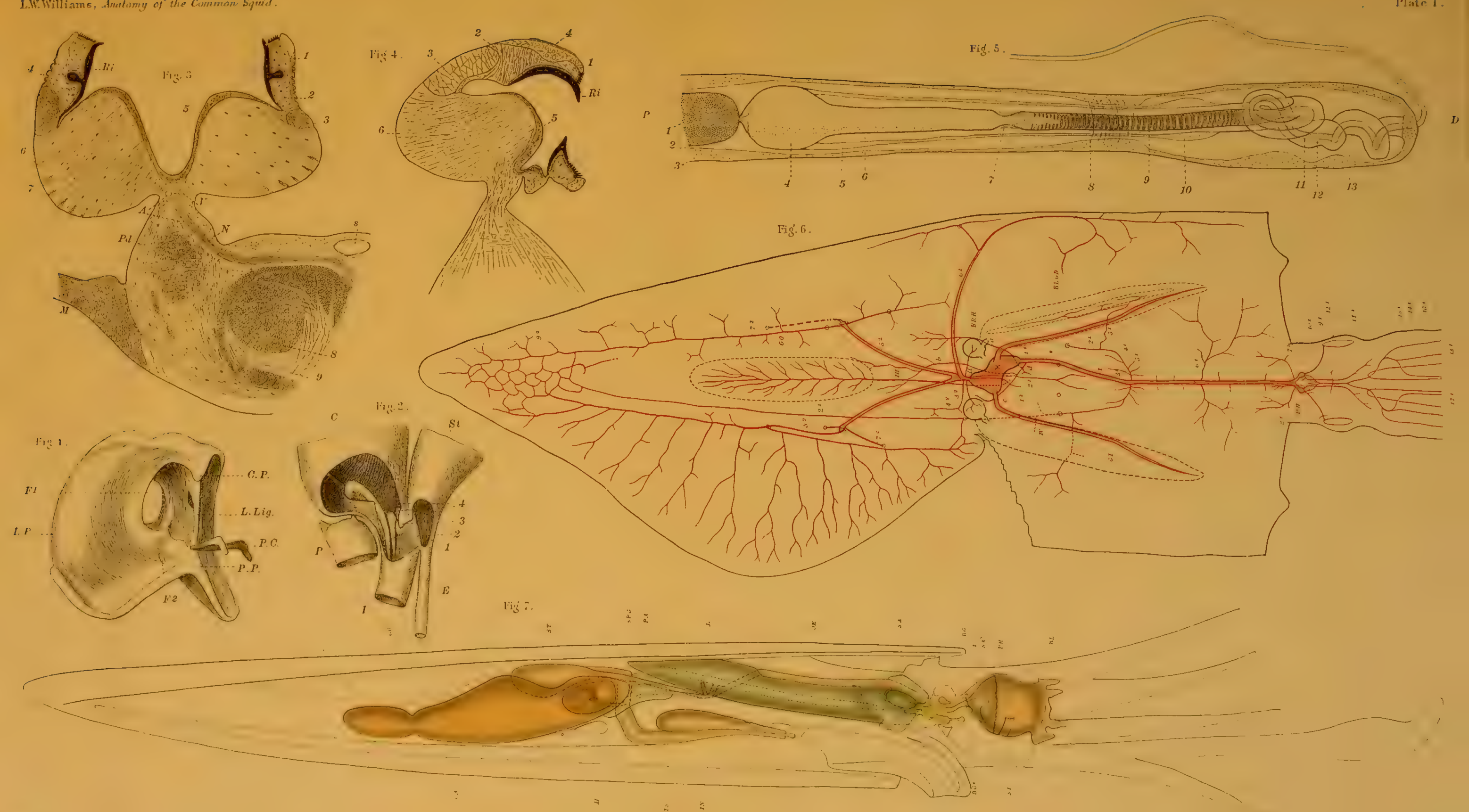



. 


$$
\text { bi } \overrightarrow{1} 0
$$






$$
\text { . }
$$ 
